\title{
Genetic mechanisms regulating proliferation and cell specification in the Drosophila embryonic CNS
}

Shahrzad Bahrampour

Department of Clinical and Experimental Medicine

Linköping University, Sweden 
Shahrzad Bahrampour, 2017

Cover picture/illustration: Confocal image of the Drosophila embryos fillets at stage 12, stained for Dpn (green), Pros (red), GsbN (blue) and PH3 (white). The front cover shows the control, and the back cover is the combinatorial misexpression of $d a-G a l / U A S$-ase, $-S o x N$, -wor, $-h b,-K r,-n u b$ leads to the widespread generation of $\mathrm{NBs}$ and GMCs, and extensive proliferation throughout the ectoderm, contrary the underlying VNC shows normal segmentation.

Published articles have been reprinted with the permission of the copyright holder.

Printed in Sweden by LiU-Tryck, Linköping, Sweden, 2017

ISBN: 978-91-7685-605-5

ISSN: 0345-0082 
$\underline{\text { Supervisor }}$

Stefan Thor, Professor of Developmental Biology

Department of Clinical and Experimental Medicine (IKE)

Linkoping University, Sweden

\section{Co-supervisor}

Jan-Ingvar Jönsson, Professor

Department of Clinical and Experimental Medicine (IKE)

Linkoping University, Sweden

Faculty opponent

Simon Sprecher, Professor of Neurobiology

Department of Biology

University of Fribourg, Switzerland 

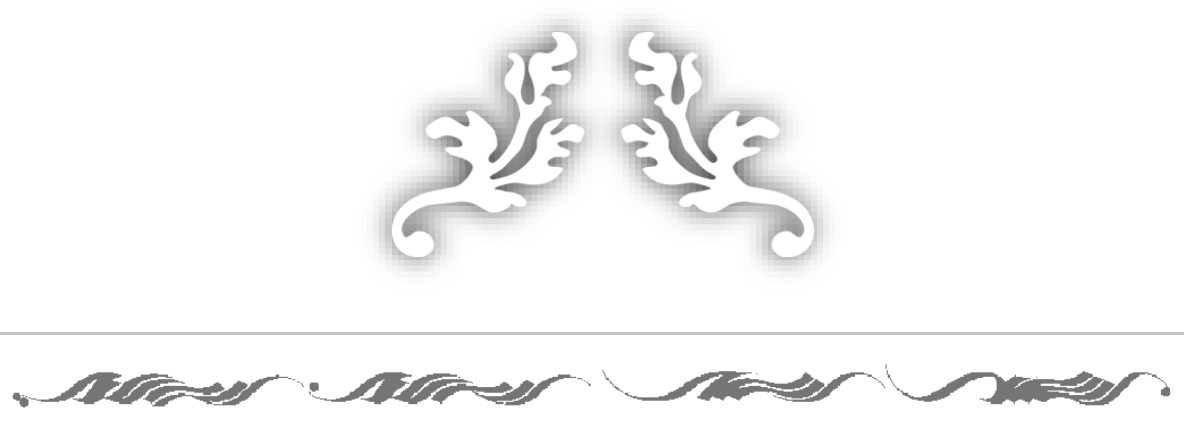

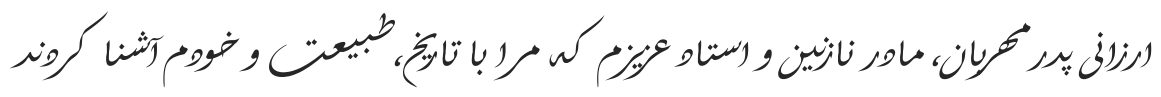

To my parents, who introduced me to nature, history and myself 


\section{Contents}

List of papers

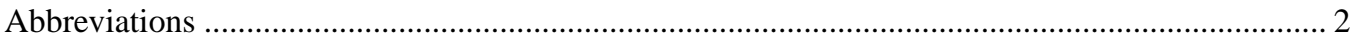

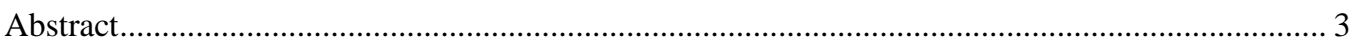

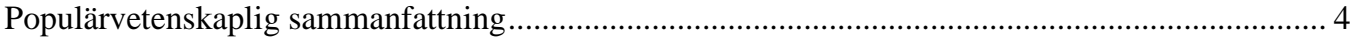

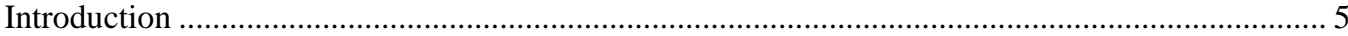

1. The central nervous system; the most complex of animal organs ........................................ 5

2. The CNS; a vast network of neurons and glia .................................................................... 5

3. Basic features of vertebrate CNS development ............................................................ 6

3.1 Intercellular and intracellular signals driving uncommitted cells to neural fate................. 7

3.2 Signals from non-neuronal cells driving uncommitted ectodermal cells to neural fate ...... 7

3.3 Neural induction involves inhibition of TGFb signaling ............................................... 7

3.4 Axial patterning is a general characteristic of the developing CNS …........................... 8

4. Drosophila: a powerful model for neurodevelopmental studies ........................................ 10

5. The Drosophila CNS forms from the four neurogenic regions ............................................ 11

6. The Drosophila CNS axial patterning along the DV and AP axes ................................... 12

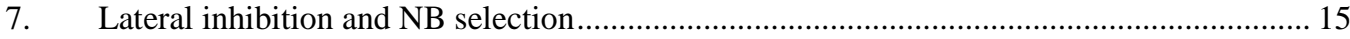

8. Temporal selectors drive cell diversity in developing embryonic Drosophila VNC ........... 16

9. Tissue/cell type selectors are critical for Drosophila embryonic CNS development ........... 18

10. Terminal selectors determine the final identity of neuronal cell types................................. 18

11. The Drosophila cell cycle machinery.............................................................................. 19

11.1. Cell fate determination dependent on cell cycle ............................................................ 20

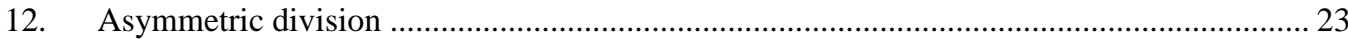

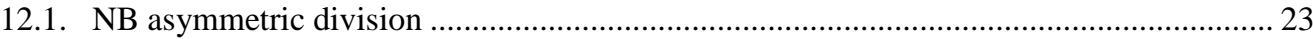

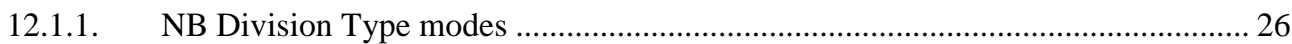

13. Reprogramming drives differentiated cells to the stem cells like state .............................. 28

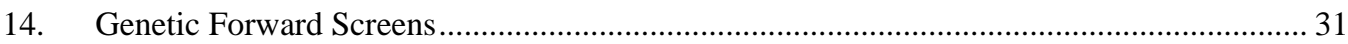

14.1. Relationship between genotype and phenotype ........................................................... 31

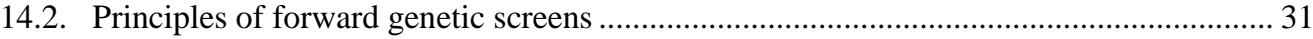

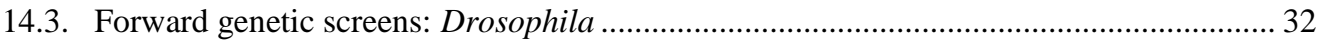

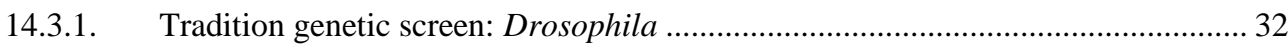

14.4. Genetic screens utilizing next generation sequencing ................................................ 33

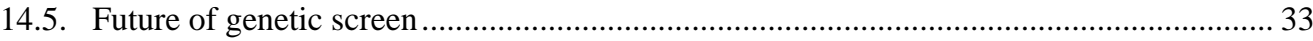

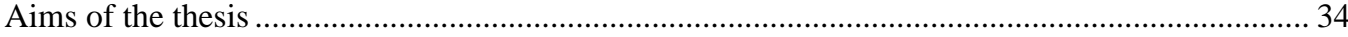

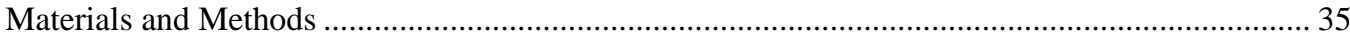

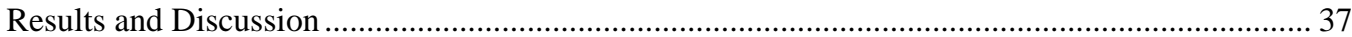


Paper I: Novel Genes Involved in Controlling Specification of Drosophila FMRFamide

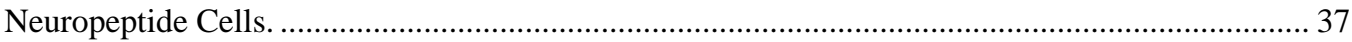

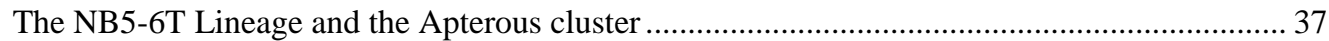

Paper II: Ctr9, a Key Component of the Paf1 Complex, Affects Proliferation and Terminal Differentiation in the Developing Drosophila Nervous System. ................................................ 41

The Paf1 Complex, an evolutionary well conserved co-factor complex for RNA Pol II............ 41

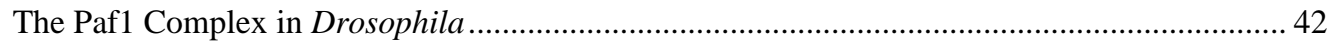

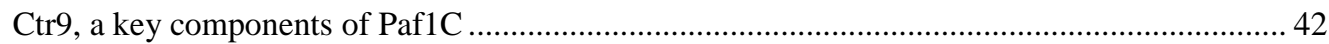

Paper III Neural Lineage Progression Controlled by a Temporal Proliferation Program............... 46

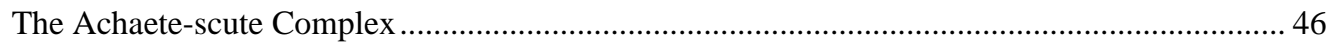

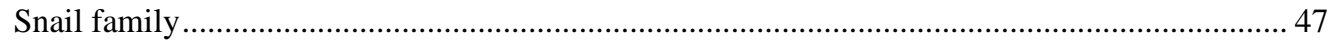

SoxB family in the developing CNS of Drosophila .................................................................. 49

Early players of temporal TFs cascade are essential for NB identity ...................................... 50

Early factors and late factors interplay govern NB identity ................................................... 51

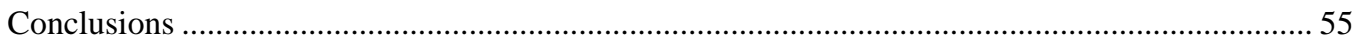

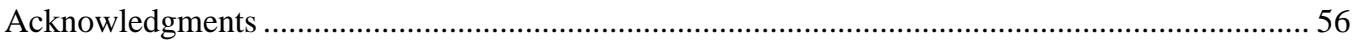

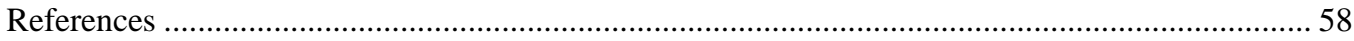




\section{List of papers}

I. Bivik, C, Bahrampour, S, Ulvklo, C, Nilsson, P, Angel, A, Fransson, F, Lundin, E, Renhorn, J, Thor, S. (2015) Novel Genes Involved in Controlling Specification of Drosophila FMRFamide Neuropeptide Cells. Genetics. 200(4):1229-44

II. Bahrampour, S, Thor, S. Ctr9, a Key Component of the Paf1 Complex, Affects Proliferation and Terminal Differentiation in the Developing Drosophila Nervous System. G3 (Bethesda) $6(10): 3229-3239$.

III. Bahrampour, S, Gunnar, E, Jonsson, C, Ekman, H, Thor, S. Neural Lineage Progression Controlled by a Temporal Proliferation Program. Submitted manuscript. 

Abbreviations
AFT Air filled trachea
AP Anteroposterior
AS-C Achaete-scute complex
Ap Apterous
BMP Bone morphogenetic portion
CNS Central nervous system
Ctr9 Cln Three Requiring 9
DV Dorsoventral
ESCs $\quad$ Embryonic stem cells
FMRFa FMRFamide (Phe-Met-Arg-Phe-NH2)
GMC Ganglion mother cell
INP Intermediate neural progenitor
MNB Midline Neuroblast
NB Neuroblast
NGS Next generation sequencing
PNS Preferably nerve system
Paf1C RNA polymerase II-associated factor-1 complex
RNA Pol II RNA polymerase II
SC Stem cell
TF Transcription factor
VNC Ventral nerve cord
WGS Whole genome sequencing
bHLH basic helix-loop-helix
e-GFP Enhanced green fluorescent protein
iPS Induced pluripotent stem cells 


\begin{abstract}
The central nervous system (CNS) consists of an enormous number of cells, and large cellular variance, integrated into an elaborate network. The CNS is the most complex animal organ, and therefore its establishment must be controlled by many different genetic programs. Considering the high level of complexity in the human CNS, addressing issues related to human neurodevelopment represents a major challenge. Since comparative studies have revealed that neurodevelopmental programs are well conserved through evolution, on both the genetic and functional levels, studies on invertebrate neurodevelopmental programs are often translatable to vertebrates. Indeed, the basis of our current knowledge about vertebrate CNS development has been greatly aided by studies on invertebrates, and in particular on the Drosophila melanogaster (fruit fly) model system.
\end{abstract}

This thesis attempted to identify novel genes regulating neural cell specification and proliferation in the CNS, using the Drosophila model system. Moreover, I aimed to address how those genes govern neural progenitor cells (neuroblasts; NBs) to obtain/maintain their stemness identity and proliferation capacity, and how they drive NBs through temporal windows and series of programmed asymmetric division, which gradually reduces their stemness identity in favor of neural differentiation, resulting in appropriate lineage progression. In the first project, we conducted a forward genetic screen in Drosophila embryos, aimed at isolating genes involved in regulation of neural proliferation and specification, at the single cell resolution. By taking advantage of the restricted expression of the neuropeptide FMRFa in the last-born cell of the NB lineage 5-6T, the Ap4 neuron, we could monitor the entire lineage progression. This screen succeeded in identifying 43 novel genes controlling different aspects of CNS development. One of the genes isolated, $C t r 9$, displayed extra Ap4/FMRFa neurons. Ctr9 encodes a component of the RNA polymerase II complex Paf1, which is involved in a number of transcriptional processes. The Paf1C, including Ctr9, is highly conserved from yeast to human, and in the past couple of years, its importance for transcription has become increasingly appreciated. However, studies in the Drosophila system have been limited. In the screen, we isolated the first mutant of Drosophila $\operatorname{Ctr} 9$ and conducted the first detailed phenotypic study on its function in the Drosophila embryonic CNS. Loss of function of $C t r 9$ leads to extra NB numbers, higher proliferation ratio and lower expression of neuropeptides. Gene expression analysis identified several other genes regulated by $\operatorname{Ctr} 9$, which may explain the $C \operatorname{tr} 9$ mutant phenotypes. In summary, we identified $\operatorname{Ctr} 9$ as an essential gene for proper CNS development in Drosophila, and this provides a platform for future study on the Drosophila Paf1C. Another interesting gene isolated in the screen was worniou (wor), a member of the Snail family of transcription factors. In contrast to Ctr9, which displayed additional Ap4/FMRFa neurons, wor mutants displayed a loss of these neurons. Previous studies in our group have identified many genes acting to stop NB lineage progression, but how NBs are pushed to proliferate and generate their lineages was not well known. Since wor may constitute a "driver" of proliferation, we decided to study it further. Also, we identified five other transcription factors acting together with Wor as pro-proliferative in both NBs and their daughter cells. These "drivers" are gradually replaced by the previously identified late-acting "stoppers." Early and late factors regulate each other and the cell cycle, and thereby orchestrate proper neural lineage progression. 


\section{Populärvetenskaplig sammanfattning}

Det centrala nervsystemet (CNS) består av hjärnan och ryggmärgen. CNS innehåller ett stort antal celler av många olika typer, integrerade i ett komplext nätverk, och följaktligen är CNS det mest komplexa organet vi har. Den korrekta etableringen av CNS är avgörande för ett fungerande nervsystem. En av de största utmaningarna inom neurobiologin är att förstå hur olika typer av nervceller bildas vid rätt tidpunkt och på rätt plats. Med tanke på den höga graden av komplexitet $\mathrm{i}$ människans CNS så utgör frågor som rör nervsystemets utveckling en betydande utmaning. Många olika genetiska mekanismer styr utvecklingen av CNS, och många av dessa är evolutionärt gemensamma med andra djurarter. Därför kan studier på CNS delvis översättas från ryggradslösa djur till ryggradsdjur, inklusive människa. I själva verket är grunden för vår nuvarande kunskap om CNS-utvecklingen hos ryggradsdjur i många aspekter baserad på studier av ryggradslösa djur, i synnerhet genom studier på bananflugan, Drosophila melanogaster. Genetiska mekanismer styr neuronala utvecklingen på många olika nivåer. Kontrollen kan exempelvis ske genom att styra antalet celldelningar av neurala stamceller (NSC), eller genom att styra cellernas öde (differentiering). Det är även viktigt att stoppa NSC vid rätt tidpunkt i utvecklingen. Att hålla balansen mellan celldelning och differentiering är avgörande för korrekt utveckling; minsta obalans kan leda till cancer eller underutveckling.

Denna avhandling innehåller tre relaterade projekt med syfte att identifiera genetiska mekanismer som reglerar den neuronala utvecklingen, och som använder Drosophilas embryonala CNS som modellsystem. I det första projektet genomfördes en genetisk undersökning på Drosophila embryon som syftade till att identifiera gener involverade i regleringen av celltillväxt och differentiering. Genom denna undersökning identifierades 43 gener som styr olika aspekter av CNS-utvecklingen. I det andra projektet behandlades en av de isolerade generna, $C t r 9$, i mer detalj. $C t r 9$ kodar för en komponent av Paf1 komplexet som är involverat i olika transkriptionella processer och styr genuttrycket av många andra gener. Vi identifierade Ctr9 för första gången i Drosophila, och genen visade sig ha $81 \%$ likhet med humana Ctr9. Denna gen är viktig för korrekt CNS utveckling i Drosophila och fungerar som en suppressorgen. Denna studie ger en plattform för framtida forskning om Drosophila Paf1C. Det tredje projektet inleddes vid identifiering genen wor i den första undersökningen. wor är känd som drivande vid celldelning. Dessutom identifierade vi fem ytterligare gener som tillsammans med wor är viktiga för celldelningar hos både NSC och deras dotterceller. Dessa drivande gener ersätts gradvis med tidigare kända gener som styr celler mot differentiering istället för celldelning. Här har vi tagit upp samspelet mellan de tidiga och sena faktorerna, hur de reglerar varandra och celltillväxten hos NSC, och därmed hur en korrekt neuronal utveckling orkestreras.

Avhandlingen har bidragit till kunskap om de genetiska mekanismerna som styr neural utveckling genom att identifiera flera nya reglerande gener, och deras samspel vid balansen mellan celltillväxt och differentiering. Upptäckterna kan belysa frågor om mänskliga nervsystemets utveckling, cancer och nervtumörrelaterade sjukdomar, samt förekomsten av underutvecklat CNS hos spädbarn. 


\section{Introduction}

\section{The central nervous system; the most complex of animal organs}

The central nervous system (CNS) is the most complex organ in metazoans, consisting of an enormous number and types of cells, integrated into an elaborate network. In the human CNS, there are several hundreds of neural cell types [1]. Our fascination of the CNS is derived from its complexity and diversity [2]. Undoubtedly, development of such an organ requires many regulatory steps and processes. Despite its complexity, the fundamental principles behind the development of the CNS are comparable to other organ developmental processes. Therefore, understanding CNS development involves many of the basic challenges common to developmental biology [1]. Moreover, the genetic mechanisms underlying neural development are highly conserved between different organisms. Indeed, the foundation of our knowledge about vertebrate neural development has to a considerable extent emerged from genetic studies on two invertebrates: the fruit fly Drosophila melanogaster and the nematode Caenorhabditis elegans [1]. One of the main issues in developmental neurobiology is to understand how the generation of neural progenitors and their behavior is controlled to produce a certain number of each cell type in the right place at the right time to construct a fully functional system.

\section{The CNS; a vast network of neurons and glia}

Cells within the nervous system can be divided into two broad classes of cells: Neurons (nerve cells) and glia. Some of the neural progenitors only give rise to neurons, and some restrictively produce glia, named glioblasts [3-5]. Although both may also emerge from the same precursor cell, called a neuroglioblast $[6,7]$.

Glial cells have been known as support cells within the nervous system for quite some time. Recent studies indicated that glial cells are also involved in CNS processes such as neurogenesis, regulating metabolic cascades, synaptogenesis and controlling their strength. Moreover, they also seem to be crucial for cellular signaling and neurotransmitter homeostasis [8, 9]. Neurons, on the other hand, constitute the main signaling units in the nervous system. The number of neurons in the human brain is estimated to be about 100 billion. Neurons display a great diversity concerning subtypes, but they share four basic morphological structures: Cell body (soma), two types of processes dendrite and axon, and presynaptic terminals [1]. The main functional and physiological features of a neuron are: directed excitation, secretion of substances and generation of cell processes, and the combination of these defines a cell as a neuron. Neurons are divided into many classes and subclasses, based on their morphology and functionality. A better understanding of functional variance between neurons will tell us about the function of CNS [1]. 
The glia to neuron ratios has been the subject of discussion over the years. Some textbooks state that glial cells outnumber neurons in the human brain [10] and that the glia population is estimated to be 10-50 times larger than neurons in the brain of many vertebrates [1]. In contrast, some studies suggest this ratio to be approximately 1:1 in different parts of the mammalian CNS, even among the various species [11-15]. The cell counting methods used in these studies is based on the widely used stereological cell counting methods [16] or the technique for cell count in large tissue samples invented by Herculano-Houzel and Lent, in 2005 [17]. Contrary, Ben Barres, experiments suggest that glial cells constitute around $80 \%$ of human brain cells, based on the amount of DNA added in the 20 prenatal weeks, a time at which there is production mainly of glia [18].

Invertebrate CNS's, in general, have a lower number of neurons than vertebrates. Also, the ratio of glia to neurons is lower e.g., in Drosophila estimated to 1:10 [6, 19, 20]. Hence, it appears that the glia to neuron ratio has increased during evolution.
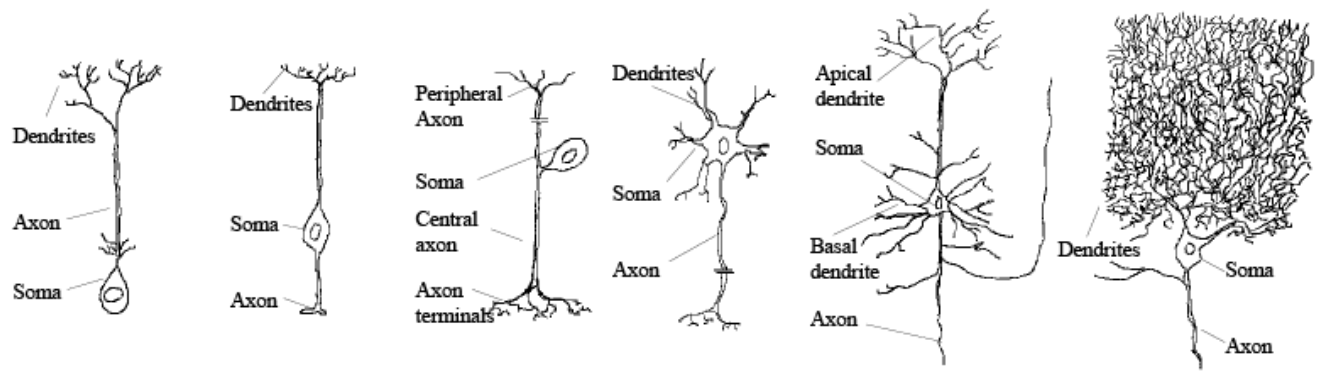

Fig. 1. Drawings of various neuron subtypes. From left to right: 1. A unipolar neuron with one processes, the typical type found in invertebrates nervous systems. 2. A bipolar neuron, retina cell. 3. A pseudo-unipolar neuron; a subclass of bipolar neurons that transfers sensory information. 4. A motor neuron of the spinal cord. 5. A pyramidal cell of the hippocampus. 6. A Purkinje cell of the cerebellum. Modified from [1, 21].

\section{Basic features of vertebrate CNS development}

In many metazoans, after formation of the tree primary germ layers i.e., ectoderm, mesoderm, and endoderm, some of the ectodermal cells obtain neural features and turn into neuroectoderm. The anterior parts of the neuroectoderm form the brain and the posterior parts will make spinal (ventral nerve) cord [1]. In the neuroectodermal regions, neural progenitor cells are established, which are undifferentiated and proliferative, and develop a specific lineage under the influence of both intrinsic and extrinsic signals. During generation of the lineage, specified postmitotic neural cells form, and this process is denoted neurogenesis. During lineage progression, cell differentiation continues after cell cycle exit, and newly born neurons and glia gradually develop specific properties e.g., elaborate 
processes and neurotransmitters during an extended period of differentiation. During this process, the gene expression and protein profile of mature neurons and glia are congruous with their function. Moreover, during CNS development many neural cells are removed by programmed cell death [1, 20].

\subsection{Intercellular and intracellular signals driving uncommitted cells to neural fate}

The process from uncommitted progenitor cells to differentiated neural cells is the result of complex programs that regulate expression of certain genes in individual cells. This scenario is generally similar to that occurring in other organ systems. The factors that program cells to certain neural cell types are both extrinsic e.g., signaling molecules produced by other cells, as well as intrinsic e.g., intracellular regulatory programs. The extrinsic factors may be provided on the surface of a neighboring cell or come from cells far away. The intracellular programs are often expressed or activated within the cells as a response to the extrinsic signals [1]. Therefore, the position that cells have throughout the development is critical for determining their fate, as different positions are exposed to various extrinsic cues.

\subsection{Signals from non-neuronal cells driving uncommitted ectodermal cells to neural fate}

In vertebrates, the neuroectoderm thickens to form the neural plate. Spemann and Mangold were awarded the Nobel Prize for their experiments on newt gastrulation, which determined that the neural plate forms under the effect of signaling from the adjacent mesodermal tissue. This work involved transplanting a group of cells destined to become dorsal mesoderm to the ventral region of another embryo. The graft, which became known as the Spemann organizer in amphibians, develops to the notochord, later on, instructed the ectodermal cells to adopt neural fate instead of epidermal cell fate. These grafts also provoked dorsalization in the ventral region of the embryo and lead to the generation of a second axis [22].

\subsection{Neural induction involves inhibition of TGFb signaling}

The molecular aspects of neural fate induction remained a question for more than six decades. In 1989, a straightforward experiment demonstrated that the ectodermal cells have neural fate as a default [23]. Shortly after that, a genetic screen for the induction of neural fate in Xenopus embryos resulted in the isolation of the noggin gene [24], and subsequently the chordin gene [25]. The role of Noggin and Chordin is to repress the TGFb signaling ligand bone morphogenetic protein-4 (BMP4) [25]. Loss of BMP4 leads to the neural fate, while intact BMP signaling causes epidermis differentiation, suggesting that preventing BMP signaling is sufficient to promote neural fate. These findings underscore the notion that ectodermal cells by default carry neural fate, and that initiation of neural fate is the consequence of inhibiting the BMP signals, by direct binding of secreted 
molecules from mesodermal cells e.g., Noggin and Chordin. Gain-of-function experiments of each of these proteins, in Xenopus, induced neural fate in ectodermal cells. Neural induction via inhibition of BMP signaling appears to effect on the expression of Sox gene family [1].

\subsection{Axial patterning is a general characteristic of the developing CNS}

Fate mapping neurons during development illustrated the two-dimensional patterning of the neuroectodermal layer, along with both the mediolateral and anteroposterior axes regulated by spatial selectors [26-29]. The commitment of the ectodermal cell to neural fate is just the beginning of a distinct developmental route that each progenitor takes, based upon their position within the neural plate. Each neural progenitor cell is exposed to two main signals; dorsoventral (DV) and anteroposterior (AP) signals. The outcome of these patterning signals divides the CNS into distinct DV and AP divisions with bilateral symmetry, and in vertebrates results in the formation of the forebrain, midbrain, hindbrain and spinal cord [1].

\subsubsection{DV patterning of the vertebrate neural tube}

An illustrative example of DV patterning stems from studies of the vertebrate (chick and mouse) spinal cord. Here, mature neurons of the vertebrate spinal cord can be categorized into two main groups: inter- and motor neurons. These two types of neurons are segregated anatomically to the dorsal and ventral half of spinal cord, respectively. This DV segregation is initiated already at the early stages of development i.e., even before neural plate closure [26-28]. Inductive signals emanating from the underlying mesodermal structure, the notochord, and from the dorsal spinal cord, the roof plate, act to pattern the spinal cord along the DV axis [1]. The notochord triggers the formation of a specialized group of cells at the ventral midline, denoted the floor plate [1].

Ventral half, SHH activity: The notochord, and subsequently the floor plate, release signals that act both locally and at long range. The locally acting signal triggers the formation of the floor plate, and the local signaling is also carried out by the floor plate itself after its formation. The short range signal promotes the differentiation of motor neurons ventrally, while the long range signal promotes dorsal interneurons. The protein mediating both of these signals is Sonic Hedgehog (SHH), which is a member of the Hedgehog family of signal transduction proteins. The Drosophila Hedgehog protein is the original member of the family, and it plays a vital role in many aspects of Drosophila embryogenesis. In the spinal cord, the proper activity of SHH is necessary and sufficient for differentiation of all cells in ventral part, including the floor plate and motor neurons, as well as dorsal interneurons. Gain-of-function studies show that misexpression of SHH within the neural tube resemble the notochord activity, and SHH loss of function prevent the formation of floor plate and motor neurons [26-28]. SHH is not only an inducer but also a morphogen and its activity is dose- 
dependent. A low-to-high gradient of SHH promotes interneuron, motor neuron, and floor plate cell differentiation, respectively [1].

SHH acts via activation of the heterodimeric transmembrane receptor Smoothened (Smo). This result in the activation of downstream protein kinases and Gli proteins. Glis are a family of zinc finger transcription factors. Gli1-2 is known to promote ventralization, while Gli3 is exclusively expressed in the dorsal part of neural tube and prevents Gli1-2 activity [26-28]. Among other TFs, some are exclusively activated by the local SHH signals e.g., hepatocyte nuclear factor, HNF$3 \beta$, which is critical for floor plate formation. Long range SHH signals regulate expression of two sets of cross-repressive transcription factors, referred as class I and II, which suppress each other's expression e.g., Pax-6 versus Nkx2.2. The phenomenon that transcription factors of class I and II are sensitive to the different level of $\mathrm{SHH}$, in addition to their cross-repressive activity, leads to defining sharp borders of their expression, which acts to dictate different progenitor identities at various DV positions. Ultimately, this results in the generation of various subclasses of inter and motor neurons at the different DV positions [29].

In addition to SHH, several BMP antagonists are expressed by the notochord i.e., Noggin, Follistatin, and Chordin. However, the only one which is expressed by the floor plate is Noggin. Notably, loss of function approaches for noggin in the mouse embryo, albeit normal expression of $\mathrm{SHH}$, resulted in CNS ventralization failure, similar to SHH mutant mouse. Also, induction of SHH in the non-neural tissue of chick embryos triggered noggin expression in neighboring cells [26-28]. Those studies suggest that SHH may act upstream of noggin for DV patterning of the vertebrate neural tube.

Dorsal half; BMP and WNT signals: Formation of the roof plate and neural crest cells in the dorsal region of neural tube of vertebrates requires signals from the nearby non-neural ectodermal cells [1, 26-28]. One of the main signals essential for triggering the neural differentiation in the dorsal half of neural tube is the BMP signal, a member of the superfamily of transforming growth factors (TGF) $\beta$ [26-28]. BMP 4 and 7 both play critical roles at the onset of dorsal neural progenitors specification, being secreted from adjacent ectodermal cells and then from the roof plate itself. Similar to SHH, BMPs also have homologs in invertebrates e.g., Decapentaplegic (Dpp) in Drosophila, which acts in embryos to pattern the dorsal region during early stages of development [26-28]. In contrast to SHH, which acts as a morphogen, BMP concentration appears uniformly distributed. Right after the closure of the neural tube, BMPs are released and lead to the generation of a variety of dorsal interneuron and sensory neurons. BMPs bind to their receptors and transduces an intercellular signal, which leads to phosphorylation of SMAD transcription factors (Mothers against decapentaplegic, Mad in Drosophila).

In addition to BMPs, WNT ligands are also involved in DV patterning. WNTs is another superfamily of growth factors, secreted from the dorsal ectoderm in vertebrate embryos e.g., Wnt1 and Wnt3a. WNTs are viewed as acting downstream of BMP. Loss-of-function and gain-offunction studies indicated that WNT signaling is involved in the generation, population, and 
differentiation of dorsal cell fates [26-28]. Hence, several signals govern the DV axis formation and distinct gene expression pattern has been identified along the DV axes [1].

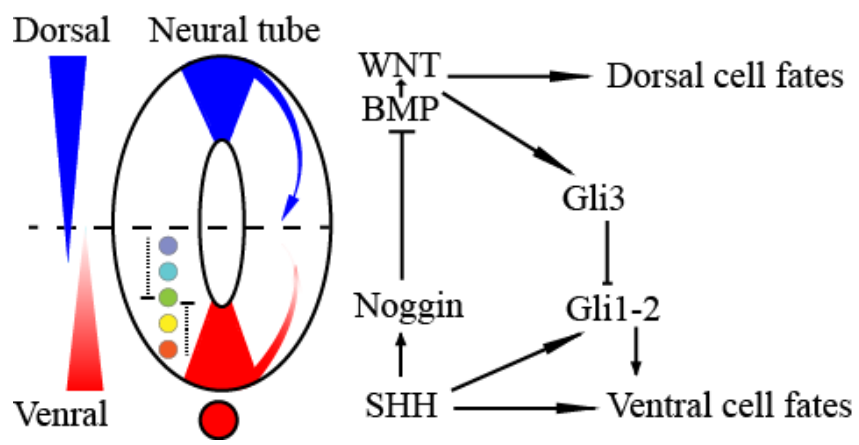

Fig. 2. Neural tube DV patterning. Scheme of main signals and players patterning the neural tube dorsoventrally in vertebrates.

\subsubsection{Anteroposterior, $\mathrm{AP}$ axis develops during several stages}

AP axis formation involves a number of signals. Some of the DV signals, such as Follistatin, Noggin, and Chordin act in the neural plate to induce more of the anterior neural cell characteristics than the posterior. However, additional signaling molecules are also needed to govern posterior neural cell differentiation. Fibroblast growth factor (FGF), a secretory family of proteins, and retinoic acid, a steroid-like molecule, are two independent signaling pathways that are required for proper neural differentiation in more posterior parts of the vertebrate CNS. However, these alone cannot explain the finer segmentation within each of the four main divisions of the CNS i.e., forebrain, midbrain, hindbrain and spinal cord [1].

Hox homeotic genes are a well-conserved family of homeobox genes, which in Drosophila are known as the Homeotic Complex, HOM-C. In mammals, 38 Hox genes are distributed in four distinct gene clusters (Hox-a to Hox-d), each located on a separate chromosome. They are exclusively expressed in the posterior parts of CNS i.e., spinal cord and hindbrain. Hox genes are involved in AP axis formation during embryogenesis in both vertebrates and Drosophila, and are themselves under the regulation of other factors, both intracellular and intercellular e.g., retinoic acid secreted from mesodermal cells [1].

\section{Drosophila: a powerful model for neurodevelopmental studies}

Due to the slow generation speed of vertebrates, the high costs, and, at least previously, limited genetic tools, relatively less complex organisms had been used to investigate the regulatory mechanism behind neural development in humans. Drosophila has been widely used for over a 
century in neurobiological studies, especially for genetic approaches. It has been discussed whether studying neurodevelopment in Drosophila can be beneficial for understanding the human CNS development. However, molecular and genetic studies in the 80 's and 90 's revealed that many of the fundamental processes underlying CNS development were indeed evolutionary conserved. Moreover, with the complete genome sequences available for Drosophila and mammals comparative analysis revealed a high level of sequence similarity between many Drosophila and human genes. Hence, the fundamental mechanisms behind the development of the CNS appear to be wellconserved from invertebrates to vertebrates and onward to humans [20, 30]. In addition, Drosophila has advantages over other model organisms for studying developmental biology; such as short life cycle, large brood size, inexpensive maintenance, relatively simple anatomy, availability of powerful genetic tools, possibility of conducting genetic screens [31, 32], fully sequenced genome [33], genetic mosaics, UAS-Gal4 misexpression transgenic system, and landing site transgenesis [34].

Drosophila developments start with 21 hours of embryogenesis after fertilization, followed by two periods of four days of larva and pupa development, respectively before it enters into adulthood. Larvae hatch with a fully formed CNS (brain and ventral nerve cord), generated during embryogenesis, which can guide the larvae through larval life. However, the larvae CNS continues developing, in particular in the pupae, and a larger more complex CNS is found in the adult Drosophila [20].

\section{The Drosophila CNS forms from the four neurogenic regions}

The body plan of Drosophila consists of six head segments, three thoracic and ten abdominal segments. The first signaling event starts from a set of maternally loaded genes e.g, bicoid and nanos along the AP axis. DV axis formation is controlled by the EGFR ligand Gurken and Toll ligand Spätzle, which leads to a gradient of BMP signaling from dorsal to ventral segments. The gradient of BMP signaling subdivides the embryo into mesectoderm, neuroectoderm, dorsal epidermis, and amnioserosa, respectively from dorsal to ventral [29-31]. The Drosophila CNS is formed from four neurogenic regions: two neurogenic regions placed bilaterally on the ventral area of the embryo by the time the embryonic body is axially patterned, and the two anterior brain neurogenic regions [35]. Within these four neurogenic regions, a subset of the ectodermal cells acquire neural progenitor identity, denoted neuroblasts (NBs) in insects. After formation of NBs, they delaminate from the epithelial layer basally and produce a fixed lineage by segregating their progenies to the interior part of the embryo. 


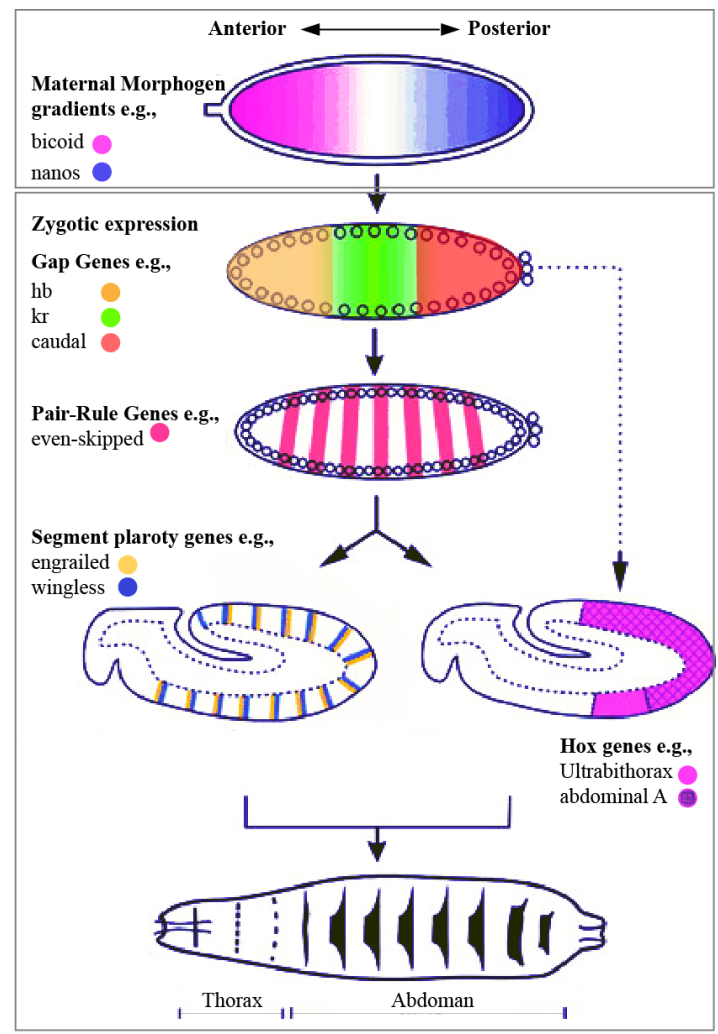

Fig. 3. The AP patterning of Drosophila during embryogenesis. The expression of the main patterning genes along the AP axis during Drosophila embryogenesis. Modified from [36]

\section{The Drosophila CNS axial patterning along the DV and AP axes}

The Drosophila embryo is segmented, and similarly, the neuroectoderm is also segmented. Along the AP axis, the two anterior neurogenic regions generates the brain, while the two posterior neurogenic regions generates the ventral nerve cord (VNC) $[1,20]$. By the end of the gastrulation, the neuroectoderm is segmented, due to the overlapping expression of axial determinant genes, known as spatial selectors [29]. This patterning is already started by the time of NB formation. CNS regionalization is provided by the activity of segment-polarity genes, gap genes, pair-rule genes and Hox genes along the AP axis, and by columnar genes along the DV axis [20, 35, 37-41]. Intrasegmental repeated expression of segment-polarity genes is placed along the entire AP axis e.g., transcription factors Engrailed and Gooseberry. Several gap genes specifically control anterior parts of the CNS i.e., empty spiracles and orthodenticle, also known as ocelliless [29, 42-44]. The activity of gap genes divides the brain into supraoesophageal and suboesophageal ganglions, each of which 
consists of three segments, most simply referred to a B1-B3 and S1-S3. Hox genes are active in the most posterior parts of the brain and VNC.

The VNC is segmented into three thoracic (T1-T3) and ten abdominal (A1-A10) segments (neuromeres). Every segment is divided into the midline and two bilateral symmetric hemisegments (hemineuromeres). Detailed studies and mapping of NBs along the VNC axes show a serially repeated group of $\sim 30$ lateral NBs per hemisegment. Also, a group of specialized midline progenitors and their progenies also develop at the midline [45]. Each particular NB is generated at a unique spatial position, which results in the expression of a selective code of NB determinants that manifest into the generation of a stereotyped lineage. The NB lineages vary in size from 2-40 cells. The lateral NBs are established in seven rows and six columns e.g., NB5-6T refers to the NB located in row 5 and column 6 in the thoracic segments. The comparatively simple structure of the Drosophila VNC, and the invariant appearance of NBs makes it a very excellent model for studying neural development [20, 29, 46, 47].

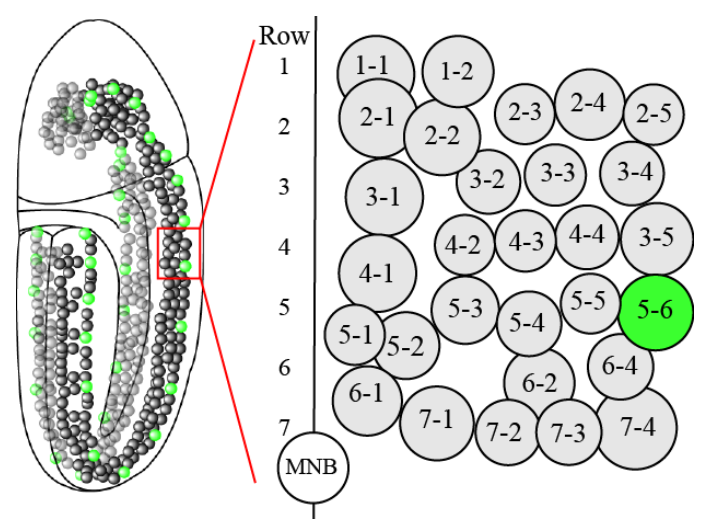

Fig. 4. The NB array. On the left, a lateral view of Drosophila embryo and its developing CNS illustrated at about stage 12 when all of the NBs are formed. On the right side, NBs ordered in seven rows and six columns, per VNC hemisegment; vertical line resembles the midline line, where the midline NB, MNB (white) is placed. The (gray) cells represent the lateral NBs, and the (green) one represents the NB5-6. Modified from [48].

DV patterning is controlled by columnar gene activity: In Drosophila, segregation of neurogenic ectoderm from the rest of the ectodermal layer is due to the function of two external signaling molecules produced by the short gastrulation ( $\mathrm{sog}$ ) and decapentaplegic (dpp) genes, which are orthologs of chordin and BMP4 in vertebrates. Although the vertebrate CNS is structurally somewhat different from that found in Drosophila, the homologous domains of the DV axis express homologous genes, denoted columnar genes i.e., ventral nervous system defective ( $v$ nd; also known 
as Drop), intermediate neuroblasts defective (ind) and muscle specific homeodomain (msh), expressed present in medial to lateral compartments, respectively. Their expression starts at the blastoderm stage and loss-of-function studies of the columnar genes showed impaired NB specification [20,35]. Columnar genes interact in a way such that the more medially/ventrally expressed is dominant over the others, known as ventral dominance i.e., vnd represses ind and msh, while ind represses msh. The ventral border of the vnd expressing domain is limited by twist (mesodermal gene) and snail. In contrast, the establishment of dorsal borders is not very clear. Dpp gradient seems to be restricting the expression of $m s h$ to the dorsal border of its domain, and Dorsal graded level which activates $v$ nd is suggested to regulate the dorsal borders of its expression domains. Dorsal and Epidermal growth factor receptor, Egfr are known for constraining the dorsal border of ind expression. Egfr function in the ind and $v n d$ expressing regions is important for NB generation, and it is critical for maintaining the ventral expression of vnd. To sum up, columnar genes are involved in NB formation within their expression segments, thought this role seems to be less clear for $m s h[35,39]$.

Hox homeotic genes are critical for an appropriate AP patterning: By the end of 1980s, the first systematic genetic screen for the genes involved in embryonic body plan formation, as well as the work by Ed Lewis, had defined many of the genetic regulatory mechanisms of Drosophila body plan formation, in particular the role of the Homeotic complex (HOM-C) [49]. More detailed studies identified a conserved $180 \mathrm{bp}$ sequence, the homeobox, in many of those regulatory genes, which encodes for a 60 aa homeodomain. This domain contains three $\alpha$-helices, where the most Cterminal one has a specific DNA binding feature. Hox hometic genes are involved in AP axis formation during embryogenesis in both mammals and Drosophila [1].

Hox homeotic genes are well conserved, and their activity during early stages of Drosophila CNS development plays a vital role in the formation of AP axis. In Drosophila, two chromosomal complexes, Antennapedia and Bithorax, encode for these homeodomain transcription factors [50]. The Antennapedia Complex (Antp-C) consists of five genes: Antennapedia (Antp), sex combs reduced (scr), labial (lab), deformed (dfd) and proboscipedia ( $p b)$. The Bithorax Complex (Bx-C) has three members: Ultrabithorax (Ubx), abdominal-A (abd-A) and Abdominal-B (Abd-B) [51]. The expression pattern of each Hox gene is linked to its place in the genome, in relation to the other family members. The genes located to the most 3' end of the cluster are expressed more anteriorly. Hox genes which are more posterior, suppress both expression and function of the ones which are expressed anteriorly to them. This phenomenon is denoted posterior prevalence and is critical for the appropriate Hox expression and for proper segmentation [52]. Similar studies on the AP patterning of the avian and mammalian neural tube suggest a high degree of conservation between invertebrates and vertebrates regarding the combinatorial role of Hox homeotic selectors in the generation of various special cell types within distinct domains of the CNS [29, 53]. 


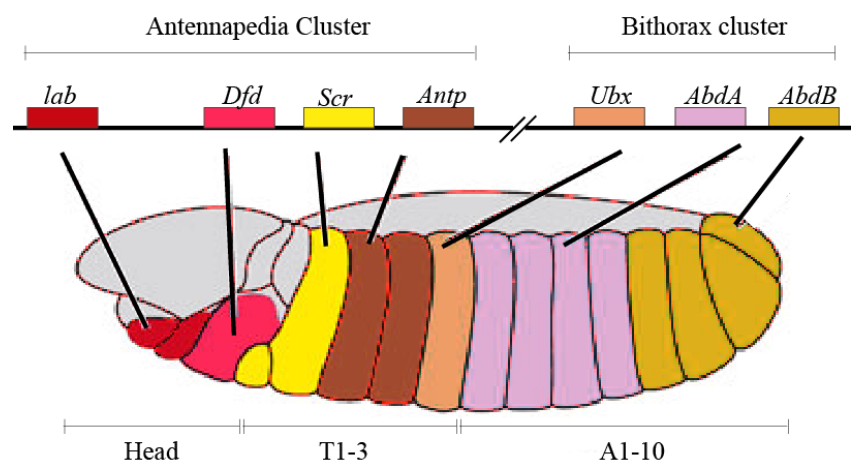

Fig. 5. The expression patterns of Hox genes in the early embryonic stage of Drosophila. On the top, the Hox genes with embryonic expression, which belong to two distinct clusters are shown on the right arm of the third chromosome. Each color represents the expression pattern of linked gene in the segmented embryo at an early stage. Modified from [54].

\section{Lateral inhibition and NB selection}

The formation of NBs is controlled by two sets of genes: proneural and neurogenic genes. Proneural genes encode bHLH transcription factors, achaete, scute and lethal of scute, located in the ASComplex [55, 56]. Proneural gene expression within the neuroectoderm is initiated before NB generation, and they have a precise pattern with partial overlaps. This mosaic pattern of AS-C expression determines where NBs form. The activity of these transcription factors within ectodermal cells drives them to the neural fate [57, 58]. Cells expressing AS-C form small clusters of around 68 cells within the neuroectoderm monolayer, denoted proneural clusters or neural equivalence groups $[7,59,60]$. Every cell in each equivalence cluster has the same potential of becoming an NB, but only one of them will be chosen as an NB [7]. Within each cluster, cells communicate via Notch signaling to select one of them to become an NB: This selection is known as lateral inhibition. Notch is a central player in development, and highly conserved among most of the multicellular organisms. The Notch intracellular cascade is activated by binding of the Notch receptor to its ligand, Delta. Activation of the Notch receptor leads to cleavage of its intracellular domain (NICD), which translocates to the nucleus and interacts with the Suppressor of hairless transcription factor, and the Mastermind co-factor. This tripartite complex activates gene expression of a family of inhibitory bHLH transcription factors; the Enhancer of split family (E(spl)). The $\mathrm{E}(\mathrm{spl})$ factors suppress the expression of the AS-C proneural genes, which reduces the neural potency of the Notch-activated cell, by down-regulation of Delta. Therefore, initially homogenous levels of Notch and Delta among the equivalence cluster is easily tilted such that a single cell with the stochastically higher expression of Delta will activate Notch in neighboring cells, hence activating $\mathrm{E}(\mathrm{spl})$ and down-regulating AS-C in these cells. The down-regulation of AS-C will lead to loss of Delta expression, hence reducing Notch activation in the cell with higher Delta. The high Notch activity in the neighboring cell lead 
to the high expression of $E(s p l)$ genes and extinguishes the expression of proneural genes, and hence drives them toward an epidermis fate [1, 58, 61]. In line with these studies, loss-of-function studies showed that mutations in the AS-C lead to impaired NB formation, and mutations in neurogenic genes turn almost all of the neuroectodermal cells to NB [20]. The fundamental genetic and molecular mechanism of the Notch-dependent selection of NBs is conserved throughout phylogeny, albeit the process is not as well understood in vertebrates [1].

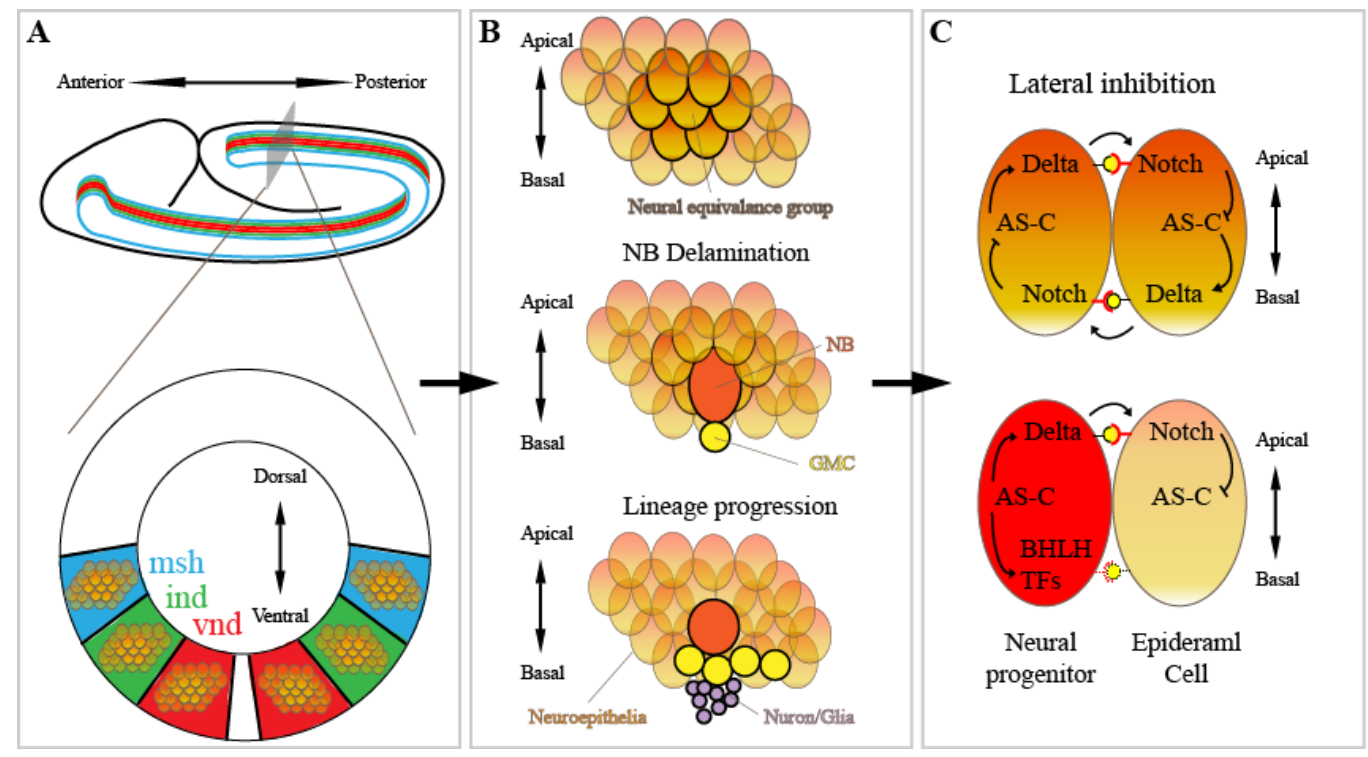

Fig. 6. NB delamination and lateral inhibition. A) The expression of the three columnar genes is shown. B) The neural equivalence cluster and the NB selection, delamination and lineage progression. C) Lateral inhibition processes leads to the selection of one NB with down-regulation of Notch activity. Modified from [7],[1].

\section{Temporal selectors drive cell diversity in developing embryonic Drosophila VNC}

In addition to DV and AP spatial patterning, embryonic NBs undergo temporal changes, which govern the lineage progression during VNC development. These temporal changes lead to programmed changes in the daughter cell types produced within the same lineage at different time points [29, 62-65]. These temporal changes are controlled by a set of transcription factors expressed in a stereotyped sequence in embryonic NBs, referred to as the temporal cascade: Hunchback (Hb) $\rightarrow$ Kruppel (Kr) $->$ Pdm1-2 -> Castor (Cas) -> Grainy head (Grh) [66, 67]. 
In most of the cases, the GMCs and their daughters continue expressing the temporal selector(s) expressed by the NB when they were born. Importantly, temporal selectors are not linked to a specific cell fate, and the canonical cascade of temporal selectors has been observed in lineages which generate totally different cell types [29, 64]. Loss-of-function studies on different temporal selectors revealed premature expression of next TFs within the cascade, or maintenance of the previous one in a longer time window, or omitting of the whole cascade [29, 67, 68]. Also, gain-offunction studies revealed that temporal TFs activate the next one in the queue and repress the next one(s) downstream, and in general terms, earlier expressed TFs in the cascade are dominant over the late ones [29, 67, 68]. On top of that, shifting from one temporal factor to another may also be regulated by additional factors, so-called switching TFs: Distal antenna (Dan) and Seven up (Svp) are both involved in controlling the transition from $\mathrm{Hb}$ to $\mathrm{Kr}$ within the cascade [29, 69, 70]. Albeit the temporal selectors play a critical role in the generation of cell type diversity, the many types of cells identified within the CNS cannot be explained exclusively by this cascade. One explanation is co-expression of two of the temporal TFs for combinatorial effect [71]. Secondly, the activity of the same transcription factors in different temporal windows during lineage progression, may regulate different cell fate e.g., Svp initially controls the $\mathrm{Hb}$ to $\mathrm{Kr}$ switch, but subsequently acts in the Cas window to control cell fate [29, 72]. Moreover, the broad expression of temporal selectors can be divided into smaller time windows by other transcription factors, denoted sub-temporal genes. Temporal selectors regulate the onset of sub-temporal genes, and their subsequent expression within the temporal window adds to the diversity of generated cell fates [29, 71]. In combination, the solo and combinatorial effects of temporal selectors, the dual roles of some factors, and the role of subtemporal factors, provide a powerful temporal cell fate specification system. Temporal transcription cascades have also been identified in larval NBs, but involve only partly overlapping genes [29].

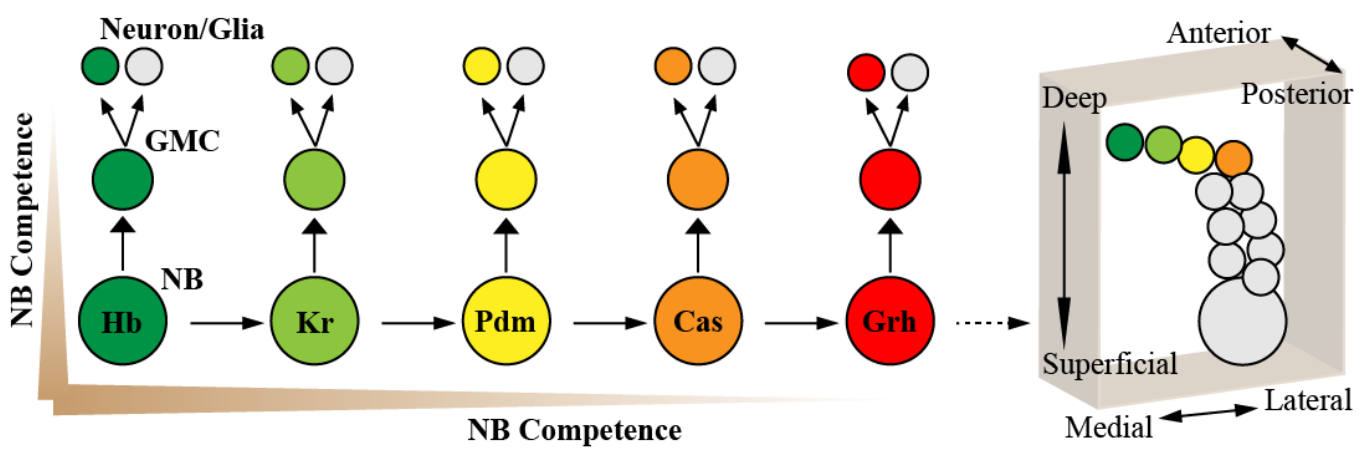

Fig. 7. Temporal selectors' expression. On the left the expression of temporal selectors is shown in the NBs of the Drosophila embryonic VNC during lineage progression. The NB expresses temporal selectors sequentially. Mostly the temporal selector that is expressed by NBs is also present in their progenies that are born within that time window. On the right, the position of a developed lineage is shown in the $3 \mathrm{D}$ view. Modified from [66, 67]. 


\section{Tissue/cell type selectors are critical for Drosophila embryonic CNS development}

Tissue/cell type selectors refer to factors which act within progenitor cells to regulate the genomic profile in a distinct, well-integrated and frequently exclusive manner, which restricts the progenitor to a particular type of tissue or cell. Their loss-of-function leads to loss of a particular type of cell or tissue, and their ectopic expression leads to expansion of their relevant tissue or type of cells [29]. These factors are mostly pioneers factors i.e.; they can bind to their genomic targets even in closed DNA regions. Hence, their activity is critical, especially during early development, for triggering transcription of silenced genes $[29,73]$. A very well-known example of cell type selectors are those inducing pluripotent stem cells, iPS factors, in mammals i.e., Sox2, Oct4, Klf4, Nanog, and Esrrb, which can govern somatic cells to a pluripotent one $[74,75]$.

In the Drosophila embryonic CNS, the only gene known to be a cell type selector is glia cells missing ( $\mathrm{gcm}$; also known as glide), which governs neural progenitors towards glial fate. Not only is its function sufficient and necessary for glia cell generation and maintenance, but it can also reprogram mesodermal cells to glia $[29,76,77]$. The glia inducing function of Gcm is upstream of a transcription factor named Reversed polarity (Repo), and the neural suppression action of $\mathrm{Gcm}$ is due to the activation of Tramtrack (Ttk; a zinc finger protein), which together with Repo represses the neural identity $[29,78]$.

\section{Terminal selectors determine the final identity of neuronal cell types}

The final specification of a neuron or glia is in part due to the remained or reassigned spatial cues, temporal factors and cell type specific selectors in the progenitor cell, which also make a direct contribution to terminal differentiation of cells [29, 79]. However, at the final step of cell differentiation another class of selectors, terminal selectors, are critical to regulating genomic responses, which lead to induction of specific molecular and morphological characteristics of the cell concerning its function and complete cell subtype identity. The term of the terminal selector for the first time was proposed by Hobert et.al. [80].

Good examples of such factors in Drosophila developing CNS are the Apterous, Islet and Lim3 TFs, which are expressed post mitotically in certain subsets of neurons, regulating their cellspecific identities e.g., axonal pathfinding pattern and neurotransmitter expression [81-83]. All of these TFs belong to homeodomain family and also contain a LIM domain (LIM-HD). The LIM domain is evolutionary well conserved and contains two zinc fingers, and proteins with LIM-HD domains are involved in many developmental programming steps in different organs and species [84].

Studies have identified Islet and Lim3 binding to the DNA regulatory regions of many effector genes required for the physiological and morphological identity of particular subtypes of motor neurons [29, 85]. Moreover, LIM-HD transcription factors show combinatorial effects to 
induce distinct cell identity e.g., expression of Lim3 in a subset of neurons positive for Islet revealed a combinatorial regulatory role of these two factors, in specific motor neuron subtypes of the Drosophila developing CNS [29, 86].

Terminal selectors are restricted to certain subtypes of cells, and they activate effector genes for specific cell morphology or functional identity. Loss-of-function of terminal selectors result in failure of terminal differentiation, evident by axon/dendrite pathfinding defects and loss of neurotransmitter expression, whereas ectopic expression of terminal selectors can lead to imposing a specific cell fate on different, but often context-related cells. Terminal selector expression may or may not be necessary for the maintenance of their induced fate throughout the cell's life. Further, it is important to consider the action of terminal selectors as selectors for a special cell subtype identity and not a certain subroutine that is common between different cell subtypes [29]. Moreover, terminal selectors may act in combinatorial codes to trigger their targets [29]. This is a logical scenario, considering the high number of distinct neuronal subtypes and the limited number of transcription factors, which necessitates the combinatorial effect of TFs for terminal selection e.g., generation of $\sim 10^{4}$ neurons and $\sim 400$ neural cell types in the embryonic Drosophila VNC [4, 87] cannot be explained by $\sim 723$ transcription factors, unless they have combinatorial code performance $[29,88]$. Although in rare cases a solo TF can be a terminal selector e.g., Dimmed is exclusively present in almost all of the neurosecretory neurons of Drosophila CNS and is both required and sufficient to trigger a battery of the genes establishing the neurosecretory identity [29, 89-91].

To sum up, terminal selectors refer to a particular functional class of TFs that are expressed in postmitotic cells and play a role in terminal differentiation, by activating the required effector genes to assign a specific neural identity evident by morphology, physiology and neurotransmitter expression [29].

\section{The Drosophila cell cycle machinery}

The cell cycle in general consists of four distinct phases: mitosis phase (M), and synthesis phase (S) when DNA replicates, which are separated by two growth phases (G1 and G2) i.e., G1>S> G2> MPhase [92]. Cell cycle progression depends upon activation of certain cyclin dependent kinase (Cdks) at specific stages of the cell cycle. Activation of Cdks is based on their binding to their specific cyclin protein, resulting in a $\mathrm{Cdk} / \mathrm{Cyc}$ heterodimer. The Cdks are continuously present within the cell, whereas Cyclin expression and degradation is typically oscillatory during the cell cycle progression. The main G1 Cdks in Drosophila are Cdk1 and Cdk2. Cdk2 controls the transition from G1 to Sphase, while Cdk1 regulates the G2>M checkpoint [92, 93]. Activity of Cdk2 is dependent on Cyclin $\mathrm{E}$ (CycE) [94, 95], whereas Cdk1 is activated by CycA, CycB and CycB3 [96, 97].

Also, the E2f1/Dp transcription factor complex has also been shown to be necessary for G1>S transition. Activation of this complex is dependent on the G1 Cdk/Cycs, via phosphorylation of its inhibitor Rbf1 (Retinoblastoma; Rb in vertebrates). Activation of E2f1 leads to upregulation of CycE 
and genes required for DNA replication and M-phase [98, 99]. Although the knowledge about exact function and interactions of E2f1 is still poor, it has been known to differ in tissue/cell type and even position of the cell within the same tissue [100].

Anaphase-promoting complex (APC) degrades cyclins expressed at the M-phase checkpoint e.g., CycA and CycB1/3, while the Skp-1-Cullin-F-box (SCF) complex mainly degrades CycE [101]. Cyclin degradation can also be regulated at another level e.g., the regulator for CycA, Rcal is an inhibitor of APC [102]. Moreover, Cdk1/CycA phosphorylation, by Wee1 and Myt1, inhibits its activity $[103,104]$. Their effects can be partly prevented by the phosphatase String, known as cdc25 in yeast and mammals $[105,106]$.

Eventually, Cyclin-dependent Kinase Inhibitors (CKIs) can block Cdk/Cyc activity e.g., Dacapo (Dap; vertebrate p21Kip1-p27Kip2) arrests cell in G1-phase, by effecting of the Cdk2/CycE activity [107, 108]. Similarly, the CKI Roughex (Rux) is an inhibitor of Cdk1/CycA [92, 109].

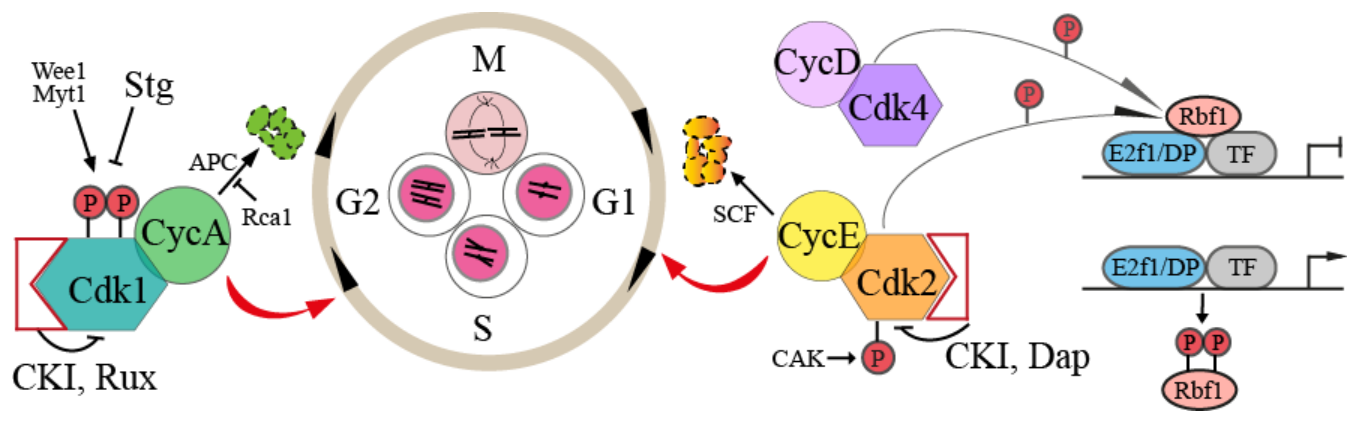

Fig. 8. The main players of the cycle machinery in Drosophila embryonic neural progenitors during mitosis. Modified from $[92,110]$.

\subsection{Cell fate determination dependent on cell cycle}

Undoubtedly, an appropriate developmental programming cannot be without a tight balance between cell specification and proliferation, which brings up the question whether these two aspects of development are coupled at some level or not? Here, the neural lineages of the Drosophila embryonic VNC have been a widely used model system to address this question [92].

The stereotyped NB lineages of the Drosophila VNC differ during embryogenesis, both morphologically and functionally, in which commitment to certain cell fate happens simultaneously with the cell cycle progression. Although this is not the case for every tissue e.g., in Drosophila wing disc generation $[92,111]$. Regulation of cell differentiation, during cell proliferation within these 
lineages, might be dependent on a cell cycle timing e.g., numbers of cell cycles; or rather linked to the cell age e.g., governed by a cascade of regulatory factors or metabolic activity [92]. Therefore, understanding of cell cycle performance and its regulation within the Drosophila embryonic NBs may shed light on these questions. As was mentioned before, typically, embryonic NBs go through rounds of asymmetric divisions to renew themselves and give rise to GMCs, which divide asymmetrically once, to produce two differentiated cells. High level of the S-phase promoter, CycE and the absence of its inhibitor, Dap, within the generated NBs, suggest that both the NBs and GMCs bypass the G1-phase [107, 108, 112]. Therefore, the main time window for NBs and GMCs fate determination is S-phase or G2-phase. NBs have 40 -minute division time, and GMS divide comparatively slower, $\sim 100$-minutes after their generation $[110,113]$. The short time of the NBs cell division, suggest that the G2-phase also must be decreased [92, 114].

On the other hand, expression of Dap is one of the main causes for cell cycle exit in GMCs' progenies. Dap onset in GMC cells occurs right before the final division, and it keeps the postmitotic cells in G1-phase. Therefore, cell fate determination of the postmitotic neural cells occurs during G1-phase $[92,107,108]$. This data led to the hypothesis that cell fate determination after and during $\mathrm{S}$-phase does not interrupt cell division, whereas, the cell fate determination before $\mathrm{S}$-phase result in cell cycle exit. In addition, it remains the question whether S-G2 cell specification is characteristic of NBs and GMCs or it is just the consequence of their fast cell cycle [92].

As mentioned before, diversity of cell identity within the fixed lineage of Drosophila VNC seems to be coupled with the cell cycle regulation, which can be a simple answer to the origin of cell fate variation. Loss-of-function studies on Drosophila NBs that cause interruptions in different phases of the cell cycle progression identified many cell identities as dependent on the cell cycle machinery $[92,115]$. This dependency might occur at three different phases i.e., the progression of S-phase, the accomplishment of cytokinesis, and cell cycle factors which are involved in cell fate determination.

Other examples of the close connection between the cell cycle and cell fate stem from studies of NB6-4 in the thoracic region of Drosophila VNC. This NB behaves as a neuroglioblast in the thoracic segments, whereas in abdominal segments it is a glioblast [116]. This contrast was revealed to depend upon the action of $C y c E$ within the thoracic segment, which is suppressed by homeodomain Hox genes in the abdominal segments (by $a b d-A$ and $A b d-B$ ) [117]. Other examples pertain to the cyclin- dependent kinase inhibitor, p27 in vertebrates (Dap in Drosophila and Cki-1 in C.elegans), which has a direct effect on cell fate determination of Muller glia [92, 118, 119].

Cell fate determination dependent on progression of S-phase: One example of cell identity linked to the S-phase progression is the expression of Even skipped (Eve) within the first GMC of NB1-1. Interrupting the S-phase by e.g., mutants in string (stg) results in loss of Eve expression within those cells, whereas loss-of-function of pebble, which inhibits cytokinesis has no effect on the activation of Eve [92, 112, 115, 120]. Moreover, introducing the DNA replication in the stg mutant flies can rescue the expression of Eve cells. This suggests the necessity of DNA 
replication for expression of certain cell fate determinants and confirms the hypothesis of Holtzer et.al. in 1975 denoted as 'Quantal cell cycle', which states that passage of a progenitor cell through a series of cell divisions regulates cell diversity by providing the silenced part of the genome possibility of active transcription $[112,121]$.

Analogous results had been observed in NB4-6T, which give rise to a neural and a glial precursor cell, where expression of Gcm within the glial precursor cell is dependent on the S-phase progression [122-124].

Cell fate determination depends on cytokinesis: Asymmetric division involves the cell cycle machinery and is linked to biased segregation of cell fate determinant factors. Therefore, daughters' cell fate is decided upon the inherited factors from their mothers. Cell fates can be either directly determined upon inherited TFs by the progenitor, or indirectly as an effect of modulator molecules triggering signaling pathways, which lead to cell differentiation in the daughter cells [92].

Prospero (Pros) is a TF that is segregated into GMCs during NB asymmetric division. Pros nuclear localization in GMC up-regulates genes specific for GMC characteristics and suppresses NB identity genes [125-127]. Impaired cell cycle progression in stg mutants result in expression of Pros within the NBs and causes their aberrant differentiation into neurons. Hence, correct finalization of cytokinesis is critical for identification of GMC fate and renewed NB divisions [92, 128].

Apart from NBs, GMCs also divide asymmetrically, and here biased segregation of Numb into one cell triggers Notch pathway in the other cell [129]. Arresting dividing NBs in the S-phase leads to specification of NBs toward Notch-off state, as Numb is expressed in the NB and blocks the Notch pathway. Therefore, cytokinesis is suggested to be essential for daughters' cell fate adoption. However, some experiments in the numb mutant background show that Notch gets activated via adjacent mesodermal cells, and NB moves towards Notch-on fate [92, 129-131].

Interestingly, expression of the temporal cascade of $\mathrm{TFs}: \mathrm{Hb} \rightarrow \mathrm{Kr} \rightarrow \mathrm{Pdm} \rightarrow \mathrm{Cas} \rightarrow \mathrm{Grh}$, has been observed as intrinsic to the NBs during lineage progression. However, the cascade is halted if the NBs arrest in their first cell cycle and the expression of $\mathrm{Hb}$ is maintained in the NB [67]. Moreover, $p b l$ mutants also showed sustained expression of $\mathrm{Hb}$, even after several nuclear divisions [132]. Therefore, transition from $\mathrm{Hb}$ to $\mathrm{Kr}$ requires cytokinesis.

Importantly, normal expression of the temporal cascade was observed in the case of $s t g, h b$ double mutants, which suggests a cell cycle-independent cellular timer regulating the cell fate, at least for NB identity in the later stages of lineage progression $[92,132]$. 


\section{Asymmetric division}

For over a century it had been agreed that the division mode of progenitors affects the cell fate of their daughters $[5,133]$, and that this is fundamental for diversity of cell fate, not only among multicellular but also for unicellular organisms [134]. The main feature of stem cells is the ability to selfrenew and produce daughter cells that are committed to a specific cell fate. During development, maintaining the balance between asymmetric and symmetric divisions is vital. An aberrant bias towards asymmetric division can lead to immature differentiation, while an increased tendency toward symmetric divisions may cause overgrowth or even cancer. Therefore, deeper knowledge of NB division type control may shed light on several aspects of cancer biology $[5,135,136]$.

\subsection{NB asymmetric division}

Drosophila embryonic NBs are one of the main models for studying the regulatory mechanisms underlying asymmetric division [134]. The asymmetric division of embryonic NBs involves the establishment of cell polarizing factors and segregation of fate determinant molecules (in the form of mRNA or protein). Moreover, the arrangement of centrosomes during mitosis and organization of spindle orientation concerning the polarizing cues and fate determinant factors is also critical. Interruption of any of those steps can influence cell proliferation/specification and hence lineage progression $[5,134]$.

Each NB produces a unique and fixed lineage during embryogenesis, based upon its particular position within the neuroectoderm, and hence its specific gene expression profile. The VNC contains a more specialized group of midline progenitors, while in this thesis the focus is on the lateral NBs. Lateral NBs may divide between 3-18 times during lineage progression, producing neurons and glia before they exit the cell cycle [5]. Despite differences in the number of cells produced per lineage, the basis of asymmetric machinery appears to be common between all NBs [38].

In the Drosophila embryonic VNC, after NBs are generated in the polarized epithelium layer, they delaminate basally. At the beginning of division, the NB mitotic spindle is coordinated with epithelial cells in their surroundings. However, during metaphase, the mitotic spindle rotates 90 degrees and aligns with the apical and basal poles [134, 137]. NBs divide asymmetrically to renew themselves and bud off a daughter cell. The daughter cell is often referred to as the ganglion mother cell (GMC). By the end of the telophase, the cell located basally is smaller in size and has received the cell determination factors for GMC (Pros, among others), while the apical cell is the NB [134]. NBs diminish in size during the series of divisions they pass through until the lineage progression is accomplished and the NB exits the cell cycle [5].

The polarity is established already in the neuroectodermal cells and maintained in NBs, by a well-conserved complex denoted the Par complex consisting of three main components: DmPar-6, Bazooka (Baz), also known as dPar-3, and atypical kinase C (aPKC). The formation of the Par-C 
occurs before NB delamination, in the neuroectodermal cells, and is stably maintained at the apical cortex of dividing NBs [5, 138-140].

Apart from the Par-C, the apical complex contains another evolutionarily conserved set of proteins i.e., Partner of Inscutable (Pins) and $\mathrm{G} \alpha_{\mathrm{i}}$, which are linked by Inscutable (Insc); their onset of expression is during NB delamination. During NB delamination, apical localization of Insc is dependent on Par-C, which synchronizes the polarization of epithelial cells and NBs, with Pins being recruited to the apical complex by Insc [134, 141, 142].

The emerging picture suggests that the co-localized position of these two apical complexes also involves direct binding between them, suggesting that Par- $\mathrm{C}$ recruits Pins- $\mathrm{C}$ to the apical pole via Insc, while Pins-C is required for the maintenance of Par-C in the NBs. Both of which are critical for regulating the apicobasal mitotic spindle orientation and asymmetric segregation of polarizers and fate determinant factors $[5,134,140,143]$.

How is the spindle orientation coordinated with NB polarity? Pins binds to the Mushroom body defective (Mud) and Kinesin heavy chain (Khc73) proteins, which are microtubule interacting proteins known to be important for controlling the mitotic spindle orientation [144]. Khc73 is a linker between astral microtubules and Discs large (Dlg), which binds to Pins-C and is connected to the Insc-Par-C on the apical cortex [5, 145]. On the other hand, the stability of Par-C is known be dependent on the contact between the neuroectodermal layer and NBs, which is critical to keep the mitotic orientation during the NB divisions aligned with the apicobasal axis. This suggests that adjacent neuroectodermal cells provide extrinsic signaling molecules to maintain mitotic spindle orientation with respect to tissue polarity during the lineage progression [146], as the mitotic spindle orientation governs the direction of tissue growth. The extrinsic Tre1 G-protein coupled receptor (GPCR), expressed in the epithelium is a candidate for providing this cue. Tre1 activates Goo protein in a classical GPCR-dependent manner [147]. Tre1 activation leads to Go $\alpha$ physically binding to Pins and to recruit Pins-Insc, and consequentially Par-C to the basal pole, thereby organizing polarization and spindle orientation of NBs on tissue polarity [148].

The outcome of NB asymmetric division is two cells of unequal size i.e., NBs of about 10$12 \mu \mathrm{m}$ and GMCs of 4-6 $\mu \mathrm{m}$. During later steps of lineage progression the differences in size between the NB and its daughter are less pronounced. The mitotic division of dividing NB is symmetric until anaphase when Astor microtubules enlarge at the apical pole and shrink at the basal side; this shifts the cleavage plane toward the basal pole [5]. Several studies suggest G-proteins i.e., G $\beta 13 \mathrm{~F}$ and G $\gamma 1$ are involved in the regulation of cell size and geometry of the spindle. Indeed, the interaction of Pins$\mathrm{G} \alpha_{\mathrm{i}}$ with Locomotion defects (Loco) regulate $\mathrm{G} \beta \gamma$ release and leads to regulation of daughter cell size, although the downstream regulators are not well known yet [5, 144, 149-151].

Proper cell polarity aligned with mitotic spindle orientation enables the biased segregation of cell fate determinant factors toward the basal pole of the dividing NB, where the GMC develops. On the NB basal pole, distinct sets of basal complexes are localized, one consisting of Brain tumor 
(Brat), Miranda (Mira), Prospero (Pros) and Staufen (Stau), and the other one contains Numb and partner of Numb (Pon). Segregation of cell fate determinant factors is dependent on Par-C interaction with certain cortically placed proteins, which are also important for spindle orientation and geometry [5]. Loss-of-function studies of Insc indicate that it is necessary for proper polarization of some basal factors e.g., Pros and Numb. During mitosis, Pros is localized on the basal crescent of the NB cell membrane by Miranda (Mira) [5, 152, 153]. Mira is also an adaptor protein for Brat and Stau. Moreover, Stau which is an RNA-binding protein recruits pros mRNA to the basal pole via Mira [154]. The activity of the homeodomain transcription factor Pros in the GMC directly inhibits cellcycle gene expression i.e., $C y c E, E 2 f 1$, stg and $C y c A$, and consequentially restricts the proliferation potential of GMCs to one final division. Pros also regulates expression of cell differentiation effector genes, and hence Pros is essential for down regulating NB potential in favor of cell differentiation $[5,155,156]$; This has been proven by both chromatin and expression profiling, which identified Pros as the suppressor of NB genes and activator of neural specification ones $[156,157]$.

Also, Brat is identified as a post-transcriptional repressor protein, which can directly bind to Mira and segregate it to into the GMC. Brat is known to suppress cell renewal genes e.g., $h b$ in GMCs [5, 158]. The loss-of-function effects of Pros and Brat showed similar effects (higher neural proliferation ratio, and also, over proliferation caused by a mutation in Brat is significantly reduced by misexpression of Pros, suggesting that Pros is acting downstream of Brat [159]. However, lossof-function of Pros is not enough to convey the GMC into an NB, which suggests there are more factors involved in the asymmetric division machinery $[38,158]$.

The very first molecular aspects of the asymmetric division were revealed by the discovery of Numb as a critical factor for the asymmetric division and cell fate determination [160]. Numb is a membrane-associated protein with a protein interaction structure called PTB. Although the function of Numb is not so well understood, loss-of-function studies identified ectopic NBs in Numb mutated clones of larval CNS [158]. Numb is also critical for establishing cell type difference between the two daughters of GMCs by inhibiting Notch signaling [1, 134]. 


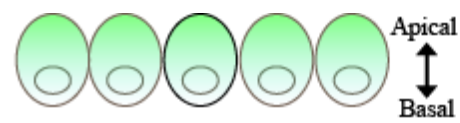

\section{Epithelial polarity}

Baz , Par-6, aPKC

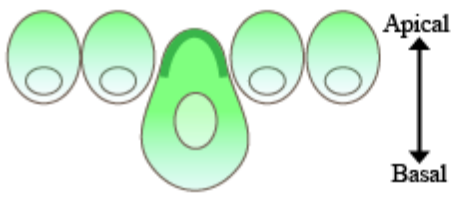

NB polarity

Baz, Incs, Pins, Gai
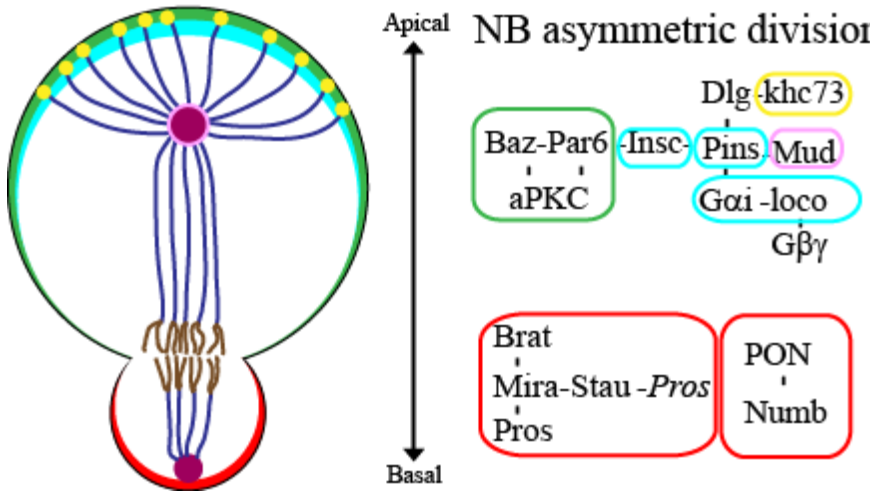

Fig. 9. NB polarity and asymmetric division machinery. On the top the AP polarity of the neuroectodermal cells and their main polarity genes. In the middle delimitation of selected NB and up-regulation of NB asymmetric machinery is shown, which leads to bias segregation of polarity and cell fate determinant factors to the GMC or NB, as illustrated below. Modified from [5, 144].

\subsubsection{NB Division Type modes}

The NBs divide asymmetrically and expand their lineage basally. Up until now, three types of asymmetric division modes have been discovered in Drosophila dividing NBs: Type II, type I and type 0.

Type II division mode is when NBs divide to self-renew and produce an intermediate progenitor (INP), which divides several times asymmetrically, to self-renew and produce GMCs, which each generates two neurons and glia. This type of division was discovered in 2008, in Drosophila larval brain [161-163]. The particular behavior of the type II NBs can be explained, at least in part, by the absence of Pros in the dividing NBs. Therefore it is not available to inhibit the self-renewal capacity in their INPs. The localization of Pros in the INPs is cytoplasmic whereas Deadpan, Dpn is in the nucleus. Dividing INP segregates Pros asymmetrically to the GMC. The expression of Pros in the dividing INPs seems to restrict the GMCs proliferation capacity [161, 162]; this was confirmed by loss-of-function of pros that lead to GMCs overgrowth [163]. In contrast with 
dividing NBs that produce two cells different in size, INPs division is symmetric concerning their morphology [161]. Interestingly the speed of division in type II window is greatly lower in comparison with the other two types of division. Type II division resembles neurogenesis in the mammalian brain, which suggests that mechanisms underlying the development of brain be highly conserved from Drosophila to mammals [161, 163].

Type I refers to when the NB divides to self-renew and buds off a GMC, which also divides once to produce two neurons or glia. This type of division was for a long time known as the canonical division mode for insect NBs, and is the most common mode of division in the Drosophila embryonic VNC $[38,110,162,164]$. In the type I window, dividing NBs express cytoplasmic Dpn and segregate Pros toward the GMCs, where Pros get nuclearized and limits the proliferation capacity of GMC to one round.

Type 0 division mode is when NBs divide asymmetrically and only once, to self-renew and directly produce one daughter cell committed to a certain fate. This division mode was discovered first in the NB 7-3 lineage, mapped by Doe lab in 2005. They identified the last division of NB give rise to a GMC that directly differentiates, and the renewed NB die [165]. This type of division was identified in many other lineages of the embryonic VNC by the Thor Lab, and also in the optic lobe of the larval brain $[110,166]$.

A regulated switch between division modes occurs in many, if not all, lineages, in the developing Drosophila VNC e.g., a programmed type I $>0$ switch. This was identified in the lineages NB5-6T, NB3-3A and NB7-3A, and is critical for correct lineage progression and consequentially VNC development [71, 110, 165-167]. All of these three types of division modes have also been observed in the developing mammalian brain [161], which suggests that fundamental molecular aspects of alternate daughter proliferation have been conserved throughout evolution [5, 168]. 

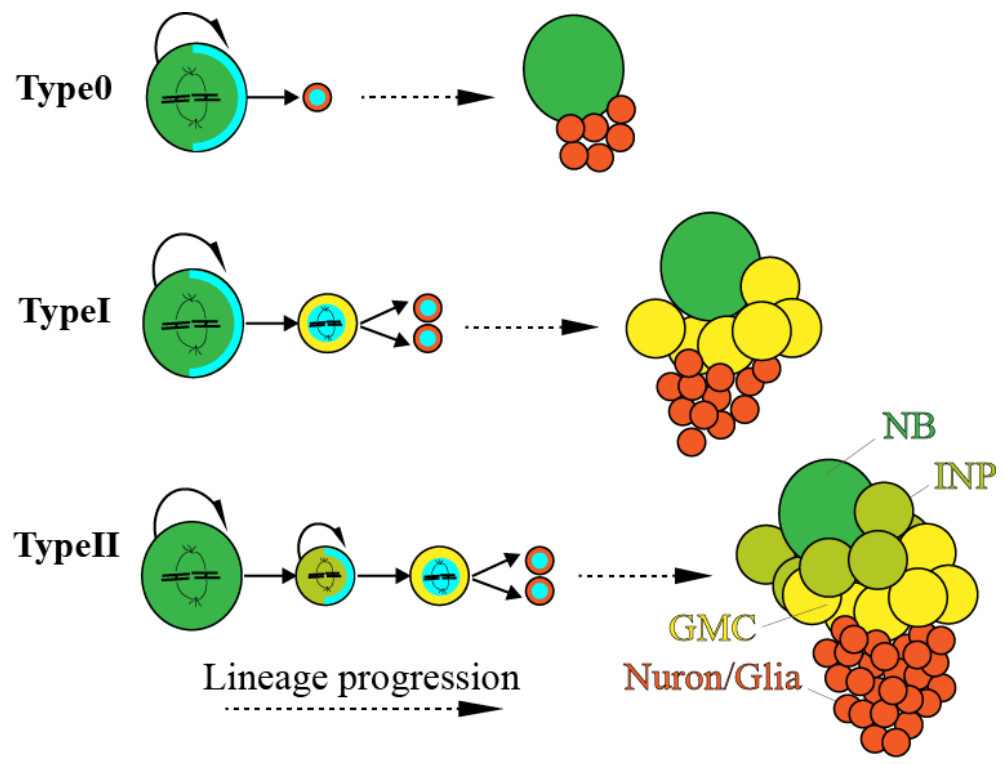

Pros $\square$ Dpn $\square$ Terminal selector marker

Fig. 10. The three NB division modes. From top to bottom, type 0 shows the NB asymmetric division that produces a daughter that directly differentiates. Type I is when the NB generates a GMC that divides once, to produce two differentiated daughter cells. Type II is when the NB divides to renew itself and produce an intermediate progenitor, which still has the self-renewal capacity for about five rounds, by which it produces five GMCs, that divides once to generate two differentiated daughter cells. The same number of NB divisions produce a very different lineage size depending upon the division mode.

\section{Reprogramming drives differentiated cells to the stem cells like state}

For many years, an important question in developmental biology had been weather cell differentiation is the result of a permanent change in the state of the genetic material or not. The generation of nucleus transplantation technique helped shed light on this issue, by identifying links between certain genes and certain cell fate [169]. To address this issue Gurdon performed the first nucleus transplantation from a fully differentiated somatic cell (intestinal epithelium of a Xenopus tadpole) to an enucleated egg, by which he cloned the first a fully functional organism [170, 171]. A couple of decades later, on the same principle, the first cloned mammal i.e., the sheep Dolly was generated from a reprogrammed zygote [172].

In 2006, Takahashi and Yamanaka discovered the combination of defined transcriptional factors, which recapitulated the Gurdon's experiment i.e., induced pluripotent identity in the fully 
differentiated cell [173]. For this, 24 regulatory genes known to be critical for embryonic stem cells, ESCs, were added to the mouse fibroblast cell culture and selected for the expression of Fbxo15 i.e., an ESC pluripotency marker. Their experiment resulted in the identification of the combination of four TFs: Oct3/4 (also known as Pou5f1), Sox2, cMyc and Klf4, the so-called OSKM "cocktail”, for re-programming the differentiated cells to pluripotent stem cells, denoted induced pluripotent stem cell, iPS [173]. The characteristic of iPS cells resembled ESCs, considering their morphology, expression of main ESCs markers, unlimited proliferation capacity. Albeit injected iPS cells to the developing mouse embryo could not generate viable chimeric animals; this can be explained by their global gene expression profile and their epigenetic state, which stands somewhere between the ESCs and the fibroblasts [173], and this indicated that reprogramming had not been fully successful.

Just one year later, Yamanaka and co-workers could enhance the reprogramming. In this approach they used the same set of factors, but selected for the expression of the homeodomain TF, Nanog. By this approach they produced iPS cells that were equivalent to the ESCs, and they succeeded in creating chimeras [174]. They showed that the gene expression profile of the generated iPS cells and their epigenome was indistinguishable from ESCs [175, 176]. In 2012, Gurdon and Yamanaka jointly received the Nobel Prize in medicine for their mentioned experiments.

The first human iPS cells were produced in two independent groups, at the same time, with two different combination of inducing factors. In 2007, Yamanaka's lab used the OSKM set of factors on human fibroblast cells [177], and the Thomson lab utilized the combination of factors: Oct4, Sox2, Nanog and Lin-28 [178].

During the past decade, several studies, especially in the mammalian system, particularly human, revealed several other combinations of factors, for reprogramming differentiated cells, and extended this from fibroblasts into e.g., keratinocytes, by application of OSKM factors [179] and Thomsons' Factors [180]; or reprogramming peripheral blood cells [181, 182] and even renal epithelial cells [183]. This development has enabled for the use of more easy-access tissues/cells for generating iPS cells, and set the stage for developing patient-specific lines of cells for regenerative medicine, cell transplantation, disease modeling and drug screening [184, 185].

Also, Yamanaka and co-workers have identified a new factor in replacement for Myc in the OSKM combination [186]. As previously it had been shown that Myc increases the chance of producing tumors in the iPS cells, albeit it promotes the efficiency of reprogramming [187]. Therefore, the Glis family member of zinc finger factors, Gli1, that is involved in many pathways that are known for promoting stemness identity e.g., Myc, Lin-28, Nanog, Essrb, and Wnt, has been identified as efficient with three other factors of OKSM [186]. 


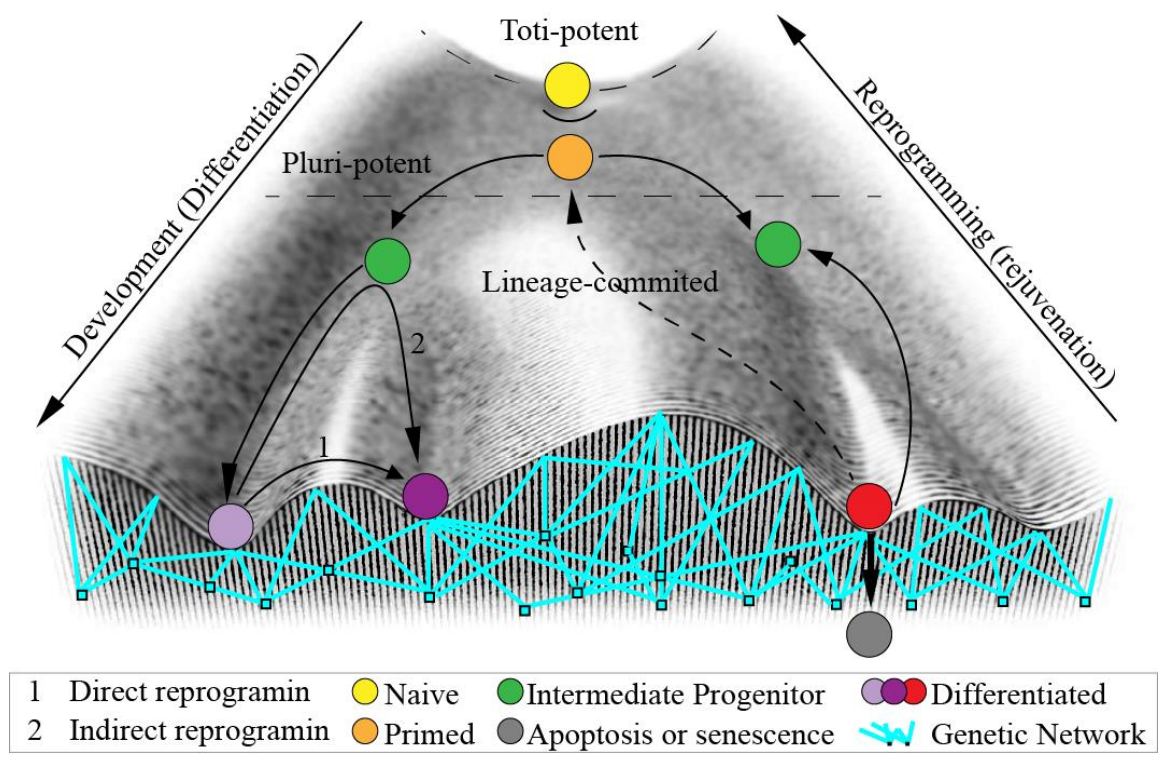

Fig. 11. Cell identity alterations in the concept of Waddington's landscape. During development a zygote i.e., totipotent stem cell, SC (yellow cell), becomes restricted to pluripotent SCs (orange cell); which generates multipotent SCs (green cell) i.e., committed to certain lineages and unipotent SCs i.e., restricted to a single cell type. The combinatorial effect of defined reprogramming factors can reprogram differentiated cells i.e., stated in the lower parts of the slope to obtain the characteristics of SCs. Modified from [188-190].

Altogether, the application of iPS cells in basic research has contributed significantly to understanding the transcription factors that are essential and necessary for the establishment of stemness identity. However, what makes the single totipotent stem cell (zygote) gradually become restricted to pluripotent, multipotent and unipotent stem cells during the generation of an enormous number of differentiated cells with tremendous diversity in cell fates is not well studied in any model system. During development, genetic mechanisms restrict the activity of stemness TFs and reduce the proliferation capacity gradually, conducive to up-regulation of cell specific and organogenesis TFs to produce an appropriate number of each cell type at the right time and the place. The progress that gradually reduces the stemness characteristics in favor of cell differentiation, concordantly with the lineage progression and development is poorly understood. As the NBs in the developing VNC of Drosophila undergo several temporal windows during the lineage progression, it can be a great model for investigating this question. 


\section{Genetic Forward Screens}

\subsection{Relationship between genotype and phenotype}

The relation between genotype and phenotype was discovered for the first time by the experiment of Gregor Mendel on garden peas in 1866 . He found that the alternation in heredity between the progeny is the outcome of differences in discrete factors which are passed to the next generations unchanged. Today, we know those factors as genes. Moreover, he found out that each pea carries two sets of factors, one from each parent. About 40 years later, Thomas Hunt Morgan used this information to introduce the chromosomal theory of heredity i.e., stating that genes are placed in a linear manner from one end to the other of each chromosome, and its location if fixed on a certain chromosome. Morgan used Drosophila for the investigation of his theory, and since then Drosophila has been one the most powerful and popular model organisms for genetics studies [1]. By following up on Mendel's findings, Wilhelm Johannsen distinguished between genotype (genetic material) of an organism and its phenotype (appearance). Genotype stands for the entire set of alleles carried in each individual's genome, while phenotype is the outcome of the functional expression of one or several genes. Many gene mutations show no effect on phenotype, as they are allelic polymorphisms and phenotypically "silent." Some cases are not silent, but they are expressed in a different but still natural way and are therefore benign e.g., when a mutation leads to a difference in color of eye or skin [1].

\subsection{Principles of forward genetic screens}

Forward genetic screen has been conducted for several decades now. This technique generates a vast range of mutations which affects the phenotype of interest. Forward genetic screens have been conducted in different laboratory model organisms, ranging from Escherichia coli to mouse, and all are framed upon the same basic principles [191-196]. The basic setup of forward genetic screens starts with generating random mutations, in a well-defined genetic background, and scoring for a particular phenotype. A wide range of mutagens has been used, including radiation and chemicals. Chemical mutagens cause point mutations or small deletions. The applied dosage of each chemical used can affect the number of mutations generated in the genome. Radiation normally leads to large deletions or translocations within the genome. This way of generating mutation typically produces a lower mutant density in comparison with the chemical mutagens, which cause point mutations, as large genomic deletions and rearrangements may impair the whole cluster of linked genes. Thus, using radiation mutagenesis, it is not always possible to identify the gene responsible for the given phenotype, even by mapping to the disrupted interval [197].

Mutant generation, by radiation or chemicals, is followed up by screening for the phenotype of interest. The next step is mapping the isolated mutants. Genetic mapping can be done by different approaches e.g., genetic complementation tests or recombinant mapping, both of which involve 
many crossing steps. Genetic mapping by complementation, as conducted in Drosophila, starts with largely deleted regions of the chromosomes, and is narrowed down to smaller regions and finally down to a smaller number of candidate genes. The candidate genes are tested against the mutant, for lethality and phenotype. Sometimes it is further validated by rescuing the mutant phenotype by gainof-function of the wild-type gene within the mutant background [197].

\subsection{Forward genetic screens: Drosophila}

One of the most utilized model organisms for genetic screening is Drosophila. One of its main advantages is that males have no mitotic recombination, and it has only four chromosomes, with the second and the third containing most of its genetic material. Also, there are many external features which help trace certain genotypes of interest e.g., different eye colors [198]. Moreover, sequencing the Drosophila genome revealed extensively shared mechanisms between Drosophila and vertebrates on the genetic level e.g., 77\% of known human disease genes have homologous in Drosophila genome [199], and a majority of genes with no Drosophila homologues still cause a related phenotype when they are expressed in Drosophila [200,201]. As Drosophila can be used for genetic screens on a large scale, they provide an unbiased approach to identified alleles for genes involve in various biological processes.

\subsubsection{Tradition genetic screen: Drosophila}

Very first screening on Drosophila was conducted on a natural population without generating any mutants by radiation or chemical treatment. Although this only lead to the isolation of spontaneous mutants it still provided basic information about the nature of the genes. Subsequently, genetic screens based upon active mutagenesis were introduced by T. Alderson, which identified the mutagenic effect of Ethyl Methane Sulfonate (EMS) when fed to adult males [202]. In 1968, Lewis and Bacher published the very first standard protocol utilizing EMS to induce mutations in the Drosophila genome [31]. Most of the EMS-induced mutations are point mutations and rarely small deletions. Therefore, EMS application gives the advantage of characterizing the mutation at a precise locus. In 1980, J. Nusslein-Vollhard and E. Wieschaus published a forward genetic screen, which subsequently leads to them receiving the Nobel Prize. They had used EMS mutagenesis and identified mutations that impair segmentation and polarity during embryogenesis [43]. This work was a seminal study concerning mutagenesis studies, since they aimed at identifying all of the essential genes involved in a given process, in a multi-cellular organism. Moreover, despite previous studies, this work had been conducted at the embryonic level, which allowed them to isolate genes that were critical for the proper generation of embryonic positional information [203]. In spite of the high efficiency of embryonic lethal screening, no screen can identify all of the essential genes playing a role in this general process: First, the product of many of those genes are maternally loaded to the embryo and will only show partial or no phenotypes, and second, the phenotypic screening is limited by our visualization set-ups. 


\subsection{Genetic screens utilizing next generation sequencing}

One of the techniques that have greatly improved the mapping of mutants identified in EMS genetic screens is whole genome sequencing, using next generation sequencing (NGS) technology. The traditional genetic mapping scheme involves multiple genetic crosses for the identification of the causal mutations. In contrast, application of NGS speeds up the whole process and can help map the causal gene at the base pair resolution without requiring many complex genetic crosses. The first application of NGS for genetic mapping was in 2009 in Arabidopsis thaliana [204].

Genetic mapping utilizing NGS involves first comparing each mutant genome sequence to a reference genome, preferably both the one deposited in Genbank, as well as from the starting strain used for mutagenesis. Various software is currently available that can help identify sequence variations (SNP-calling), and govern if they are affecting coding regions of genes and if they may alter the function of the protein. Because EMS is a powerful mutagen, mutants often carry a large number of de-novo mutations, several of which may be affecting coding parts of different genes. Therefore, in the second step, each mutant is tested against deletions/alleles for several candidate genes [197]. Identifying the gene underlying the phenotype of interest is greatly facilitated by having multiple EMS alleles, since only this gene will be mutated in all of the allelic mutants.

\subsection{Future of genetic screen}

The power of forward genetic screen pertains to the fact that they are highly efficient, can cover the whole genome, and that multiple genes are screened at the same time in each mutant. However, they are also labor some and time-consuming, and hence expensive. In particular the genetic mapping of the mutants tends to take time, often more so than the initial mutagenesis and phenotypic screening. It may come a day when forward genetic screen is not anymore approached, due to development of faster, easier and cheaper ways of knocking out every gene e.g., by using RNA interference (RNAi). However, RNAi has several limitations e.g., a low effect for knocking down genes during Drosophila embryonic stages. In contrast, systematic knock-out of each gene in the Drosophila genome is under way, by the use of several approaches; transposon mutagenesis and CRISPR/Cas9 mutagenesis. Hence, at a future stage, one could argue that having access to mutants for all genes in the Drosophila genome will leave no need for genetic screens. However, a strong argument against this reasoning is that EMS mutagenesis can generate a range of mutations in the same gene, from amorphs, hypomorphs to neomorphs. Indeed, many of the behavioral screens have isolated hypomorphic mutations in essential genes, with their phenotype not being scorable in a null mutant of the same gene [205]. Moreover, during the last decade, genetic mapping set-ups have been enhanced both technologically and methodologically. Further, the use of NGS, as outlined above, greatly speeds up the mapping process. Altogether, it is believable that forward genetic screen may continue to be utilized as an important approach in the future of Drosophila genetics for quite some time. 


\section{Aims of the thesis}

This $\mathrm{Ph} . \mathrm{D}$. thesis aimed to identify novel regulatory genes and the genetic mechanisms whereby they regulate neural cell proliferation, resulting in the production of an exact number of each cell type during lineage progression; by utilizing genetic approaches on embryonic Drosophila VNC thoracic segments.

This goal confines to three related projects:

\section{Paper I}

A forward genetic screen was conducted, by visualizing the last-born cell of the lineage NB5-6T the Ap4/FMRFa neuron. The screen setup was aimed at isolating regulatory genes involved in both neural cell proliferation and specification, in reference to lineage progression at different levels.

\section{Paper II}

To characterize the function of $C t r 9$, a component of the transcriptional and epigenetic complex (Paf1C), as a regulator of cell specification and proliferation in the developing Drosophila CNS.

\section{Paper III}

To understand which genes and mechanisms promote the proliferation capacity of NBs and their daughter cells, and how such genes gradually become replaced by genes in favor of neural differentiation. 


\section{Materials and Methods}

\section{Immunohistochemistry, IHC}

IHC is a commonly used technique both in the clinical and basic scientific setting. IHC is used to detect individual biomolecules, mainly markers for distinct cellular identity or events, by the principle of antibody binding [206]. This technique is widely used since 1941 to identify e.g., the localization and distribution of biological markers, and the variation of their expression in different cell types [207]. Visualization of the antibody is commonly done by enzymatic reaction or different fluorophore tags i.e., immunofluorescence [208]. IHC approach is used in all of the papers of this thesis. The CNS of the fly embryo and the wing discs of the L3 larva were dissected at the proper stage [209] and placed on the poly-lysine-coated glass slides. They were fixed in $4 \%$ paraformaldehyde (PFA) to conserve the cellular and molecular 3D structure of the tissue intact. The fixed samples were incubated in the blocking buffer, containing horse serum, which reduces the background and unspecific binding, plus detergent, Triton-X $30 \%$ for permeabilizing the cell membranes. The primary antibodies, which are tested for validity in mutant backgrounds, are added to the tissue, and subsequently visualized by fluorophore-tagged secondary antibodies (as mentioned in details within each paper).

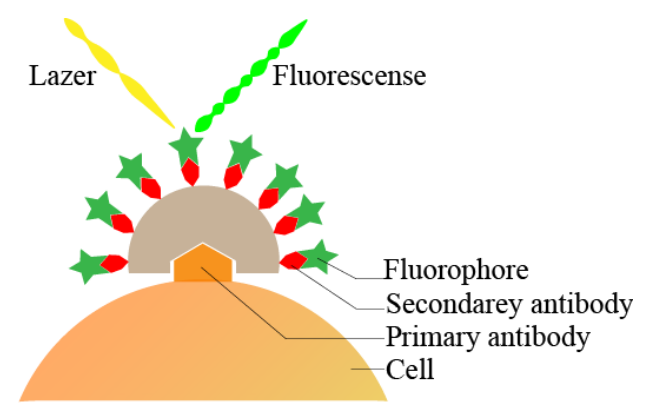

Fig. 12. The principle of IHC. By taking advantage of high selectivity and affinity of antibodyantigen binding and sensitivity of fluorophore, certain biomolecules are detectable. Modified from [208].

\section{Transgenic lines, UAS-Gal4, Gal80 system}

The UAS-Gal4 system is commonly used in genetic studies in the Drosophila, and enables the controlled expression of selected genes in every wanted tissue or prices cell type. Gal4 is a yeast transcriptional activator gene, and has a particular binding site denoted UAS. By inserting the UAS activation sequence upstream of the gene of interest, and additionally introducing Gal4 under a certain promoter active in a given cell type or at the certain time point, allows for ectopic expression 
of the gene of interest in the particular cell type or at the specific time [34]. By introducing a temperature sensitive mutant of the Gal80 protein (Gal80[ts]), which binds and inactivates the Gal4 protein but can be inactivated at higher temperature, the system was developed into enabling for controlling the expression of any gene of interest both spatially and temporally [210]. In this thesis, the UAS-Gal4 system was utilized for gain-of-function assays.

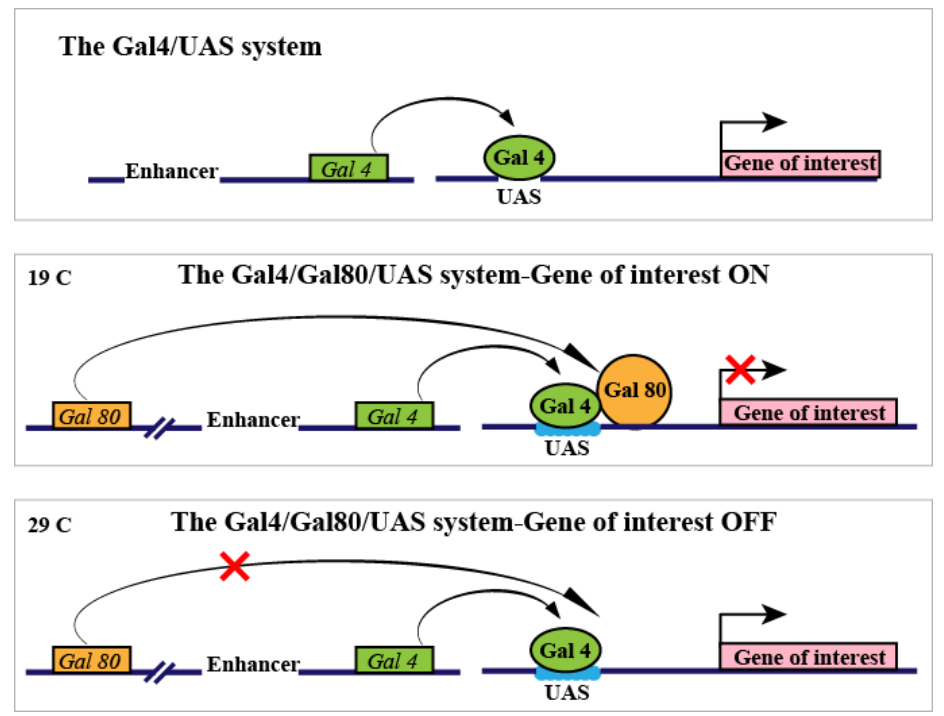

Fig. 13. UAS-Gal4, Gal80 systems. Modified from [210]

RNA-Seq: Description and instructions on RNA-Seq data collection and analysis are mentioned with details in the paper II and III.

EMS-based forward genetic screen and mapping by NGS: The details on inducing mutations in the Drosophila genome, utilizing EMS, is referred to the Paper I. Furthermore, for the detailed description of mapping using NGS, please see the Paper I.

Transgenic Drosophila stains: The constructs utilized per each experiment are mentioned with detail per paper.

Confocal Scanning and Imaging, Antibodies and Statistical methods: Described in detail in the papers I, II, and III. 


\section{Results and Discussion}

Paper I: Novel Genes Involved in Controlling Specification of Drosophila FMRFamide Neuropeptide Cells.

As mentioned above, one of the powerful and widely used methods for identification of novel regulatory genes and involved in developmental processes is forward genetic screens, in particularity on Drosophila. Moreover, a significant advantage of studying neurodevelopment using the Drosophila embryonic VNC is the possibility of monitoring single NBs and their entire progenies, a single lineage, during development. Herein paper I; we conducted a genetic screen aimed to identified novel genes and genetic regulation involved in the CNS development during embryogenesis, and for this approach, we used lineage of the NB5-6T as a model within the model.

\section{The NB5-6T Lineage and the Apterous cluster}

The NB5-6T lineage: NB5-6T is one of the most well-studied lineages in the embryonic VNC. Restricted expression of the homeobox gene ladybird early (lbe) and ladybird late (lbl) in this lineage, can be utilized as a marker to visualize NB5-6T and all its progeny i.e., the entire lineage can be detected upon lbe expression [211]. These homeodomain proteins are required for proper lineage progression in NB5-6, and loss-of-function studies identified lbe as involved in regulation of cell specification in glial cells and neurons of this lineage [211, 212].

Apterous cluster: The last born four cells in the NB5-6T lineage, generated in a type 0 division window, are denoted the Apterous (Ap) cluster due to their expression of Ap, a LIM-HD protein. This cluster of four neurons, the Ap1-4 neurons (five in T1) is located laterally in each thoracic hemisegment [213]. Loss-of-function studies identified Ap as an essential factor for axon pathfinding of these interneurons. Most of the Ap neurons are interneurons, projecting their axons along a common ipsilateral fascicle [213], whereas Ap4/FMRFa, has a different axon projection and sends its axon towards the midline and out of VNC into the neurohemal organ, which is known as FMRFa release sites [81]. Apart from Ap, there are more cell fate determinant factors identified in the Ap neurons e.g., Collier (Col), Eyes absent (Eya), the transcriptional cofactor Dachshund (Dac), Dimmed (Dimm) and the BMP pathway [89, 91, 214]. Ap1 and Ap4 express neuropeptides i.e., Ap1/Neuropeptide like precursor protein 1, Nplp1 [215] and Ap4/FMRFa [216]. Restricted expression of these neuropeptides in distinct subtypes of Ap neurons, allow us to use them as specific markers to distinguish between them i.e., Ap1/ Nplp1 and Ap4/FMRFa. 

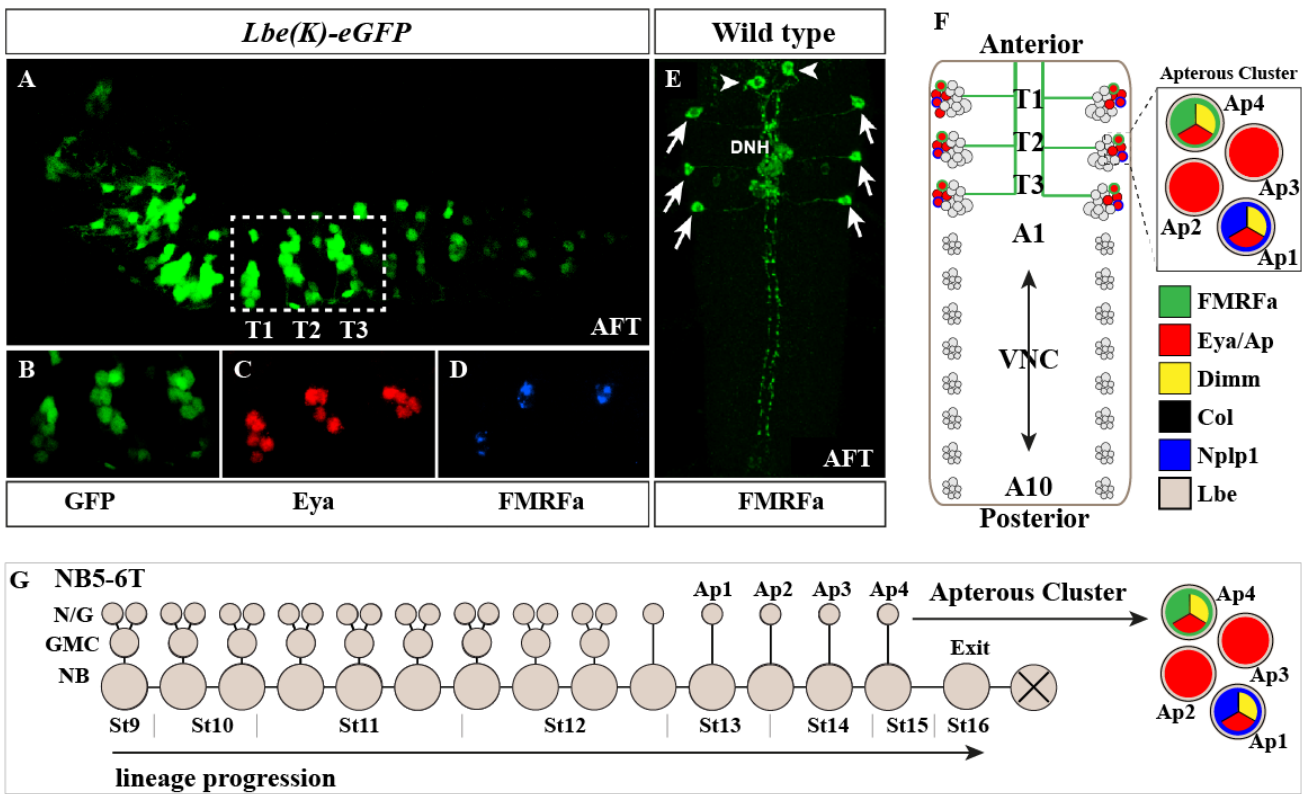

Fig. 14. The NB5-6T lineage in the Drosophila CNS at the late embryonic stage. (A-E) Confocal image of the Drosophila embryo at stage AFT. A) The lateral view of the whole CNS shows GFP reporter for the lbe marking the NB5-6 lineages in both T and A segments. (B-D) The close-up view for several markers expressed in NB5-6T i.e., lbe-eGFP, Eya and FMRFa. E) The ventral view of VNC shows the expression of six Ap4/FMRFa cells, visualized by transgenic GFP reporter, FMRFa$e G F P$. F) The carton shows the NB5-6 in the thoracic and abdominal segment, with the zoomed illustration of the Ap cluster in the NB5-6T and several of their molecular markers. G) The schematic illustration of the NB5-6T lineage progression during embryogenesis stages and formation of Ap cluster. Modified from [217].

NB5-6T lineage as a model: The NB5-6T lineage is hence a great model for studying neurodevelopment for several reasons: First, it has a relatively large lineage size, 20 cells. Second, it generates both neurons and glia. Third, it displays the type I>0 switch in NB division mode during late stages of lineage progression. Fourth, is well-mapped and there are a number of specific markers available for the NB5-6 and its competence windows, as well as certain markers for several exclusive subtypes of neurons. Thus, this lineage can be used to address several questions regarding the genetic programs underlying asymmetric division, temporal competence changes, the type I $>0$ daughter proliferation mode switch, as well as glia and neuron subtype specification. 
The forward genetic screen: In Paper I, we conducted a forward genetic screen, aimed at identifying genes involved in the various developmental processes underlying lineage progression and cell fate specification. The screen setup took advantage of the restricted expression of the neuropeptide FMRFa to the NB5-6T lineage, as there are only six NB5-6Ts in the entire Drosophila VNC, the expression of Ap4/FMRFa is limited to six cells among 10,000 of the Drosophila VNC. Therefore, an alteration in the phenotype of the six Ap4/FMRFa cells, suggests a casual mutation in a gene that is required for a neuro-developmental process e.g., regulating the NB identity, proliferation capacity, temporal and spatial cues, cell specification, NB division type I $>0$ switch, and cell cycle exit.

Herein the expression of Ap4/FMRFa is visualized by inserting the upstream region of the $F M R F a$ gene, which has been used previously to control expression in the Ap4 cells exclusively, upstream of the eGFP reporter, and generating transgenic lines [81, 218, 219]. After testing a large number of transgenic lines, two Ap4/FMRFa-eGFP transgenic lines were identified, one on second and one on third chromosomes, that allowed for detecting eGFP expression in the Ap4 neurons of the living embryos and larvae under the fluorescent microscope.

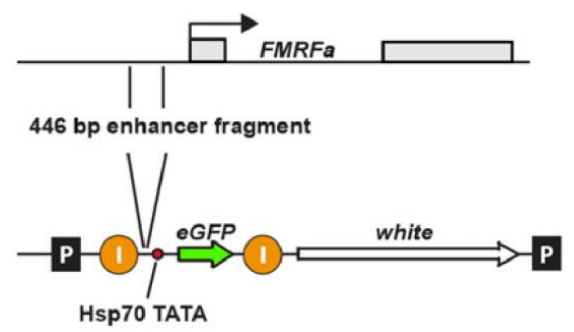

Fig. 15. The FMRFa-eGFP reporter construct. The transgene line has the Tv enhancer of the $F M R F a$ gene inserted upstream of the $e G F P$ reporter. Modified from [217].

FMRFa-eGFP screen: We confirmed the reliability of the FMRFa-eGFP transgenic lines by testing the expression of eGFP in the mutant lines known to interrupt the Ap4/FMRFa formation e.g., dimm, also mutants which were known for no effect on those cells e.g., isl as the positive and negative controls respectively. Drosophila males were randomly mutagenized, utilizing EMS [220], and crossed to the females carrying balancer chromosomes II or III, leading to the establishment of 9,781 mutant lines. The mutant screening for the altered expression of $F M R F a$-eGFP at the late embryonic stages or early larva, isolated 611 mutant lines, categorized into five groups based on the observed eGFP phenotypes i.e., loss, ectopic, double, variable, and other eGFP expression patterns. This was followed by an extra step of screening for the eGFP expression in preference for more severe alternation in the FMRFa-eGFP expression that left us with 277 mutant lines. 
Screen for other Ap cluster markers: At the next step, mutants were screened for the expression of other markers of the Ap cluster by using antibodies against Eya, Dimm, Nplp1, pMad also proFMRFa for the endogenous expression of FMRFa; alteration in the expression of any of these markers subdivided the mutants into sub-groups. The mapping of the Ap/markers, suggested some of the mutants lines might be new alleles for the marker that shows alternation in its expression pattern, e.g. the mutant line which had lost the expression of Eya might carry a mutation in the gene eya. Therefore, those mutants were crossed to the null allele of the candidate genes. The mutant line which failed to compliment the loss-of-function of the null allele of the candidate marker gene in the Ap cluster were reported as a new allele of that marker, which held true for few lines.

Mapping by deficiency kit: The rest of mutant lines were mapped against the deficiency kit from Bloomington i.e., a collection of Drosophila strains carrying deletions with known break points, which uncovers the whole Drosophila genome. This mapping was based on the assumption that causal mutants are lethal. Therefore, landing on a deletion interval, which did not complement the mutant line, meant that a lethal mutation was located in this interval of the genome and that can be the causal mutant for the observed phenotype. However, the lethality-based mapping was not entirely straightforward for two main reasons: First, some of the mutant lines carried several lethal mutations on the same chromosome; second, some of the mutations affecting FMRFa-eGFP were not lethal. Nevertheless, it often helped to narrow the area of search on the genome to a small interval where a few genes could be identified as candidates responsible for the observed phenotype. However, due to the lack of mutant alleles for every single gene in the Drosophila genome, deficiency mapping only succeeded in mapping a subset of mutant lines.

Mapping by WGS: In a subsequent approach, we used the whole genome sequencing, WGS for mapping the mutant lines which deficiency mapping failed to identify. In order to use WGS for mapping, the nonallelic mutants were crossed, and the heterozygous larvae carrying two causal mutants were collected for DNA extraction. The genome sequence of the mutant lines was aligned with the reference genome (from GenBank). The WGS approach leads to the identification of 19 causal mutant alleles for 23 sequenced mutant lines i.e., $82.6 \%$ efficiency.

One of the main weaknesses of forward genetic screens is failure to uncover genes that have maternal load, since the phenotype caused by that mutation can be masked due to its maternal expression. Moreover, essential genes functioning during the early stages of development could be missed on our screen. However, the precise setup of this screen, with single lineage resolution made it possible to identify various genes involved in a variety of developmental processes i.e., 79 alleles of 43 novel genes categorized into 17 broad groups upon their suggested function e.g., epigenetic factors, cell cycle genes, temporal and spatial cues, NB and temporal genes, cell fate determinants. To conclude, the genes identified by the screen were pursued for further investigations, and indeed the two following papers included in this thesis are based on the findings of this forward genetic screen. 
Paper II: Ctr9, a Key Component of the Paf1 Complex, Affects Proliferation and Terminal Differentiation in the Developing Drosophila Nervous System.

\section{The Paf1 Complex, an evolutionary well conserved co-factor complex for RNA Pol II}

The developmental processes relies on the gene expression profile of the cells. The gene expression profile is the result of transcription processes controlled by co- and transcription factors, plus their interplay with the epigenetic machinery [221, 222]. Impaired function of these factors or an interruption in their interaction, can lead to imperfect lineage progression, with resultant defective development [223]. Epigenetic complexes may have a confined role or pleiotropic function.

The RNA polymerase II-associated factor- 1 complex, Paf1C is a pleiotropic epigenetic complex, consists of five canonical members: Ctr9, Paf1, Rtf1, Leo1 and Cdc73 (also known as Parafibromin (Hrpt2) in mammalian and Hyrax in Drosophila) [224]. All five canonical members of this complex had been identified in Saccharomyces cerevisiae at first. Paf-1 protein was the earliest member of this complex identified over 20 years ago in association with RNA polymerase II (RNA Pol II) [225]. Shortly after, the same group identified another component of this complex in partnership with both Paf-1 and RNA Pol II, formerly known as Cell division cycle protein, Cdc73, a cell cycle regulatory factor [226]. Later, the other three members i.e., Ctr9, Leo1, Rtf1 were also found in with RNA Pol II and Paf1C [227, 228]. However, none of the Paf1C components are vital for yeast in normal condition, although they are involved in several transcriptional and posttranscriptional processes [229], and they modulate DNA-histone modification [224, 230, 231].

Studies on several members of Paf1C in more complex organisms including human suggest that Paf1C is molecularly and functionally well conserved from yeast to human [224, 230]. Moreover, contrary with the Paf1C in yeast, functional studies identified several members of Paf1C as essential factors in various metazoans including humans; they identified Paf1C required for many developmental processes e.g., DNA repair and cell cycle regulation [224, 230, 232], as well as modulating chromatin structure and regulating transcriptional processes of numerous genes. For instance, several studies showed that Paf1C promote histone trimethylation of H3K4 and H3K36, and ubiquitination of $\mathrm{H} 2 \mathrm{BK} 123$; Paf1C is involved in chromatin remodeling, transcription elongation and it mediates transcriptional termination for RNA polymerase II [224, 230]. Inanition, several studies have suggested relations between Wnt or Notch signaling and different components of Paf1C [233-236]. Further, some of the Paf1C components e.g., Ctr9 are identified as a tumor suppressor factor in various organisms especially in human [232, 237-241].

Moreover, members of Paf1C appears to function mostly within the Paf $1 \mathrm{C}$, as the functional studies on several members of Paf1C in yeast identified them functioning in the same processes; albite few non-overlapping functions were identified that could be due to their role independent of the Paf1C [229]. 
In addition, studies in yeast suggested that changing the levels of three members of this complex i.e., Paf1, Cdc73 and Ctr9 altered the stability of other protein members e.g., Loss-of-function of Ctr9 affected the level of Paf1, Rtf1 and Leo1 [226, 242]. Similar studies have been observed on human Paf1C, suggesting binary links between different members of this complex, additionally Paf1 and Ctr9 seems to be the main proteins for maintaining the complex scaffold [243], whereas Cdc73 is suggested for direct binding to the RNA Pol II [226, 244].

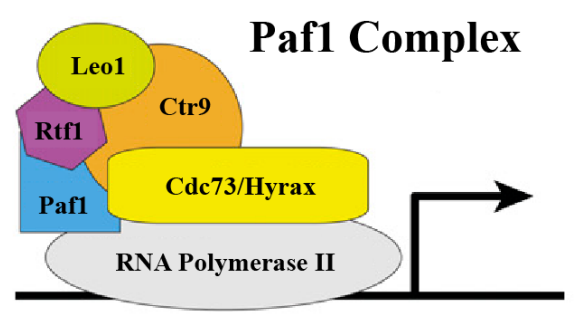

Fig. 16. The Paf1C. Canonical components of the Paf1C in association with RNA Polymerase II; modified from [245].

\section{The Paf1 Complex in Drosophila}

Paf1C is highly conserved from yeast to human. Despite the comprehensive studies on different members of Paf-1C in both yeast and human, studies in Drosophila have been very limited. A recent study in Drosophila identified dCdc73 also named Hyrax (Hyx) as a tumor suppressor factor, by finding an unexpected link between Hyrax and the Wnt pathway. They have shown Hyrax and consequently Paf1C, directly control the transcription of Wnt target genes via $\beta$-catenin [233]. Moreover, Drosophila Rtf1 (Restores TBP function 1) was identified as an essential protein during development and found to be involved in the histone modification for $\mathrm{H} 3 \mathrm{~K} 4$ and $\mathrm{H} 2 \mathrm{~b}$, suggesting that its function is conserved from yeast to human. The same study showed that dRtf1 affects the transcription level of Notch target genes [235]. Also, dpaf-1 is an essential gene and involves in methylation of H3K4 [246]. Lastly, Leo1 (Left open reading frame 1) is the least studied Paf1C member in Drosophila; that is also an essential gene identified by the Berkeley Drosophila genome project [247].

\section{Ctr9, a key components of Paf1C}

Before the identification of Ctr9 as a protein member of Paf1C, Ctr9 (Cln Three Requiring 9) has been genetically discovered as a regulatory gene involved in the G1 phase of the cell cycle in yeast [248-250]. Furthermore, a mutation in Ctr9 impairs both cell cycle and cell growth in yeast [250]. Loss-of-function studies on Ctr9 in yeast, identified it as a histone modifiers for H3K36, via Set2 methyltransferase [251]. Therefore, the $\mathrm{Ctr} 9 / \mathrm{Paf} 1 \mathrm{C}$ affects the accessibility of genes and regulate their expression levels [230]. 
Moreover, Ctr9 is required for obtaining and maintaining the embryonic stem cell (ESC) identity e.g., the expression of oct4, Nanog, Sox2 are significantly reduced in the Ctr9 mutant, and loss-of-function of $C t r 9$ caused ESC differentiation [252]. Additionally, studies in mammals showed that $\operatorname{Ctr} 9$ is necessary for early human development (implantation), and loss-of-function of $h C t r 9$ results in the reduction of $\mathrm{H} 3 \mathrm{~K} 36$ trimethylation [223]. In addition, $C t r 9$ is identified as a tumor suppressor factor e.g., studies on human identified mutations in Ctr9 to be liable for Wilms tumor i.e., embryonal kidney cancer [238], and some types of breast cancer [241].

After our publication (Paper II) a recent study on Ctr9 in Drosophila shows Ctr9 to be required for the proper morphology of germ line cells. The loss-of-function of $C t r 9$ causes cell loss in the germ lines, which can be rescued by overexpression of human $h C \operatorname{tr} 9$ in the $\operatorname{Ctr} 9$ knockdown Drosophila germline [253]; this study suggests both structure and function of Ctr9 is conserved between Drosophila and humans, at least in the germline.

\begin{tabular}{|c|c|c|c|c|}
\hline \multicolumn{5}{|l|}{ Dm Ctr9 } \\
\hline TPR & TPR & TPR & TPR & \\
\hline \multicolumn{4}{|c|}{$\mathrm{TPR}=$ TetraTricopeptide Reapeat } & 1150 aа \\
\hline \multicolumn{4}{|c|}{ 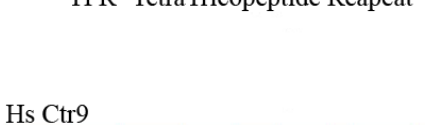 } & $\mid \begin{array}{l}68 \% \text { identity } \\
81 \% \text { Similarity }\end{array}$ \\
\hline TPR & TPR & TPR & TPR & \\
\hline
\end{tabular}

Fig. 17. Ctr9 protein in Drosophila and Humans; Modified from [245]

In Paper II, I carried out a detailed functional and phenotypic study on the gene Ctr9 (GC2469), identified in the screen in Paper I. Due to the high level of homology between CG2469 and human Ctr9 i.e., 68\% aa identity and $81 \%$ similarity we denoted GC2469 as Ctr9 in Drosophila. As mentioned before, Ctr9 is a component of Paf1C [224], and because of the limited study of this complex in Drosophila, and because of its connection another member of Paf1C i.e., Rtf1 to the Notch pathway in Drosophila [235], I decided to study this gene in more detail. Ctr9 has a high maternal and ubiquitous zygotic transcription at early stages; however, from stage 7 its expression is limited to the developing CNS.

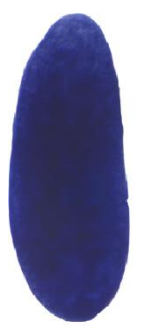

Stage: 1-3

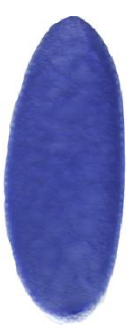

Stage: 4-6

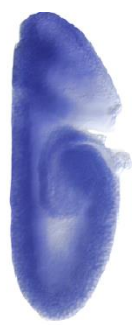

Stage: $7-8$
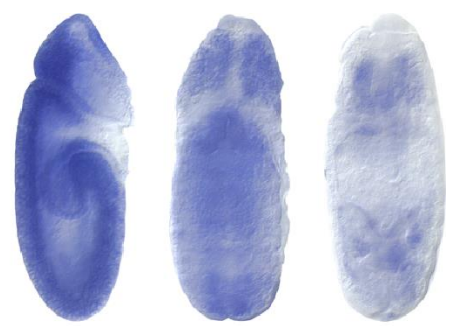

Stage: 11-12 Stage: 13-16. 
Fig. 18. Ctr9 expression. The RNA in situ hybridization images for expression of $\operatorname{Ctr} 9$ in the wildtype at several stages of embryogenesis. Modified from Berkeley Drosophila Genome Project, BDGP http://www.flyexpress.net

Here we have isolated two alleles for $\operatorname{Ctr} 9$ that we have deposited at the Bloomington Drosophila Stock Center now. The allele $C t r 9^{120 p 23}$ carries a nonsense mutation at the beginning of the $C \operatorname{tr} 9$ open-reading frame. $C \operatorname{tr} 9^{120 p 23}$ is homozygous lethal by the end of the embryogenesis and leads to severe loss of the expression of Ap4/FMRFa and one extra Ap/Eya cell within the cluster.

The homozygous lines of $C \operatorname{tr} 9^{120 p 23}$ and heterozygous $C \operatorname{tr} 9^{120 p 23} / C \operatorname{tr} 9^{D f}$ has similar defects in Ap cluster i.e., loss of Ap4/FMRFa and the extra number of Ap/Eya cell, which are significantly different from wild type but not between the hetero- and homozygous lines of Ctr9 mutant and deficiency lines. Hence, the phenotypic analysis between $C \operatorname{tr} 9^{120 p 23 / 120 p 23}$ and $C t r 9^{120 p 23 / D f}$, and being the nonsense mutation in $\operatorname{Ctr}^{120{ }^{23}}$, suggest this allele is most likely null.

Further, the more detailed phenotypic analysis revealed loss of Ap1/Nplp1 also in the Ctr9 mutant embryos, although the expression of some other cell fate terminal markers e.g., Dimm, Dac, pMad was maintained as in the wild type [214]. Gain-of-function of $C \operatorname{tr} 9$ with a CNS-specific driver, in the $\operatorname{Ctr} 9$ mutant embryos, completely rescued the effect of $\operatorname{Ctr} 9$ mutant on the expression of Eya, FMRFa, and Nplp1 in the Ap cluster; although it could not rescue the overall viability more than providing an increase in the number of embryos making into L1 larvae. Therefore, we conclude that Ctr9 is an essential gene, required for the neurodevelopment of Drosophila during embryogenesis.

The loss of the Ap1/Nplp1, Ap4/FMRFa, and extra Ap/Eya cell formation evident in Ctr9 mutants, suggested a differentiation and anti-proliferative role of $C t r 9$. By looking at the proliferation ratio of NBs and GMCs in the Ctr9 mutant CNS at different stages of embryogenesis, both in the lineage NB5-6T and the three thoracic segments, we identified the significant increase in NB division and to a lesser extent GMCs. Moreover, the total number of generated NB in Ctr9 mutants showed a slight but significant increase. This finding indicates that $C \operatorname{tr} 9$ regulates NB formation and proliferation capacity.

The regulatory role of $\operatorname{Ctr} 9$ on the proliferation capacity prompted us to investigate the possible link between $C t r 9$ and the key factors of the cell cycle machinery i.e., CycE, E2f1, Stg and Dap [110]. Intensity analysis pointed to $C t r 9$ as a negative regulator of E2f1 in NBs, whereas other cell cycle genes were unaffected. Furthermore, we analyzed the putative interaction between $C t r 9$ and the late temporal genes cas and grh. Ctr9 mutants show a slight increase in the protein level of Grh i.e., the last gene of the temporal cascade, critical for NB cell cycle exit [110]. This finding matches with the dissection of the lineage NB5-6T, at different embryonic stages of from 12-17, in the $C \operatorname{tr} 9$ mutant, where lineage progression was unaltered until stage 15 . However, at subsequent stages, where wild type NB shows a stereotyped cell cycle exit, $\operatorname{Ctr} 9$ mutants display one more round of division of NB5-6T before exiting the cell cycle. 
Furthermore, as mentioned, previous studies have suggested links between Paf1C and Notch target genes e.g., the HES genes [235, 236], and we know that Notch is critical for NB division type I $>0$ switch [167, 254]. Hence, we tested the level of $E(s p l)-H L H m 8$ i.e., a core player in Notch signaling of developing CNS [167], to detect a putative relation between Ctr9 and Notch. Although Ctr9 mutants showed no effect on $E(s p l)-H L H m 8-G F P$, our transcription analysis revealed six of the other Notch target genes [255] to be effected in the Ctr9 mutants: E(spl)m6, E(spl)m5-HLH, E(spl)m4, Him, peb and stg.

Further, in parallel to the loss of FMRFa and Nplp1 neuropeptides in the lineage NB5-6T in Ctr9 mutants, we analyzed the expression of the four more neuropeptides [256] i.e., Leucokinin (Lk), Capability (Capa), Corazonin (Crz), and Crustacean cardioactive peptide (CCAP). All of them showed significant reduction or loss in $\operatorname{Ctr} 9$ mutant. This finding was confirmed by our RNA-Seq data where we noted down-regulation of all of these genes and some additional neuropeptides.

Based upon the known role of Paf1C in histone modification [251], we also identified Ctr9 as an important factor for $\mathrm{H} 3 \mathrm{~K} 4 \mathrm{me} 3$ in NBs during CNS development, which suggests that $\mathrm{Ctr} 9$ function in neurodevelopment is dependent on the Paf1C. To confirm this assumption we were interested in addressing the role of other members of Paf1C in the developing CNS of Drosophila.

Unfortunately, as mentioned before, the study of Paf1C in Drosophila has been limited, and there are no available alleles for other components of Paf1C in Drosophila apart from hyrax [233]. Interestingly, similar to Ctr9 mutants, hyrax mutants show reduction of FMRFa/Ap4, Nplp1/Ap1 and one other Eya/Ap cell per lineage, which supports the notion that Ctr9 functions in VNC development as a member of the Paf1C. Lastly, the Gene Ontology profile of Ctr 9 mutants identified an alteration in the transcription level of a high number of genes involved in the adult homeostatic processes e.g., metabolic and oxidative biological processes.

One of the major limitations of this study is the maternal load of $C \operatorname{tr} 9$, which is most likely masking the effect of the mutation. I speculate that removing both maternal and zygotic Ctr9 will lead to more severe effects, especially during the earlier stages of VNC development. Moreover, generating mutants for other members of the Paf1C in Drosophila e.g., by using CRISPR/Cas9 can address the role of $\mathrm{Ctr} 9 / \mathrm{Paf} 1 \mathrm{C}$ in the neurodevelopment with more details and can address the interaction between the five members of Paf1C in Drosophila. To conclude, this study introduced the gene Ctr9 in Drosophila and provided mutant alleles for it. Furthermore, it presented detailed phenotypic and functional analysis of Ctr9 in the concept of CNS development and introduced the path for future studies on Paf1C in Drosophila. 
Paper III Neural Lineage Progression Controlled by a Temporal Proliferation Program.

Gurdon's experiment proved that the function of the genome is changeable [170, 171]. Later, Takahashi and Yamanaka identified transcriptional programs that can revert cell into stem cells [173]. During the very past decade, several combinations of different transcription factors were identified that can reprogram fibroblasts into iPS cells; stem cell-like cells.

These phenomena hold true in the term of neural development as well. In the Drosophila embryo, neural development can be said to start when NBs form by lateral inhibition and delaminate from the overlaying neuroectoderm [257]. The generation and delamination of NBs is coordinated with rapid alternation in their gene expression. Therefore, the genes which are highly expressed in the newly born NBs, can be considered as the main candidates for regulating the main features of an NB, which is its stemness identity and high proliferation capacity. Good candidates for NB identity genes belong to the Acheaete-scute Complex, Snail family, SoxB family, and the early temporal genes i.e., $\mathrm{Hb}, \mathrm{Kr}$ and $\mathrm{Pdm} 1-2$.

\section{The Achaete-scute Complex}

AS-C is a genomic region containing the four related genes: $a c, s c, l$ 'sc and asense (ase) that all code for proteins with a bHLH DNA binding domain. The AS-C contains five different genomic regions i.e., achaete, lethal of $s c$, scute $(s c) \alpha,(s c) \beta$ and $(s c) \gamma$, which are separated by non-coding DNA suggested to be regulatory elements [258]. In the scute (sc) $\gamma$ region, two transcription units have been identified i.e., T1 and ase, formerly known as T8. T1 molecular structure and expression are distinct from AS-C compounds, and it is absent during embryonic stages [259]. ase is known to be involved in neurogenesis, and is expressed in many NBs and proliferating cells in both embryonic and larval CNS [258].

Proneural components of AS-C: Three of the AS-C genes are denoted proneural genes: achaete (ac), scute (ac) and lethal of scute (l'sc). They have expressed already at the blastula stage and rapidly increase in the proneural clusters for NB selection [258], but quickly are down-regulated from them [257]. Although these genes act in the core of the NB generation process, their rapid down-regulation suggests that they do not play a critical role in driving NB identity during lineage progression.

asense (ase): Although ase expression is both temporally and spatially close to the other members of AS-C, ase is characterized more as neural precursor gene than a proneural one, due to its restricted expression in the neural progenitor cells and prolonged expression [260]. In contrast to the three proneural members of the AS-C, the onset of ase expression is right after gastrulation, in the selected NBs [260]. Expression of ase RNA and its protein has been identified in the nucleus of all delaminating NBs but not in the proneural clusters, in contrast to the proneural genes. Also, ase expression stays on for a longer period in all of the NBs and it is expressed in some of the GMCs as 
well [260, 261]. The highest level of ase RNA expression is observed at the embryonic stage 10-11 $[258,262]$, and its expression is still detectable until relatively late stages of embryogenesis i.e., stage 16 in the ventroperipheral region of the VNC and also in the brain [260, 261]. Loss-of-function of proneural genes leads to impaired expression of ase and its expression is lost if NBs do not form [260], whereas gain-of-function of ase in sensory organ precursors (SOPs) can bypass the necessity of $a c$ and $s c$ for the formation of SOPs [260, 263]. In addition, loss-of-function of neurogenic genes results in differentiation of epidermal cells to neural fate [20], which is coupled with expanding the expression of ase in those cells [260]. These studies identified AS-C genes, including ase itself, as regulators of ase expression, but the results did suggest that there must be other upstream genes that also control ase expression level [260,261,263]. Although ase has not been identified as a regulatory gene for NB identity or lineage progression, the genetic studies suggest ase may be involved in driving stemness identity in the NBs and repressing cell fate determining factors during early neurogenesis [157]. Ase is homologous to Ascl1 (aka Mash1) in vertebrates, which is critical for neural stem cell identity and both of them have the high tendency of binding on the same motif on chromatin [264].

\section{Snail family}

The Snail is the founding member of another family of genes which up-regulates at the time that proneural factors disappear from the newly born NBs [265, 266], in addition to ase [258, 259]. The Snail family encodes zinc finger TFs, and there are three members in Drosophila i.e., snail (sna), escargot (esg) and worniu (wor); these genes function in part redundantly to regulate the development of CNS [267].

Snail (Sna): sna was identified in the first systematic genetic screen for the embryonic patterning [203]. sna has an early role in the ventral region of the blastula, acting together with twist to establish the border between the mesodermal cells and the neuroectodermal layer, where it downregulates shortly after invagination [268, 269]. sna expresses again in most of the delaminating NBs [267]. sna encodes a TF with five zinc fingers in the DNA binding domain [270]. Functional studies have identified the regulatory effects of $a c, s c$, and $v n d$ on the expression of sna [265, 271]. In addition, Snail1 in vertebrates is known to be involved in cancer metastasis [272].

Escargot (Esg): The other gene of this family is esg, which shows a dynamic expression pattern during embryogenesis, and it does not demonstrate a broad expression in the NBs, unlike sna and wor; albeit esg RNA is detectable in the ventral part of neuroectoderm [267]. Esg is detectable in the midline NB and some of the GMCs during early stages of CNS development [273]. Also, functional studies identified sna and wor to play more prominent roles than esg in the developing CNS [267]. esg expression has been observed in the imaginal discs of larva, and it was found to regulate the cell cycle via cdc2 kinase [274]. Loss-of-function of both sna and esg affects the proper formation of wing disks, albeit CNS development was not severely affected [274]. This suggested the presence of some other protein(s) in the CNS which has redundancy and masks the absence of sna and esg in the CNS [267]. 
Worniu (Wor): wor is the last member of the Snail family identified in Drosophila, and it shows high protein structure homology and functional relation with two other members [267]. Lossof-function of the entire Snail family affected the expression of neural determinants genes e.g., $p d m 2$ and eve, and impaired axon pathfinding at the later stages. Their loss-of-function effect can be notably rescued by transgenic expression of any of them [267]. Dissection of wor expression reviled no maternal load for wor RNA. Its zygotic expression is detectable at the onset of neurogenesis i.e., stage 8 in the small group of cells in the head region [267], and at stage 9 wor is expressed in the delaminating NBs [275]. At Stage 10 it is expressed in most of the NBs and stays in CNS for a longer period [267]. wor expression is restricted to CNS, and in contrary to its broad expression in NBs its RNA was only detected in a minority of GMCs, and no Wor protein in any GMC $[267,276]$. The expression pattern of sna is spatially and temporarily close to wor, albeit in some cells it is detected at a lower level [267]. A functional study identified wor as a downstream target for proneural genes i.e., $a c, s c$, l'sc, as well as ind and $v n d$ but not $m s h$ in NBs. This study suggested critical roles for the Snail family, particularly wor, within the NBs [276]. In addition, wor was identified in our genetic screen that suggests it to be critical for lineage progression and driving NBs in type I division mode [217].

The Snail family regulates both cell proliferation and asymmetric division of NBs. Functional studies identified the Snail family to be involved in the proliferation and asymmetric division control via regulating Stg and Insc [273, 276]. Loss-of-function of the entire Snail family leads to the significant reduction of Insc and Stg, and mis-localization of basal complexes i.e., Pros, Mira, Numb and Pon in dividing NBs [273, 276]; and reduce the expression of GMC determinants e.g., Pros in the GMCs [276]. Interestingly, dissecting the transcription control of insc identified necessity of Snail family for proper transcription of insc at the early stages i.e., stage 9-10 of neurogenesis but not at the later stages i.e., stage 11 and onward [273]. The Snail family is essential to assure the translation of Insc in stage 11; this effect is more likely to be indirect via an unknown mechanism [273]. Moreover, the defect observed in the basal-complex polarization and spindle orientation due to the absent of Snail family is more severe than mutation of insc itself. Although these phenotypes can be fully rescued by transgenic expression of insc in the Snail family mutant. Altogether the results suggest that the Snail family regulatory effect on proliferation via Stg and asymmetric division partly dependent on Insc [273, 276].

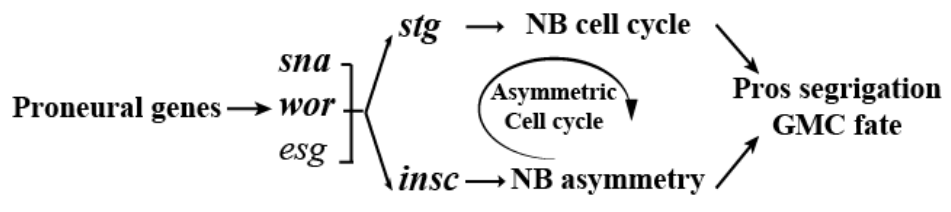

Fig. 19. The regulatory effect of the Snail family on NB asymmetric division and proliferation. Modified from [276]. 


\section{SoxB family in the developing CNS of Drosophila}

General features of the Sox family: The Sox family of TF coding genes have a wellconserved high mobility group domain (HMG), a sequence-specific DNA binding motif with 50\% homology to the HMG motif of the sex determining protein SRY. Sox family genes are limited to metazoans, and they are known to be involved in cell fate determination and differentiation in several developmental processes, including CNS development [277, 278].

SoxB family in Drosophila: The SoxB family HMG motif has the highest level of similarity with SRY motif i.e., >85\% bp identity [279]. The SoxB genes in Drosophila, several vertebrates, and all mammals are expressed in the neuroectoderm from the very early stages of development [279-282]. An extensive genetic study identified eight Sox genes in the Drosophila genome, expressed in the embryogenesis and larval stages dynamically [277].

SoxN and D: Two of those genes, SoxNeuro (SoxN) and Dichaete (D), belong to the SoxB category, and they act prior and simultaneous with proneural genes in the developing CNS of the Drosophila embryo [281]. Several studies identified the function of $\operatorname{Sox} N$ and $D$ to be involved in neural development and NB generation [281-285]. SoxN, also named SoxB1 (SOX1/2/3 in vertebrates), and $D$, also named SoxB2-1 or Fish-Hook (Sox2 in vertebrates) [277], are homologous to Sox 2 i.e., a key factor in Yamanaka reprogramming cocktail [173]. The expression pattern of $D$ is restricted to the medial and intermediate $\mathrm{NBs}$ of the $\mathrm{VNC}$, while the expression of SoxN covers medial and lateral NBs in the developing VNC [280]. D and SoxN are also co-expressed in distinct regions of the brain and PNS [280].

Expression and structure of SoxN and D: $\operatorname{SoxN}$ is one of the earliest expressed panneuroectodermal genes [280]. SoxN HMG motif shows more than $90 \%$ aa identity with the one in human SOX1/2/3 proteins, and similar to other members of the Sox family SoxN has no intron [278]. SoxN has a dynamic embryonic expression, with onset right after cellularization in the anterior regions, and later at the gastrulation stage, in the entire neurogenic regions. From stage 8, SoxN expression is restricted to the CNS, but down-regulated at later stages of embryogenesis [280]. The early expression of $D$ in the developing embryo is similar to the pattern of pair-rule genes; after gastrulation, it is broadly expressed in the neuroectoderm. $D$ is weakly expressed from stage 7 in the midline NBs, which increases at stage 9 [283], but decreases later on until stage 16 [283]. By the initiation of NB delamination, the expression of D is very dynamic, and its onset is slightly after $\operatorname{SoxN}[281]$.

Sox $N$ and $D$ function in the neuroectoderm: Loss-of-function studies identified both redundant and distinct function for SoxN and $D$ in the developing CNS [281]. Loss-of-function of early genes involve in the DV patterning, i.e., $d p p$, sog, twi, identified $S o x N$ as being downstream i.e., $d p p$ and twi negatively, and sog positively, regulate $\operatorname{SoxN}$ expression in the neuroectodermal layer [280]. Regulation of early expression of $D$ is known to be downstream of EGF and related of the DV patterning genes ind and vnd [286]. Also, $D$ is essential for proper expression of pair-rule 
genes e.g., eve [284, 287]. In addition, both SoxN and $D$ regulate the expression of ac [281]. Lossof-function of SoxN and $D$ suggests them to be involved in the formation of equivalence groups, but it is not linked to Notch signaling [281, 282, 286]. These data identifies the early effect of SoxN and $\mathrm{D}$ at the level of neurectoderm. Interestingly, Loss of function of SoxN results in loss of ac expression in lateral NBs and reduction in other NBs [281]. $D$ mutants show partial de-repression of $a c$ in the intermediate column NBs [281]. Interestingly, the double mutants' phenotype is synergic (the global level of $a c$ is lower) and additive (in the intermediate column $a c$ is de-repressed in some of the NBs) $[281,286]$. These data suggest an antagonist function for $\operatorname{SoxN}$ and $D$ in the intermediate NBs before germ layer retraction [281]. The differences between $\operatorname{SoxN}$ and $D$ function might be due to their distinct protein interacts via their non-HMD domains, where they have lower similarity in their structure and sequence [281, 283, 288]. A good example for the antagonistic function of SoxN and $\mathrm{D}$ is their opposite effect on the expression of $a c$, which is suggested to be mediated by the interaction between $\mathrm{D}$ and Ind in the intermediate columns, whereas such relation is not predicted between Ind and SoxN [281, 286]. Although functional studies suggest SoxN functions in parallel with DV patterning factors i.e., Vnd, Ind, Msh for regulating AS-C proneural genes [281, 289]. Moreover, a functional study identified SoxN as a regulator of $D$ expression, but only in the anterior region of the CNS [281].

Sox $N$ and $\boldsymbol{D}$ function in neurogenesis: Loss-of-function of SoxN resulted in missing certain NBs i.e., majorly intermediate and lateral NBs and their lineages [281]. Also, a mutation in $D$ results in loss of some of the medial NBs [286]. SoxN, D double mutants display stronger phenotype within the NBs that normally express both SoxN and D i.e., NBs in the intermediate columns [281]. Furthermore, loss-of-function of $D$ showed distinct defects in the formation and differentiation glial cells and disturbed axonal pathfinding in the midline lineages, where $D$ is the only expressed sox gene [283, 285]. Moreover, a functional study of $D$ in the developing midline NBs identified an interaction between Sox family and proteins containing a POU domain, as an evolutionarily conserved concept in of CNS development e.g., D/Vvl in Drosophila and Sox2/Oct3 in mammals $[283,285]$. In addition, previous studies have identified $D$ regulatory effect on the pan-neural gene ase, and SoxN on Cas that is essential for neurogenesis [282,290]. These data suggest that apart from the function of $\operatorname{SoxN}$ and $D$ at the level of the neuroectoderm formation, they both are essential for NB formation and specification, with possible partial redundancy in their function.

\section{Early players of temporal TFs cascade are essential for NB identity}

The temporal transcription factors (described in section 8 above) were originally identified in the temporal cascade, expressed in the NBs during VNC development. They are regulating neural progenitor competence during lineage progression [64]. In addition to controlling temporal competence changes, we postulated that early expressed temporal genes i.e., $\mathrm{Hb}>\mathrm{Kr}>\mathrm{Pdm}$ are also putative candidates for governing the initial NB identity, and hence stemness and proliferation capacity of NBs during lineage progression. This assumption is due to that some of them $(\mathrm{Kr}$ and 
Pdm) share similarities with the factors of the canonical reprogramming factors OSKM [173]; their early expression pattern in the NBs and their lineages [64] and limited studies which identified links between pan-neural genes and the early temporal factors [282, 290].

\section{The genetic mechanisms governing the NB identity are conserved between Drosophila and vertebrates}

Many of the reprogramming factors critical for stemness identity are evolutionary conserved, suggesting a common core set of regulatory genes and interfaces for regulating self-renewal and proliferation capacity e.g., Klf4 and Sox 2 are homologous of Drosophila $\mathrm{Kr}$ and SoxN [173]. Also, SNAII in the mouse cortex controls the proliferation of progenitor cells via regulation of cdc $25 \mathrm{~b}$ (Stg) [291], also adding SNAII to the OKSM combination of factors, enhances the mouse fibroblast to iPS cells reprogramming [292]. Further, Oct1-2 in mammalians is related to Pdm1-2 in Drosophila [293]. In addition, Ascl1 i.e., the mammalian ortholog of Ase, induces daughter proliferation in the mouse adult brain [294, 295].

\section{Early factors and late factors interplay govern NB identity}

The early expression of the Ase, Wor, SoxN plus the three early temporal genes made us list them as 'early factors.' Although their function in NBs are evidenced to some extent [260, 261, 267, 273, 281-285], their expression and function with respect to the NB and daughter proliferation, as well as their regulatory interactions been poorly addressed $[282,290]$.

Here in the last project of this thesis, I aimed to address the genetic mechanisms by which the proliferation capacity and the stemness identity of NBs and their daughters gradually gets restricted during lineage progression. To this end, we analyzed the endogenous expression pattern of six early genes, consisting of wor from the Snail family, SoxN from the SoxB family, the ase neural progenitor gene, and the three early temporal factors i.e., $\mathrm{Hb}, \mathrm{Kr}, \mathrm{Pdm}$, during various stages of development. All of these early factors show gradual down-regulation during development, both globally and in the lineage NB5-6T, indicating a temporal expression pattern for all of them.

A gradual decline in the early factors' expression coordinates with tuning down the proliferation in NBs and their daughter cells, both by affecting the type I $>0$ daughter proliferation switch, which occurs majorly between stage 12 to 14, and also by controlling the NB cell cycle exit. Indeed, both loss-of-function and gain-of-function studies revealed anticipated changes in NB and daughter proliferation. Moreover, the expression pattern of the early factors mirrors the expression of two other temporal factors present at the two last windows of the cascade i.e., cas and grh plus the Hox gene Antp. [71, 296]. Due to the expression time of Cas, Grh and Antp we call these tree genes late factors from now on. 

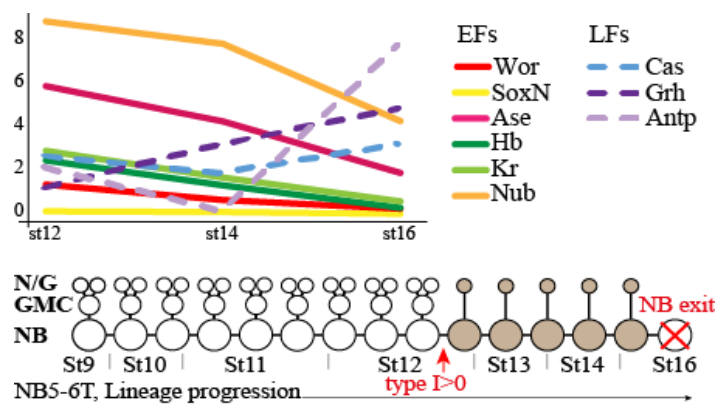

Fig. 20. Expression of the early and late factors. The graph shows the expression of the early factors in contrast to the late factors in the NBs, at several embryonic stages. The cartoon below depicts the lineage NB5-6T progression. Modified from Paper III.

The opposite expression pattern of the early and late factors suggest an opposite action between them, by which early factors drive NB identity, NB proliferation capacity and type I division, and they gradually get replaced by late factors which drive, type 0 division and ultimately NB stop. Expression analysis of early factors in early factor mutants and misexpression identified several links between them. In addition, regulatory links were found between the early factors and the late factors. Hence, an elaborate network of early and late factors regulating each other emerged.

Moreover, previous studies on the SoxB and Snail family identified their cell fate regulatory role upon the expression of cell-specific markers e.g. Eve [276, 281, 297], additional to the known regulatory role of the canonical temporal genes on NB competence and cell fate determination. Therefore, here we conclude not only $\mathrm{Hb}, \mathrm{Kr}, \mathrm{Pdm}$, but also three neural progenitor factors, i.e., Ase, Wor, SoxN, act as temporal genes.

In addition, functional analysis unraveled that many of the early factors promoted cell cycle progression by acting on the four key players of the cell cycle machinery i.e., CycE, E2f1, Stg and Dap [110]. The regulation effect of late factors, on four main cell cycle gene but Stg, has been addressed previously in our lab [110].

This finding identifies a multi-step regulation between early and late temporal factors to control the key cell cycle genes. Overall, early factors drive the type I division mode mainly by suppressing Dap, a key trigger for the type I>0 switch [110], and they promote proliferation by activating E2f, CycE and Stg. Whereas late factors trigger, type I $>0$ switch by activating Dap and tune down and stop the proliferation by inhibiting the three other cell cycle genes. 

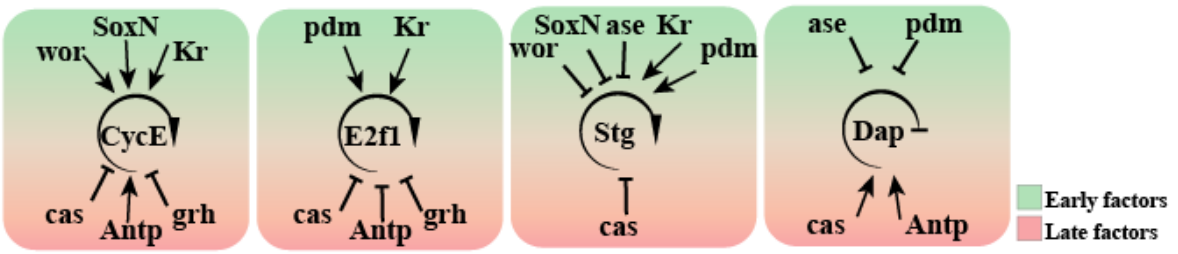

Fig. 21. Temporal genes regulate cell cycle machinery. The links between early and late factors, and the four main players of cell cycle machinery in Drosophila embryonic NBs. Modified from Paper III and [110].

Moreover, over-expression of the three pan-neural factors i.e., Ase, Wor, SoxN with a ubiquitous driver, leads to the ectopic generation of NBs and daughters. It also increased the proliferation ratio of NB and daughter cells in the embryonic stage 12, the similar result has been observed by over-expression of the three early temporal genes, i.e., $h b, K r$, and $p d m$. We assumed that the combination of three pan-neural genes with the temporal factor $\mathrm{Kr}$ i.e., the homolog of the Klf4 gene in mammals used in the Yamanaka cocktail for reprogramming and generation of iPS cells [173], may have a synergistic effects of the increased number of generated NBs and GMCs and their proliferation ratio. From this point, we combined four factors: Ase, Wor, SoxN, and Kr, as the Quad cocktail. As expected, ubiquitous over-expression of the Quad cocktail leads to a more severe effect in both cell number and proliferation ratio in the neuroectoderm of the embryos at stage 12 . Therefore, early factors have a combinatorial effect to established NB identity and prompt proliferation capacity in both NBs and GMCs.

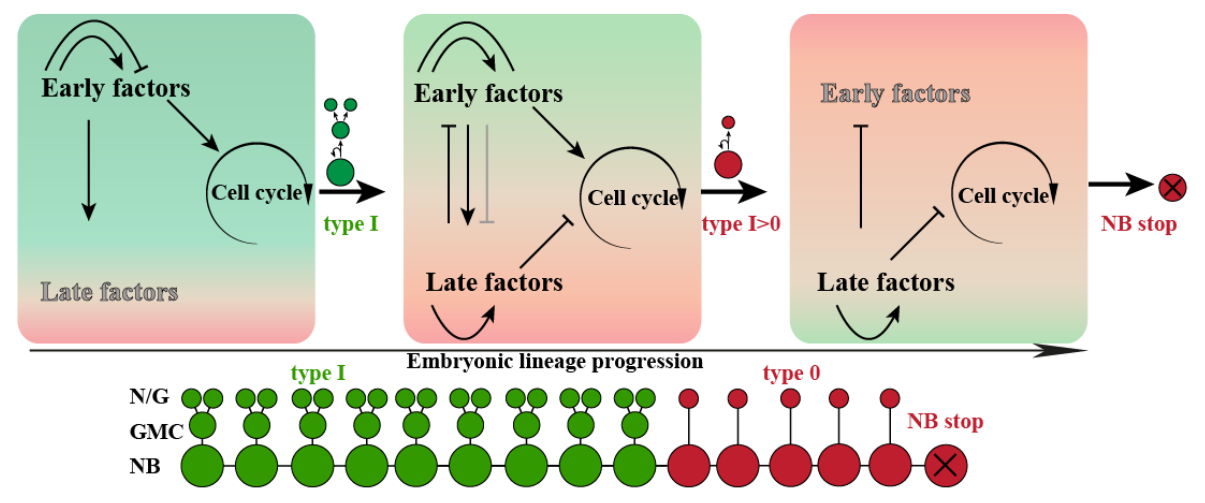

Fig. 22. The model for the elaborate interplay between early and late temporal factors in the context of lineage progression. The interplay between early factors driving NB proliferation and type I daughter proliferation, and the late factors stopping NBs and switching division type I $>0$ of daughters. Modified from Paper III. 
In addition, gain-of-function of the Quad cocktail was sufficient to reprogram the developing wing disc of the L3 larva to a neural fate. Data indicates that combinatorial effect of early factors is both required and sufficient to induce NB identity. Indeed expressing the Quad cocktail in the wing disk not only triggers NB identity but also triggers neurogenesis, detected by the expression of Repo and Elav, glial and neural markers.

Interestingly, the ratio between the induced neurons and glial cell in the wing disk resembled the neural to glial cell ratio in the Drosophila CNS, i.e., 1:10 [6, 19, 20]. Moreover, the combination of early factors also introduced the NB asymmetric machinery in the wing disk detected by expression of Pros, Mira and Insc. In conclusion, our data suggest that the Quad cocktail is sufficient for establishing NB identity and regulate the correct lineage progression.

Strikingly, mis-expression of the Quad cocktail leads to reduction of the overall size of the wing disks, which can be explained by the introduction of the asymmetric machinery of the Drosophila embryonic NBs into the wing discs. We conclude that the Quad cocktail establishes a specific type of stem cell i.e., multipotent NBs which divide in the type I window, contrary with Yamanaka OSKM "cocktail" which induces pluripotent stem cells that likely show symmetric division [173].

As described in section 13 above, one of the main issues for using iPS cells for cell therapy is that a high percentage of iPS cells turn into tumorigenic cells and induce cancer [186]. Our data suggest that reprograming differentiated cell to the multipotent stem cell in reference to lineage progression, instead of pluripotent stem cells, may reduce the chance of tumor formation in the reprogrammed cells. Albeit identification of transcription factors that can reprogram the differentiated cell to a very specific type of multipotent stem cells requires very detailed studies and deeper knowledge about lineage progression and stem cell competence in reference to cell fate determination.

Moreover, the combination of all six early factors could drive NB formation broadly in the ectoderm with the intact CNS patterning, detected by the expression of GsbN, which indicate that these factors can set up the NB identity without interfering with the VNC patterning programs. 


\section{Conclusions}

In conclusion, the three papers of this thesis attempted to identify novel regulatory genes controlling cell specification and proliferation in the CNS.

The first paper of this thesis succeeded to identify 43 genes involved in the embryonic CNS development of Drosophila. These findings were achieved through a forward genetic screen. Due to the high sensitivity of the screen setup the genes identified cover a vast range of putative functions i.e., from chromatin modulators, RNA processing, cell cycle regulators and NB identity genes, to cell fate determinants and neuropeptides.

The second and third papers built upon the genes identified the screen.

In the second paper, we studied the $C \operatorname{tr} 9$ gene; a key member of Paf1C. This project was the first detailed phenotypic and functional study of Ctr9 in Drosophila. We identified Ctr 9 as an essential gene during embryogenesis, when its expression is mainly limited to the developing CNS. We identified $\operatorname{Ctr} 9$ to be involved in NB generation and proliferation control in both NBs and GMCs, as well as terminal differentiation and histone modification. Moreover, loss-of-function of hyrax, another member of Paf1C in Drosophila, mimicked the phenotype of Ctr9 mutants. Given the known function of Paf1C in the histone modification, and the similar phenotypes in $C t r 9$ and hyrax mutants, this suggests that the role of $C t r 9$ in the developing CNS is in the complex of Paf1C.

Finally, in the third paper, based on the isolation of the gene wor, a NB identity gene, in the first project, in addition to the other putative NB identify factors, we attempt to encode the regulatory mechanisms than tune down this factors in a timely manner and decrease the proliferation capacity in favor of cell differentiation. We identified six TFs expressed temporally in the early windows of lineage progression, and that drive NB proliferation and type I daughter division, whereas another set of factors i.e., three late TFs, gradually take their place and trigger the type I $>0$ switch and NB cell cycle exit. We identified regulatory effects between early factors themselves and with late factors, while they both affect the cell cycle machinery in the opposite direction. 


\section{Acknowledgments}

'This Thesis' is done for the very little that I have learned and the infinity that I still do not know, merely with whom I shared the search for 'More.' It took four years and the whole of my 'lifetime' and involved many people to make it possible. It is a great pleasure to thank each who has been a contributor to 'the thesis' or to the 'lifetime.' I would like to show my gratitude to everyone (who is/was) on floor 13; particularly Jan-Ingvar Jönsson, Mikael Sigvardsson, Jörg Cammenga groups for every Monday meeting, which I have benefited from.

I owe my deepest gratitude to my worthy, esteemed and humble supervisor Stefan Thor, who has been extraordinarily supportive and tolerant. His warm encouragement and enthusiasm plus his constructive comments and adequate guidance are invaluable to me. He always bestowed self-confidence and strength in me, and he taught me not only about science but also about how to be a scientist.

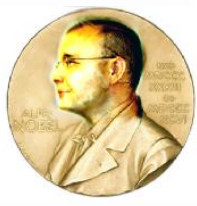
I have developed the most under your supervision, and you have a rare gift for that! In one word, if I could go back to the time when I was about to apply for Ph.D. I would undoubtedly ask for a position in your lab; I am just not so sure how high my chances would be ...!!! ()

I also would like to show my greatest appreciation to my co-supervisor, Jan-Ingvar Jonsson for his encouragements, supports, and comments during these years. You are an excellent scientist, and an outstanding manager; having you as my co-supervisor was an honor for me.

My heartfelt appreciations to: Annika, who has been a full support in various ways from the very beginning. Your warm heart made it easier for me to break the ice. Thanks for being so delightful. Carolin, my lady; the life, and soul of the Thor party, you have always been there for me with your whole heart. Whenever I was in hot water, you chilled me out; Danke schön. Helen, thank you for your great support during all these years, working with you was my precious. Anna, for your pleasant smile, and showing me how to dissect. Magnus, who warmly shared his knowledge and experiences and always inspired confidence in me. Your unique sense of humor is so missed and Daniel my dear colleague, all the best in the US. Josefine, sweetest office partner, your cheerful spirit always brought light to our office, which I turned into a cave. Caroline, for all good moments we had, especially in the Big Apple, was quite a trip. Erika, for the amusing rollercoaster ride on the last project, and all the best with your super cool job. Behzad, my homeboy, how has made his support always available. Nothing is better than sharing your root with someone decent. All the best for you and your sweetheart. Johannes, my German quality buddy; for your warm heart and willing mind and true personality, Chakerim. Nacho, Mia amigo, for turning everything to be so enjoyable, from cleaning to Queens; you have always (not almost) been supportive and comforting, a friend like you is once per life. Hugo, ... the sun is shining, and so are you, all the best pal. Susanne, my brainy gal, for being high-spirited and easy going; being with you is thoroughly fun. Jonathan you joined the lab lately, but feels as if I know you for a long time; it shall be since you do not wear any mask and it is wonderful. Jesus, for engaging discussion and fun we had, good luck with your almond trees. Johan, my exquisite pal, for substantial support, lively discussion, adventures fikas, relaxing teas and unique friendship. Elisa, for every fun event you arranged and laughter you brought, all the best for the rest. 
Sumit, my confident pal, thanks for all your helpful support and interesting discussions on the way back home. Rajesh my international pal, for all your valuable help, enjoyable moments, and sincere friendship. Mia Mano for being transparent and unique and for all estimable moment you made, as you know the value of life. Shadi, for being so enchanting, all the best in life and science as you deserve. Amir, who has been with me from the beginning of my life in Sweden; you know how to appreciate life and make it pleasant for others, mercy for every support and joy. Santoosh, for being a true friend unconditionally, you are so missed buddy; all the best with your little one and life. Amitha my gal, for all memorable moments we made and every fun we had. Karl, after these years, I still miss you as you left yesterday, live your life as Karl does. Giulia, my little gal, your pure and warm heart is so missed, take a good care of it. Maite for your sweet and fresh attitude, and joy we had. Ramy for being so amazing, sensible and great, you always make me speechless; thank you for being in my life. Mohamad and Shiva, I hope your home be always as warm as your hearts and as green as your garden, Negar for your gem heart, and every unrepeatable time we had, back home and in Switzerland. Negah your warm heart is so missed missy, all the best in Harvard; and all the gang in the love street, having friends valuable as you is priceless. Tanaz for your pure heart and transparency, you are one of a kind. Zahra, my true gal, wish your life full of the glory of your Bahraran; you are more than a friend. Lili Yare-Dabestani and Mahi, for over 20 years of gratifying friendship and memories which recalling them delights my gloomy days. Also to all my other wonderful friends in every corner of the world, who I am gifted by their presence in my life. I tried my best to express how grateful I am to you all, but whatever I say it misses. Here I may seize the moment to express my deepest gratitude to my beloved family; not only 'the thesis' but also my 'lifetime' would not have been a reality without them.

* Expressing the suffocated words in the throat of everyday life is an excuse to lit up this inky draft! For the pure kindness of my Mom and good will of my Dad, who gifted me the feeling of being loved, from before my birth; I am always indebted to your selfless devotion and open arms, which I find the safest place ever. And for the transparency of my sisters Azin and Eliana, for every moment which we lived together and made the sky of our life, sunny and rainy. And for my aunt, who brighten the laughter and her presence is the appreciation for the essence of life; and my lovely granny who is merry like a Christmas gift. And for the honor of my dearest uncle, your benignity is beyond me and my explanations.

Here I am, in the existence of every concept in the world, quietly overloaded with unspoken words...as Sohrab Sepehri says: 'O, exquisite start, enchanted expressions still sorely missed'...

$$
\begin{aligned}
& \text { * و بهانهى روشنى اين سياهل، بيان حرفهايى بانشند كه در كلوى روزمركى زندكى مانده. ارز انى مهربانى مامان و صفاى بابا }
\end{aligned}
$$

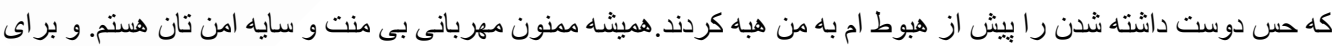

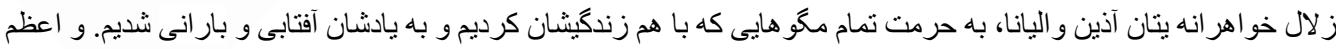

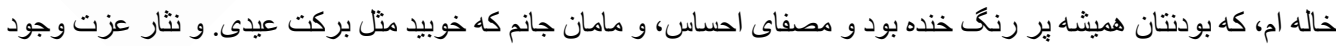

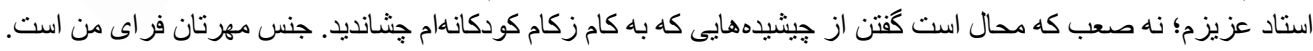

$$
\begin{aligned}
& \text { در جمع،... من و اين همه سكوت سرشار از ناكفته ها! به قول سهر ب...اي شروع لطيف! جاي الفاظ مجذوب ، خالي }
\end{aligned}
$$




\section{References}

1. Kandel, E.R., et al., Principles of neural science. Vol. 4. 2000: McGraw-hill New York.

2. $\quad$ Richter, S., et al., Invertebrate neurophylogeny: suggested terms and definitions for a neuroanatomical glossary. Front Zool, 2010. 7: p. 29.

3. Bossing, T., et al., The embryonic central nervous system lineages of Drosophila melanogaster. I. Neuroblast lineages derived from the ventral half of the neuroectoderm. Dev Biol, 1996. 179(1): p. 41-64.

4. Schmid, A., A. Chiba, and C.Q. Doe, Clonal analysis of Drosophila embryonic neuroblasts: neural cell types, axon projections and muscle targets. Development, 1999. 126(21): p. 4653-89.

5. Wu, P.S., B. Egger, and A.H. Brand, Asymmetric stem cell division: lessons from Drosophila. Semin Cell Dev Biol, 2008. 19(3): p. 283-93.

6. Jones, B.W., Transcriptional control of glial cell development in Drosophila. Dev Biol, 2005. 278(2): p. 26573.

7. Egger, B., J.M. Chell, and A.H. Brand, Insights into neural stem cell biology from flies. Philos Trans R Soc Lond B Biol Sci, 2008. 363(1489): p. 39-56.

8. Nedergaard, M., B. Ransom, and S.A. Goldman, New roles for astrocytes: redefining the functional architecture of the brain. Trends Neurosci, 2003. 26(10): p. 523-30.

9. Ou, J., et al., Analysis of Glial Distribution in Drosophila Adult Brains. Neuroscience Bulletin, 2016. 32(2): p. $162-170$.

10. Bear, M.F., B.W. Connors, and M.A. Paradiso, Neuroscience. Vol. 2. 2007: Lippincott Williams \& Wilkins.

11. Dombrowski, S.M., C.C. Hilgetag, and H. Barbas, Quantitative architecture distinguishes prefrontal cortical systems in the rhesus monkey. Cereb Cortex, 2001. 11(10): p. 975-88.

12. Christensen, J.R., et al., Neocortical and hippocampal neuron and glial cell numbers in the rhesus monkey. Anat Rec (Hoboken), 2007. 290(3): p. 330-40.

13. Herculano-Houzel, S., et al., Cellular scaling rules for primate brains. Proc Natl Acad Sci U S A, 2007. 104(9): p. 3562-7.

14. Bjugn, R. and H.J. Gundersen, Estimate of the total number of neurons and glial and endothelial cells in the rat spinal cord by means of the optical disector. J Comp Neurol, 1993. 328(3): p. 406-14.

15. Hilgetag, C.C. and H. Barbas, Are there ten times more glia than neurons in the brain? Brain Struct Funct, 2009. 213(4-5): p. 365-6.

16. West, M.J., Stereological methods for estimating the total number of neurons and synapses: issues of precision and bias. Trends Neurosci, 1999. 22(2): p. 51-61.

17. Herculano-Houzel, S. and R. Lent, Isotropic fractionator: a simple, rapid method for the quantification of total cell and neuron numbers in the brain. J Neurosci, 2005. 25(10): p. 2518-21.

18. Dobbing, J. and J. Sands, Quantitative growth and development of human brain. Arch Dis Child, 1973. 48(10): p. 757-67.

19. Awasaki, T. and T. Lee, New tools for the analysis of glial cell biology in Drosophila. Glia, 2011. 59(9): p. 1377-86.

20. Sprecher, S., Drosophila Neural Development, in eLS. 2001, John Wiley \& Sons, Ltd.

21. Cajal, S.R., y. 1933 Histology. London: Bailliere, Tindall and Cox.

22. Sander, K. and P.E. Faessler, Introducing the Spemann-Mangold organizer: experiments and insights that generated a key concept in developmental biology. Int J Dev Biol, 2001. 45(1): p. 1-11.

23. Grunz, H. and L. Tacke, Neural differentiation of Xenopus laevis ectoderm takes place after disaggregation and delayed reaggregation without inducer. Cell differentiation and development, 1989. 28(3): p. 211-217.

24. Smith, W.C. and R.M. Harland, Expression cloning of noggin, a new dorsalizing factor localized to the Spemann organizer in Xenopus embryos. Cell, 1992. 70(5): p. 829-840.

25. Piccolo, S., et al., Dorsoventral patterning in Xenopus: inhibition of ventral signals by direct binding of chordin to BMP-4. Cell, 1996. 86(4): p. 589-598.

26. Reissmann, E. and A.H. Brivanlou, Neuronal Subtype Identity Regulation, in eLS. 2001, John Wiley \& Sons, Ltd.

27. Cowan, W.M., Molecular and cellular approaches to neural development. 1997: Oxford University Press, USA.

28. Edlund, T. and T.M. Jessell, Progression from extrinsic to intrinsic signaling in cell fate specification: a view from the nervous system. Cell, 1999. 96(2): p. 211-224.

29. Allan, D.W. and S. Thor, Transcriptional selectors, masters, and combinatorial codes: regulatory principles of neural subtype specification. Wiley Interdisciplinary Reviews: Developmental Biology, 2015. 4(5): p. 505528. 
30. Reichert, H., Evolutionary conservation of mechanisms for neural regionalization, proliferation and interconnection in brain development. Biology letters, 2009. 5(1): p. 112-116.

31. Lewis, E.B.B., F., Method for feeding ethyl-methane sulfonate (EMS) to Drosophila males. Drosoph.

.1968. 43.

32. St Johnston, D., The art and design of genetic screens: Drosophila melanogaster. Nat Rev Genet, 2002. 3(3): p. $176-88$.

33. Clark, A.G., et al., Evolution of genes and genomes on the Drosophila phylogeny. Nature, 2007. 450(7167): p. 203-18.

34. Brand, A.H. and N. Perrimon, Targeted gene expression as a means of altering cell fates and generating dominant phenotypes. Development, 1993. 118(2): p. 401-15.

35. Urbach, R. and G.M. Technau, Dorsoventral patterning of the brain: a comparative approach. Adv Exp Med Biol, 2008. 628: p. 42-56.

36. Sanson, B., Generating patterns from fields of cells. <span class="subtitle" $>$ Examples from <em>Drosophila</em> segmentation</span>, 2001. 2(12): p. 1083-1088.

37. Bhat, K.M., Segment polarity genes in neuroblast formation and identity specification during Drosophila neurogenesis. Bioessays, 1999. 21(6): p. 472-85.

38. Skeath, J.B. and S. Thor, Genetic control of Drosophila nerve cord development. Curr Opin Neurobiol, 2003. 13(1): p. 8-15.

39. Skeath, J.B., At the nexus between pattern formation and cell-type specification: the generation of individual neuroblast fates in the Drosophila embryonic central nervous system. Bioessays, 1999. 21(11): p. 922-31.

40. McDonald, J.A., et al., Dorsoventral patterning in the Drosophila central nervous system: the vnd homeobox gene specifies ventral column identity. Genes Dev, 1998. 12(22): p. 3603-12.

41. Doe, C.Q., Molecular markers for identified neuroblasts and ganglion mother cells in the Drosophila central nervous system. Development, 1992. 116(4): p. 855-63.

42. Hirth, F., et al., Developmental defects in brain segmentation caused by mutations of the homeobox genes orthodenticle and empty spiracles in Drosophila. Neuron, 1995. 15(4): p. 769-78.

43. Nusslein-Volhard, C. and E. Wieschaus, Mutations affecting segment number and polarity in Drosophila. Nature, 1980. 287(5785): p. 795-801.

44. Reichert, H., Conserved genetic mechanisms for embryonic brain patterning. Int J Dev Biol, 2002. 46(1): p. 81-7.

45. Klämbt, C., J.R. Jacobs, and C.S. Goodman, The midline of the Drosophila central nervous system: a model for the genetic analysis of cell fate, cell migration, and growth cone guidance. Cell, 1991. 64(4): p. 801-15

801-15.

46. Technau, G.M., C. Berger, and R. Urbach, Generation of cell diversity and segmental pattern in the embryonic central nervous system of Drosophila. Dev Dyn, 2006. 235(4): p. 861-9.

47. Skeath, J.B., At the nexus between pattern formation and cell-type specification: the generation of individual neuroblast fates in the Drosophila embryonic central nervous system. Bioessays, 1999. 21(11): p. 922-931.

48. Doe, C.Q., S. Fuerstenberg, and C.Y. Peng, Neural stem cells: from fly to vertebrates. Developmental Neurobiology, 1998. 36(2): p. 111-127.

49. Lewis, E.B., A gene complex controlling segmentation in Drosophila. Nature, 1978. 276(5688): p. 565-70.

50. Hirth, F., B. Hartmann, and H. Reichert, Homeotic gene action in embryonic brain development of Drosophila. Development, 1998. 125(9): p. 1579-89.

51. Gehring, W.J., U. Kloter, and H. Suga, Evolution of the Hox gene complex from an evolutionary ground state. Curr Top Dev Biol, 2009. 88: p. 35-61.

52. Capovilla, M. and J. Botas, Functional dominance among Hox genes: repression dominates activation in the regulation of Dpp. Development, 1998. 125(24): p. 4949-57.

53. Dasen, J.S., Transcriptional networks in the early development of sensory-motor circuits. Curr Top Dev Biol, 2009. 87: p. 119-48.

54. Pearson, J.C., D. Lemons, and W. McGinnis, Modulating Hox gene functions during animal body patterning. Nat Rev Genet, 2005. 6(12): p. 893-904.

55. Villares, R. and C.V. Cabrera, The achaete-scute gene complex of D. melanogaster: conserved domains in a subset of genes required for neurogenesis and their homology to myc. Cell, 1987. 50(3): p. 415-24.

56. Garcia-Bellido, A. and P. Santamaria, Developmental Analysis of the Achaete-Scute System of DROSOPHILA MELANOGASTER. Genetics, 1978. 88(3): p. 469-86. 
57. Skeath, J.B. and S.B. Carroll, Regulation of proneural gene expression and cell fate during neuroblast segregation in the Drosophila embryo. Development, 1992. 114(4): p. 939-46.

58. Martin-Bermudo, M.D., et al., Distribution and function of the lethal of scute gene product during early neurogenesis in Drosophila. Development, 1991. 113(2): p. 445-54.

59. Simpson, P. and C. Carteret, A study of shaggy reveals spatial domains of expression of achaete-scute alleles on the thorax of Drosophila. Development, 1989. 106(1): p. 57-66.

60. Stern, C., Two or three bristles. Sci Prog (New Haven), 1955. Series 9: p. 41-84.

61. Skeath, J.B. and S.B. Carroll, Regulation of achaete-scute gene expression and sensory organ pattern formation in the Drosophila wing. Genes Dev, 1991. 5(6): p. 984-95.

62. Okano, H. and S. Temple, Cell types to order: temporal specification of CNS stem cells. Curr Opin Neurobiol, 2009. 19(2): p. 112-9.

63. Jacob, J., C. Maurange, and A.P. Gould, Temporal control of neuronal diversity: common regulatory principles in insects and vertebrates? Development, 2008. 135(21): p. 3481-9.

64. Kohwi, M. and C.Q. Doe, Temporal fate specification and neural progenitor competence during development. Nat Rev Neurosci, 2013. 14(12): p. 823-38.

65. Li, X., Z. Chen, and C. Desplan, Temporal patterning of neural progenitors in Drosophila. Curr Top Dev Biol, 2013. 105: p. 69-96.

66. Brody, T. and W.F. Odenwald, Programmed transformations in neuroblast gene expression during Drosophila CNS lineage development. Dev Biol, 2000. 226(1): p. 34-44.

67. Isshiki, T., et al., Drosophila neuroblasts sequentially express transcription factors which specify the temporal identity of their neuronal progeny. Cell, 2001. 106(4): p. 511-21.

68. Kambadur, R., et al., Regulation of POU genes by castor and hunchback establishes layered compartments in the Drosophila CNS. Genes Dev, 1998. 12(2): p. 246-60.

69. Kanai, M.I., M. Okabe, and Y. Hiromi, seven-up Controls switching of transcription factors that specify temporal identities of Drosophila neuroblasts. Dev Cell, 2005. 8(2): p. 203-13.

70. Kohwi, M., L.S. Hiebert, and C.Q. Doe, The pipsqueak-domain proteins Distal antenna and Distal antennarelated restrict Hunchback neuroblast expression and early-born neuronal identity. Development, 2011. 138(9): p. 1727-35.

71. Baumgardt, M., et al., Neuronal subtype specification within a lineage by opposing temporal feed-forward loops. Cell, 2009. 139(5): p. 969-82.

72. Benito-Sipos, J., et al., Seven up acts as a temporal factor during two different stages of neuroblast 5-6 development. Development, 2011. 138(24): p. 5311-20.

73. Mann, R.S. and S.B. Carroll, Molecular mechanisms of selector gene function and evolution. Curr Opin Genet Dev, 2002. 12(5): p. 592-600.

74. Kassar-Duchossoy, L., et al., Mrf4 determines skeletal muscle identity in Myf5:Myod double-mutant mice. Nature, 2004. 431(7007): p. 466-71.

75. Young, R.A., Control of the embryonic stem cell state. Cell, 2011. 144(6): p. 940-54.

76. Cattenoz, P.B. and A. Giangrande, New insights in the clockwork mechanism regulating lineage specification: Lessons from the Drosophila nervous system. Dev Dyn, 2015. 244(3): p. 332-41.

77. Bernardoni, R., A.A. Miller, and A. Giangrande, Glial differentiation does not require a neural ground state. Development, 1998. 125(16): p. 3189-200.

78. Giesen, K., et al., Glial development in the Drosophila CNS requires concomitant activation of glial and repression of neuronal differentiation genes. Development, 1997. 124(12): p. 2307-16.

79. Doe, C.Q., D. Smouse, and C.S. Goodman, Control of neuronal fate by the Drosophila segmentation gene even-skipped. Nature, 1988. 333(6171): p. 376-8.

80. Wenick, A.S. and O. Hobert, Genomic cis-regulatory architecture and trans-acting regulators of a single interneuron-specific gene battery in C. elegans. Dev Cell, 2004. 6(6): p. 757-70.

81. Benveniste, R.J., et al., Cell type-specific regulation of the Drosophila FMRF-NH2 neuropeptide gene by Apterous, a LIM homeodomain transcription factor. Development, 1998. 125(23): p. 4757-65.

82. Thor, S. and J.B. Thomas, The Drosophila islet gene governs axon pathfinding and neurotransmitter identity. Neuron, 1997. 18(3): p. 397-409.

83. Lund, K., et al., Islet expression of Rhombotin and Isl-1 suggests cell type specific exposure of LIM-domain epitopes. Endocrine, 1995. 3(6): p. 399-408.

84. Bach, I., The LIM domain: regulation by association. Mech Dev, 2000. 91(1-2): p. 5-17.

85. Wolfram, V., et al., The transcription factors islet and Lim3 combinatorially regulate ion channel gene expression. J Neurosci, 2014. 34(7): p. 2538-43. 
86. Thor, S., et al., A LIM-homeodomain combinatorial code for motor-neuron pathway selection. Nature, 1999. 397(6714): p. 76-80.

87. Rickert, C., et al., Morphological characterization of the entire interneuron population reveals principles of neuromere organization in the ventral nerve cord of Drosophila. J Neurosci, 2011. 31(44): p. 15870-83.

88. Hammonds, A.S., et al., Spatial expression of transcription factors in Drosophila embryonic organ development. Genome Biol, 2013. 14(12): p. R140.

89. Hewes, R.S., et al., The bHLH protein Dimmed controls neuroendocrine cell differentiation in Drosophila. Development, 2003. 130(9): p. 1771-1781.

90. Hamanaka, Y., et al., Transcriptional orchestration of the regulated secretory pathway in neurons by the bHLH protein DIMM. Curr Biol, 2010. 20(1): p. 9-18.

91. Allan, D.W., et al., Regulators acting in combinatorial codes also act independently in single differentiating neurons. Neuron, 2005. 45(5): p. 689-700.

92. Fichelson, P., et al., Cell cycle and cell-fate determination in Drosophila neural cell lineages. Trends Genet, 2005. 21(7): p. 413-20.

93. Datar, S.A., et al., The Drosophila cyclin D-Cdk4 complex promotes cellular growth. Embo j, 2000. 19(17): p. 4543-54.

94. Lehner, C.F. and P.H. O'Farrell, Drosophila cdc2 homologs: a functional homolog is coexpressed with a cognate variant. Embo j, 1990. 9(11): p. 3573-81.

95. Knoblich, J.A., et al., Cyclin E controls $S$ phase progression and its down-regulation during Drosophila embryogenesis is required for the arrest of cell proliferation. Cell, 1994. 77(1): p. 107-20.

96. Lehner, C.F. and P.H. O'Farrell, Expression and function of Drosophila cyclin A during embryonic cell cycle progression. Cell, 1989. 56(6): p. 957-68.

97. Jacobs, H.W., J.A. Knoblich, and C.F. Lehner, Drosophila Cyclin B3 is required for female fertility and is dispensable for mitosis like Cyclin B. Genes Dev, 1998. 12(23): p. 3741-51.

98. Duronio, R.J., et al., E2F-induced $S$ phase requires cyclin E. Genes Dev, 1996. 10(19): p. 2505-13.

99. Du, W., et al., $R B F$, a novel $R B$-related gene that regulates $E 2 F$ activity and interacts with cyclin $E$ in Drosophila. Genes Dev, 1996. 10(10): p. 1206-18.

100. Kawamori, A., K. Shimaji, and M. Yamaguchi, Control of e2f1 and PCNA by Drosophila transcription factor DREF. Genesis, 2013. 51(11): p. 741-50.

101. Vodermaier, H.C., APC/C and SCF: controlling each other and the cell cycle. Curr Biol, 2004. 14(18): p. R787-96.

102. Grosskortenhaus, R. and F. Sprenger, Rcal inhibits APC-Cdh1(Fzr) and is required to prevent cyclin degradation in G2. Dev Cell, 2002. 2(1): p. 29-40.

103. Campbell, S.D., et al., Drosophila Weel kinase rescues fission yeast from mitotic catastrophe and phosphorylates Drosophila Cdc2 in vitro. Mol Biol Cell, 1995. 6(10): p. 1333-47.

104. Adams, M.D., et al., The genome sequence of Drosophila melanogaster. Science, 2000. 287(5461): p. 218595.

105. Edgar, B.A. and P.H. O'Farrell, Genetic control of cell division patterns in the Drosophila embryo. Cell, 1989. 57(1): p. 177-87.

106. Edgar, B.A. and P.H. O'Farrell, The three postblastoderm cell cycles of Drosophila embryogenesis are regulated in $G 2$ by string. Cell, 1990. 62(3): p. 469-80.

107. de Nooij, J.C., M.A. Letendre, and I.K. Hariharan, A cyclin-dependent kinase inhibitor, Dacapo, is necessary for timely exit from the cell cycle during Drosophila embryogenesis. Cell, 1996. 87(7): p. 1237-47.

108. Lane, M.E., et al., Dacapo, a cyclin-dependent kinase inhibitor, stops cell proliferation during Drosophila development. Cell, 1996. 87(7): p. 1225-35.

109. Foley, E., P.H. O'Farrell, and F. Sprenger, Rux is a cyclin-dependent kinase inhibitor (CKI) specific for mitotic cyclin-Cdk complexes. Curr Biol, 1999. 9(23): p. 1392-402.

110. Baumgardt, M., et al., Global programmed switch in neural daughter cell proliferation mode triggered by a temporal gene cascade. Dev Cell, 2014. 30(2): p. 192-208.

111. Potter, C.J. and T. Xu, Mechanisms of size control. Curr Opin Genet Dev, 2001. 11(3): p. 279-86.

112. Weigmann, K. and C.F. Lehner, Cell fate specification by even-skipped expression in the Drosophila nervous system is coupled to cell cycle progression. Development, 1995. 121(11): p. 3713-21.

113. Hartenstein, V., Rudloff, E. and Campos-Ortega, J. A., The pattern of proliferation of the neuroblasts in the wild-type embryo of Drosophila melanogaster. Roux Arch. dev. Biol., 1987. 196(8): p. 473-485.

114. Foe, V.E., G. Odell, and B. Edgar, Mitosis and morphogenesis in the Drosophila embryo: point and counterpoint. The development of Drosophila melanogaster, 1993. 1: p. 149-300. 
115. Cui, X. and C.Q. Doe, The role of the cell cycle and cytokinesis in regulating neuroblast sublineage gene expression in the Drosophila CNS. Development, 1995. 121(10): p. 3233-43.

116. Schmidt, H., et al., The embryonic central nervous system lineages ofDrosophila melanogaster. Developmental biology, 1997. 189(2): p. 186-204.

117. Berger, C., et al., A critical role for cyclin E in cell fate determination in the central nervous system of Drosophila melanogaster. Nat Cell Biol, 2005. 7(1): p. 56-62.

118. Ohnuma, S., et al., p27Xic1, a Cdk inhibitor, promotes the determination of glial cells in Xenopus retina. Cell, 1999. 99(5): p. 499-510.

119. Kostic, I., S. Li, and R. Roy, cki-1 links cell division and cell fate acquisition in the C. elegans somatic gonad. Dev Biol, 2003. 263(2): p. 242-52.

120. Lehner, C.F., The pebble gene is required for cytokinesis in Drosophila. J Cell Sci, 1992. 103 ( Pt 4): p. 1021 30 .

121. Holtzer, H., et al., Lineages, quantal cell cycles, and the generation of cell diversity. Q Rev Biophys, 1975. 8(4): p. 523-57.

122. Jones, B.W., et al., glial cells missing: a genetic switch that controls glial versus neuronal fate. Cell, 1995. 82(6): p. 1013-23.

123. Hosoya, T., et al., glial cells missing: a binary switch between neuronal and glial determination in Drosophila. Cell, 1995. 82(6): p. 1025-36.

124. Akiyama-Oda, Y., et al., Distinct mechanisms triggering glial differentiation in Drosophila thoracic and abdominal neuroblasts 6-4. Dev Biol, 2000. 222(2): p. 429-39.

125. Doe, C.Q., et al., The prospero gene specifies cell fates in the Drosophila central nervous system. Cell, 1991. 65(3): p. 451-64.

126. Vaessin, H., et al., prospero is expressed in neuronal precursors and encodes a nuclear protein that is involved in the control of axonal outgrowth in Drosophila. Cell, 1991. 67(5): p. 941-53.

127. Spana, E.P. and C.Q. Doe, The prospero transcription factor is asymmetrically localized to the cell cortex during neuroblast mitosis in Drosophila. Development, 1995. 121(10): p. 3187-95.

128. Hartenstein, V. and J.W. Posakony, Sensillum development in the absence of cell division: the sensillum phenotype of the Drosophila mutant string. Dev Biol, 1990. 138(1): p. 147-58.

129. Buescher, M., et al., Binary sibling neuronal cell fate decisions in the Drosophila embryonic central nervous system are nonstochastic and require inscuteable-mediated asymmetry of ganglion mother cells. Genes Dev, 1998. 12(12): p. 1858-70.

130. Lear, B.C., J.B. Skeath, and N.H. Patel, Neural cell fate in rcal and cycA mutants: the roles of intrinsic and extrinsic factors in asymmetric division in the Drosophila central nervous system. Mech Dev, 1999. 88(2): p. 207-19.

131. Wai, P., B. Truong, and K.M. Bhat, Cell division genes promote asymmetric interaction between Numb and Notch in the Drosophila CNS. Development, 1999. 126(12): p. 2759-70.

132. Grosskortenhaus, R., et al., Regulation of temporal identity transitions in Drosophila neuroblasts. Dev Cell, 2005. 8(2): p. 193-202.

133. Lemaire, P., Unfolding a chordate developmental program, one cell at a time: invariant cell lineages, shortrange inductions and evolutionary plasticity in ascidians. Dev Biol, 2009. 332(1): p. 48-60.

134. Jan, Y.N. and L.Y. Jan, Polarity in cell division: what frames thy fearful asymmetry? Cell, 2000. 100(6): p. 599-602.

135. Morrison, S.J. and J. Kimble, Asymmetric and symmetric stem-cell divisions in development and cancer. Nature, 2006. 441(7097): p. 1068-74.

136. Clarke, M.F. and M. Fuller, Stem cells and cancer: two faces of eve. Cell, 2006. 124(6): p. 1111-5.

137. Kaltschmidt, J.A., et al., Rotation and asymmetry of the mitotic spindle direct asymmetric cell division in the developing central nervous system. Nat Cell Biol, 2000. 2(1): p. 7-12.

138. Kuchinke, U., F. Grawe, and E. Knust, Control of spindle orientation in Drosophila by the Par-3-related PDZ-domain protein Bazooka. Curr Biol, 1998. 8(25): p. 1357-65.

139. Petronczki, M. and J.A. Knoblich, DmPAR-6 directs epithelial polarity and asymmetric cell division of neuroblasts in Drosophila. Nat Cell Biol, 2001. 3(1): p. 43-9.

140. Schober, M., M. Schaefer, and J.A. Knoblich, Bazooka recruits Inscuteable to orient asymmetric cell divisions in Drosophila neuroblasts. Nature, 1999. 402(6761): p. 548-51.

141. Yu, F., et al., Analysis of partner of inscuteable, a novel player of Drosophila asymmetric divisions, reveals two distinct steps in inscuteable apical localization. Cell, 2000. 100(4): p. 399-409.

142. Schaefer, M., et al., A protein complex containing Inscuteable and the Galpha-binding protein Pins orients asymmetric cell divisions in Drosophila. Curr Biol, 2000. 10(7): p. 353-62. 
143. Wodarz, A., et al., Bazooka provides an apical cue for Inscuteable localization in Drosophila neuroblasts. Nature, 1999. 402(6761): p. 544-7.

144. Zhong, W. and W. Chia, Neurogenesis and asymmetric cell division. Curr Opin Neurobiol, 2008. 18(1): p. 411.

145. Siegrist, S.E. and C.Q. Doe, Microtubule-induced Pins/Galphai cortical polarity in Drosophila neuroblasts. Cell, 2005. 123(7): p. 1323-35.

146. Siegrist, S.E. and C.Q. Doe, Extrinsic cues orient the cell division axis in Drosophila embryonic neuroblasts. Development, 2006. 133(3): p. 529-36.

147. Schaefer, M., et al., Heterotrimeric G proteins direct two modes of asymmetric cell division in the Drosophila nervous system. Cell, 2001. 107(2): p. 183-94.

148. Yoshiura, S., N. Ohta, and F. Matsuzaki, Tre1 GPCR signaling orients stem cell divisions in the Drosophila central nervous system. Dev Cell, 2012. 22(1): p. 79-91.

149. Fuse, N., et al., Heterotrimeric G proteins regulate daughter cell size asymmetry in Drosophila neuroblast divisions. Curr Biol, 2003. 13(11): p. 947-54.

150. Izumi, Y., et al., Differential functions of $G$ protein and Baz-aPKC signaling pathways in Drosophila neuroblast asymmetric division. J Cell Biol, 2004. 164(5): p. 729-38.

151. Yu, F., et al., Distinct roles of Galphai and Gbeta13F subunits of the heterotrimeric G protein complex in the mediation of Drosophila neuroblast asymmetric divisions. J Cell Biol, 2003. 162(4): p. 623-33.

152. Ikeshima-Kataoka, H., et al., Miranda directs Prospero to a daughter cell during Drosophila asymmetric divisions. Nature, 1997. 390(6660): p. 625-9.

153. Shen, C.P., L.Y. Jan, and Y.N. Jan, Miranda is required for the asymmetric localization of Prospero during mitosis in Drosophila. Cell, 1997. 90(3): p. 449-58.

154. Li, P., et al., Inscuteable and Staufen mediate asymmetric localization and segregation of prospero RNA during Drosophila neuroblast cell divisions. Cell, 1997. 90(3): p. 437-47.

155. Li, L. and H. Vaessin, Pan-neural Prospero terminates cell proliferation during Drosophila neurogenesis. Genes Dev, 2000. 14(2): p. 147-51.

156. Choksi, S.P., et al., Prospero acts as a binary switch between self-renewal and differentiation in Drosophila neural stem cells. Dev Cell, 2006. 11(6): p. 775-89.

157. Southall, T.D. and A.H. Brand, Neural stem cell transcriptional networks highlight genes essential for nervous system development. EMBO J, 2009. 28(24): p. 3799-807.

158. Lee, C.Y., et al., Brat is a Miranda cargo protein that promotes neuronal differentiation and inhibits neuroblast self-renewal. Dev Cell, 2006. 10(4): p. 441-9.

159. Bello, B., H. Reichert, and F. Hirth, The brain tumor gene negatively regulates neural progenitor cell proliferation in the larval central brain of Drosophila. Development, 2006. 133(14): p. 2639-48.

160. Rhyu, M.S., L.Y. Jan, and Y.N. Jan, Asymmetric distribution of numb protein during division of the sensory organ precursor cell confers distinct fates to daughter cells. Cell, 1994. 76(3): p. 477-91.

161. Bello, B.C., et al., Amplification of neural stem cell proliferation by intermediate progenitor cells in Drosophila brain development. Neural Dev, 2008. 3: p. 5.

162. Boone, J.Q. and C.Q. Doe, Identification of Drosophila type II neuroblast lineages containing transit amplifying ganglion mother cells. Dev Neurobiol, 2008. 68(9): p. 1185-95.

163. Bowman, S.K., et al., The tumor suppressors Brat and Numb regulate transit-amplifying neuroblast lineages in Drosophila. Dev Cell, 2008. 14(4): p. 535-46.

164. Egger, B., et al., Regulation of spindle orientation and neural stem cell fate in the Drosophila optic lobe. Neural Dev, 2007. 2: p. 1.

165. Karcavich, R. and C.Q. Doe, Drosophila neuroblast 7-3 cell lineage: a model system for studying programmed cell death, Notch/Numb signaling, and sequential specification of ganglion mother cell identity. J Comp Neurol, 2005. 481(3): p. 240-51.

166. Bertet, C., et al., Temporal patterning of neuroblasts controls Notch-mediated cell survival through regulation of Hid or Reaper. Cell, 2014. 158(5): p. 1173-86.

167. Ulvklo, C., et al., Control of neuronal cell fate and number by integration of distinct daughter cell proliferation modes with temporal progression. Development, 2012. 139(4): p. 678-89.

168. Gotz, M. and W.B. Huttner, The cell biology of neurogenesis. Nat Rev Mol Cell Biol, 2005. 6(10): p. 777-88.

169. King, T.J. and R. Briggs. Serial transplantation of embryonic nuclei. in Cold Spring Harbor symposia on quantitative biology. 1956. Cold Spring Harbor Laboratory Press.

170. Gurdon, J.B., The developmental capacity of nuclei taken from intestinal epithelium cells of feeding tadpoles. Development, 1962. 10(4): p. 622-640. 
171. Gurdon, J.B., T.R. Elsdale, and M. Fischberg, Sexually mature individuals of Xenopus laevis from the transplantation of single somatic nuclei. Nature, 1958. 182(4627): p. 64-5.

172. Wilmut, I., et al., Viable offspring derived from fetal and adult mammalian cells. Clones and clones: Facts and fantasies about human cloning, 1999. 21.

173. Takahashi, K. and S. Yamanaka, Induction of pluripotent stem cells from mouse embryonic and adult fibroblast cultures by defined factors. Cell, 2006. 126(4): p. 663-76.

174. Okita, K., T. Ichisaka, and S. Yamanaka, Generation of germline-competent induced pluripotent stem cells. nature, 2007. 448(7151): p. 313-317.

175. Wernig, M., et al., In vitro reprogramming of fibroblasts into a pluripotent ES-cell-like state. Nature, 2007. 448(7151): p. 318-24.

176. Maherali, N., et al., Directly reprogrammed fibroblasts show global epigenetic remodeling and widespread tissue contribution. Cell Stem Cell, 2007. 1(1): p. 55-70.

177. Takahashi, K., et al., Induction of pluripotent stem cells from adult human fibroblasts by defined factors. Cell, 2007. 131(5): p. 861-72.

178. Yu, J., et al., Induced pluripotent stem cell lines derived from human somatic cells. Science, 2007. 318(5858): p. 1917-20.

179. Aasen, T., et al., Efficient and rapid generation of induced pluripotent stem cells from human keratinocytes. Nat Biotechnol, 2008. 26(11): p. 1276-84.

180. Maherali, N., et al., A high efficiency system for the generation and study of human induced pluripotent stem cells. Cell Stem Cell, 2008. 3(3): p. 340-5.

181. Staerk, J., et al., Reprogramming of human peripheral blood cells to induced pluripotent stem cells. Cell Stem Cell, 2010. 7(1): p. 20-4.

182. Loh, Y.H., et al., Reprogramming of T cells from human peripheral blood. Cell Stem Cell, 2010. 7(1): p. 15-9.

183. Zhou, T., et al., Generation of human induced pluripotent stem cells from urine samples. Nat Protoc, 2012. 7(12): p. 2080-9.

184. Maherali, N. and K. Hochedlinger, Guidelines and techniques for the generation of induced pluripotent stem cells. Cell Stem Cell, 2008. 3(6): p. 595-605.

185. Inoue, H., et al., iPS cells: a game changer for future medicine. The EMBO journal, 2014. 33(5): p. $409-417$.

186. Maekawa, M., et al., Direct reprogramming of somatic cells is promoted by maternal transcription factor Glis1. Nature, 2011. 474(7350): p. 225-9.

187. Nakagawa, M., et al., Generation of induced pluripotent stem cells without Myc from mouse and human fibroblasts. Nature biotechnology, 2008. 26(1): p. 101-106.

188. Yamanaka, S., Elite and stochastic models for induced pluripotent stem cell generation. Nature, 2009. 460(7251): p. 49-52.

189. Takahashi, K. and S. Yamanaka, A developmental framework for induced pluripotency. Development, 2015. 142(19): p. 3274-3285.

190. Waddington, C.H., The strategy of the genes. A discussion of some aspects of theoretical biology. With an appendix by H. Kacser. The strategy of the genes. A discussion of some aspects of theoretical biology. With an appendix by H. Kacser., 1957: p. ix+-262.

191. Forsburg, S.L., The art and design of genetic screens: yeast. Nat Rev Genet, 2001. 2(9): p. 659-68.

192. Patton, E.E. and L.I. Zon, The art and design of genetic screens: zebrafish. Nat Rev Genet, 2001. 2(12): p. 956-66.

193. Jorgensen, E.M. and S.E. Mango, The art and design of genetic screens: caenorhabditis elegans. Nat Rev Genet, 2002. 3(5): p. 356-69.

194. Page, D.R. and U. Grossniklaus, The art and design of genetic screens: Arabidopsis thaliana. Nat Rev Genet, 2002. 3(2): p. 124-36.

195. Shuman, H.A. and T.J. Silhavy, The art and design of genetic screens: Escherichia coli. Nat Rev Genet, 2003. 4(6): p. 419-31.

196. Kile, B.T. and D.J. Hilton, The art and design of genetic screens: mouse. Nat Rev Genet, 2005. 6(7): p. $557-$ 67.

197. Schneeberger, K., Using next-generation sequencing to isolate mutant genes from forward genetic screens. Nat Rev Genet, 2014. 15(10): p. 662-76.

198. Rubin, G.M. and E.B. Lewis, A brief history of Drosophila's contributions to genome research. Science, 2000. 287(5461): p. 2216-8.

199. Reiter, L.T., et al., A systematic analysis of human disease-associated gene sequences in Drosophila melanogaster. Genome Res, 2001. 11(6): p. 1114-25. 
200. Feany, M.B. and W.W. Bender, A Drosophila model of Parkinson's disease. Nature, 2000. 404(6776): p. 3948.

201. Fortini, M.E., et al., A survey of human disease gene counterparts in the Drosophila genome. J Cell Biol, 2000. 150(2): p. F23-30.

202. Alderson, T., Ethylation versus methylation in mutation of Escherichia coli and Drosophila. 1964.

203. Nüsslein-Volhard, C., E. Wieschaus, and H. Kluding, Mutations affecting the pattern of the larval cuticle inDrosophila melanogaster. Wilhelm Roux's archives of developmental biology, 1984. 193(5): p. 267-282.

204. Schneeberger, K., et al., SHOREmap: simultaneous mapping and mutation identification by deep sequencing. Nat Methods, 2009. 6(8): p. 550-1.

205. Sokolowski, M.B., Drosophila: genetics meets behaviour. Nat Rev Genet, 2001. 2(11): p. 879-90.

206. Dong, P., et al., Division of labour between Myc and G1 cyclins in cell cycle commitment and pace control. Nat Commun, 2014. 5: p. 4750.

207. Coons, A.H., H.J. Creech, and R.N. Jones, Immunological properties of an antibody containing a fluorescent group. Experimental Biology and Medicine, 1941. 47(2): p. 200-202.

208. Ramos-Vara, J.A. and M.A. Miller, When Tissue Antigens and Antibodies Get Along. Veterinary Pathology, 2013. 51(1): p. 42-87.

209. Campos-Ortega, J.A. and V. Hartenstein, Stages of Drosophila embryogenesis, in The Embryonic Development of Drosophila melanogaster. 1997, Springer. p. 9-102.

210. McGuire, S.E., Z. Mao, and R.L. Davis, Spatiotemporal Gene Expression Targeting with the TARGET and Gene-Switch Systems in <em>Drosophila</em>. Science's STKE, 2004. 2004(220): p. pl6-pl6.

211. De Graeve, F., et al., The ladybird homeobox genes are essential for the specification of a subpopulation of neural cells. Developmental biology, 2004. 270(1): p. 122-134.

212. Gabilondo, H., et al., Neuronal Cell Fate Specification by the Convergence of Different Spatiotemporal Cues on a Common Terminal Selector Cascade. PLoS Biol, 2016. 14(5): p. e1002450.

213. Lundgren, S.E., et al., Control of neuronal pathway selection by the Drosophila LIM homeodomain gene apterous. Development, 1995. 121: p. 1769-1773.

214. Miguel-Aliaga, I., D.W. Allan, and S. Thor, Independent roles of the dachshund and eyes absent genes in BMP signaling, axon pathfinding and neuronal specification. Development, 2004. 131(23): p. 5837-5848.

215. Baumgardt, M., et al., Specification of neuronal identities by feedforward combinatorial coding. PLoS Biol, 2007. 5(2): p. e37.

216. Schneider, L.E., M.S. Roberts, and P.H. Taghert, Cell type-specific transcriptional regulation of the Drosophila FMRFamide neuropeptide gene. Neuron, 1993. 10(2): p. 279-291.

217. Bivik, C., et al., Novel Genes Involved in Controlling Specification of Drosophila FMRFamide Neuropeptide Cells. Genetics, 2015. 200(4): p. 1229-44.

218. Barolo, S. and J.W. Posakony, Three habits of highly effective signaling pathways: principles of transcriptional control by developmental cell signaling. Genes Dev, 2002. 16(10): p. 1167-81.

219. Schneider, L.E., M.A. O'Brien, and P.H. Taghert, In situ hybridization analysis of the FMRFamide neuropeptide gene in Drosophila. I. Restricted expression in embryonic and larval stages. J Comp Neurol, 1991. 304(4): p. 608-22.

220. Koundakjian, E.J., et al., The Zuker collection: a resource for the analysis of autosomal gene function in Drosophila melanogaster. Genetics, 2004. 167(1): p. 203-206.

221. Cantone, I. and A.G. Fisher, Epigenetic programming and reprogramming during development. Nat Struct Mol Biol, 2013. 20(3): p. 282-9.

222. Leeb, M. and A. Wutz, Establishment of epigenetic patterns in development. Chromosoma, 2012. 121(3): p. 251-62.

223. Zhang, K., J.M. Haversat, and J. Mager, CTR9/PAF1c regulates molecular lineage identity, histone H3K36 trimethylation and genomic imprinting during preimplantation development. Dev Biol, 2013. 383(1): p. 15 27.

224. Jaehning, J.A., The Pafl complex: platform or player in RNA polymerase II transcription? Biochim Biophys Acta, 2010. 1799(5-6): p. 379-88.

225. Shi, X., et al., Paflp, an RNA polymerase II-associated factor in Saccharomyces cerevisiae, may have both positive and negative roles in transcription. Mol Cell Biol, 1996. 16(2): p. 669-76.

226. Shi, X., et al., Cdc73p and Paflp are found in a novel RNA polymerase II-containing complex distinct from the Srbp-containing holoenzyme. Mol Cell Biol, 1997. 17(3): p. 1160-9.

227. Mueller, C.L. and J.A. Jaehning, Ctr9, Rtf1, and Leo1 are components of the Pafl/RNA polymerase II complex. Mol Cell Biol, 2002. 22(7): p. 1971-80. 
228. Squazzo, S.L., et al., The Pafl complex physically and functionally associates with transcription elongation factors in vivo. Embo j, 2002. 21(7): p. 1764-74.

229. Penheiter, K.L., et al., A posttranscriptional role for the yeast Paf1-RNA polymerase II complex is revealed by identification of primary targets. Mol Cell, 2005. 20(2): p. 213-23.

230. Tomson, B.N. and K.M. Arndt, The many roles of the conserved eukaryotic Pafl complex in regulating transcription, histone modifications, and disease states. Biochim Biophys Acta, 2013. 1829(1): p. 116-26.

231. Betz, J.L., et al., Phenotypic analysis of Paf1/RNA polymerase II complex mutations reveals connections to cell cycle regulation, protein synthesis, and lipid and nucleic acid metabolism. Mol Genet Genomics, 2002. 268(2): p. 272-85.

232. Newey, P.J., M.R. Bowl, and R.V. Thakker, Parafibromin--functional insights. J Intern Med, 2009. 266(1): p. 84-98.

233. Mosimann, C., G. Hausmann, and K. Basler, Parafibromin/Hyrax activates Wnt/Wg target gene transcription by direct association with beta-catenin/Armadillo. Cell, 2006. 125(2): p. 327-41.

234. Mosimann, C., G. Hausmann, and K. Basler, The role of Parafibromin/Hyrax as a nuclear Gli/Ci-interacting protein in Hedgehog target gene control. Mech Dev, 2009. 126(5-6): p. 394-405.

235. Tenney, K., et al., Drosophila Rtfl functions in histone methylation, gene expression, and Notch signaling. Proc Natl Acad Sci U S A, 2006. 103(32): p. 11970-4.

236. Akanuma, T., et al., Pafl complex homologues are required for Notch-regulated transcription during somite segmentation. EMBO Rep, 2007. 8(9): p. 858-63.

237. Dey, P., et al., Human RNA polymerase II-association factor 1 (hPaf1/PD2) regulates histone methylation and chromatin remodeling in pancreatic cancer. PLoS One, 2011. 6(10): p. e26926.

238. Hanks, S., et al., Germline mutations in the PAF1 complex gene CTR9 predispose to Wilms tumour. Nat Commun, 2014. 5: p. 4398.

239. Muntean, A.G., et al., The PAF complex synergizes with MLL fusion proteins at HOX loci to promote leukemogenesis. Cancer Cell, 2010. 17(6): p. 609-21.

240. Takahashi, A., et al., SHP2 tyrosine phosphatase converts parafibromin/Cdc73 from a tumor suppressor to an oncogenic driver. Mol Cell, 2011. 43(1): p. 45-56.

241. Zeng, $\mathrm{H}$. and W. Xu, Ctr9, a key subunit of PAFC, affects global estrogen signaling and drives ERalphapositive breast tumorigenesis. Genes Dev, 2015. 29(20): p. 2153-67.

242. Mueller, C.L., et al., The Pafl complex has functions independent of actively transcribing RNA polymerase II. Molecular cell, 2004. 14(4): p. 447-456.

243. Kim, J., M. Guermah, and R.G. Roeder, The human PAF1 complex acts in chromatin transcription elongation both independently and cooperatively with SII/TFIIS. Cell, 2010. 140(4): p. 491-503.

244. Amrich, C.G., et al., Cdc73 subunit of Pafl complex contains C-terminal Ras-like domain that promotes association of Pafl complex with chromatin. Journal of Biological Chemistry, 2012. 287(14): p. 1086310875.

245. Bahrampour, S. and S. Thor, Ctr9, a Key Component of the Paf1 Complex, Affects Proliferation and Terminal Differentiation in the Developing Drosophila Nervous System. G3 (Bethesda), 2016. 6(10): p. 3229-3239.

246. Adelman, K., et al., Drosophila Paf1 modulates chromatin structure at actively transcribed genes. Mol Cell Biol, 2006. 26(1): p. 250-60.

247. Spradling, A.C., et al., The Berkeley Drosophila Genome Project gene disruption project: Single P-element insertions mutating 25\% of vital Drosophila genes. Genetics, 1999. 153(1): p. 135-177.

248. Di Como, C.J., H. Chang, and K.T. Arndt, Activation of CLN1 and CLN2 G1 cyclin gene expression by BCK2. Mol Cell Biol, 1995. 15(4): p. 1835-46.

249. Foreman, P.K. and R.W. Davis, CDP1, a novel Saccharomyces cerevisiae gene required for proper nuclear division and chromosome segregation. Genetics, 1996. 144(4): p. 1387-97.

250. Koch, C., et al., A role for Ctr9p and Paflp in the regulation G1 cyclin expression in yeast. Nucleic Acids Res, 1999. 27(10): p. 2126-34.

251. Chu, Y., et al., Regulation of histone modification and cryptic transcription by the Burl and Paf1 complexes. The EMBO journal, 2007. 26(22): p. 4646-4656.

252. Ding, L., et al., A genome-scale RNAi screen for Oct4 modulators defines a role of the Paf1 complex for embryonic stem cell identity. Cell stem cell, 2009. 4(5): p. 403-415.

253. Chaturvedi, D., et al., Drosophila CG2469 Encodes a Homolog of Human CTR9 and Is Essential for Development. G3 (Bethesda), 2016. 6(12): p. 3849-3857.

254. Lehmann, R., et al., On the phenotype and development of mutants of early neurogenesis in Drosophila melanogaster. Roux's Arch. Dev. Biol., 1983. 192: p. 62-74. 
255. Krejci, A., et al., Direct response to Notch activation: signaling crosstalk and incoherent logic. Sci Signal, 2009. 2(55): p. ra1.

256. Park, D., et al., Mapping peptidergic cells in Drosophila: where DIMM fits in. PLoS One, 2008. 3(3): p. e1896.

257. Hartenstein, V. and A. Wodarz, Initial neurogenesis in Drosophila. Wiley interdisciplinary reviews. Developmental biology, 2013. 2(5): p. 701-721.

258. Gonzalez, F., et al., Molecular analysis of the asense gene, a member of the achaete-scute complex of Drosophila melanogaster, and its novel role in optic lobe development. Embo J, 1989. 8(12): p. 3553-62.

259. Alonso, M.C. and C.V. Cabrera, The achaete-scute gene complex of Drosophila melanogaster comprises four homologous genes. Embo J, 1988. 7(8): p. 2585-91.

260. Brand, M., et al., asense is a Drosophila neural precursor gene and is capable of initiating sense organ formation. Development, 1993. 119(1): p. 1-17.

261. Dominguez, M. and S. Campuzano, asense, a member of the Drosophila achaete-scute complex, is a proneural and neural differentiation gene. EMBO J, 1993. 12(5): p. 2049-60.

262. Campos-Ortega, J.A. and V. Hartenstein, The embryonic development of Drosophila melanogaster. 2013: Springer Science \& Business Media.

263. Jarman, A.P., et al., The regulation and function of the helix-loop-helix gene, asense, in Drosophila neural precursors. Development, 1993. 119(1): p. 19-29.

264. Castro, D.S., et al., Proneural bHLH and Brn proteins coregulate a neurogenic program through cooperative binding to a conserved DNA motif. Developmental cell, 2006. 11(6): p. 831-844.

265. Ip, Y.T., M. Levine, and E. Bier, Neurogenic expression of snail is controlled by separable CNS and PNS promoter elements. Development, 1994. 120(1): p. 199-207.

266. Alberga, A., et al., The snail gene required for mesoderm formation in Drosophila is expressed dynamically in derivatives of all three germ layers. Development, 1991. 111(4): p. 983-92.

267. Ashraf, S.I., et al., The mesoderm determinant Snail collaborates with related zinc-finger proteins to control Drosophila neurogenesis. The EMBO Journal, 1999. 18(22): p. 6426-6438.

268. Kosman, D. and M. Levine, Establishment of the mesoderm-neuroectoderm boundary in the Drosophila embryo. Science, 1991. 254(5028): p. 118.

269. Leptin, M., twist and snail as positive and negative regulators during Drosophila mesoderm development. Genes \& development, 1991. 5(9): p. 1568-1576.

270. Boulay, J., C. Dennefeld, and A. Alberga, The Drosophila developmental gene snail encodes a protein with nucleic acid binding fingers. Nature, 1987. 330(6146): p. 395-398.

271. Skeath, J.B., G.F. Panganiban, and S.B. Carroll, The ventral nervous system defective gene controls proneural gene expression at two distinct steps during neuroblast formation in Drosophila. Development, 1994. 120(6): p. 1517-24.

272. Hemavathy, K., S.I. Ashraf, and Y.T. Ip, Snail/slug family of repressors: slowly going into the fast lane of development and cancer. Gene, 2000. 257(1): p. 1-12.

273. Cai, Y., W. Chia, and X. Yang, A family of snail-related zinc finger proteins regulates two distinct and parallel mechanisms that mediate Drosophila neuroblast asymmetric divisions. The EMBO journal, 2001. 20(7): p. 1704-1714.

274. Fuse, N., S. Hirose, and S. Hayashi, Determination of wing cell fate by the escargot and snail genes in Drosophila. Development, 1996. 122(4): p. 1059-1067.

275. Campos-Ortega, J., In Bate, M. and Arias, AM,(eds.), The Development of Drosophila melanogaster. 1993, Cold Spring Harbor Laboratory Press.

276. Ashraf, S.I. and Y.T. Ip, The Snail protein family regulates neuroblast expression of inscuteable and string, genes involved in asymmetry and cell division in Drosophila. Development, 2001. 128(23): p. 4757-4767.

277. Crémazy, F., P. Berta, and F. Girard, Genome-wide analysis of Sox genes in Drosophila melanogaster. Mechanisms of Development, 2001. 109(2): p. 371-375.

278. Wegner, M., From head to toes: the multiple facets of Sox proteins. Nucleic acids research, 1999. 27(6): p. 1409-1420.

279. Collignon, J., et al., A comparison of the properties of Sox-3 with Sry and two related genes, Sox-1 and Sox-2. Development, 1996. 122(2): p. 509-520.

280. Cremazy, F., P. Berta, and F. Girard, Sox neuro, a new Drosophila Sox gene expressed in the developing central nervous system. Mech Dev, 2000. 93(1-2): p. 215-9.

281. Overton, P.M., et al., Evidence for differential and redundant function of the Sox genes Dichaete and SoxN during CNS development in Drosophila. Development, 2002. 129(18): p. 4219-28. 
282. Buescher, M., F.S. Hing, and W. Chia, Formation of neuroblasts in the embryonic central nervous system of Drosophila melanogaster is controlled by SoxNeuro. Development, 2002. 129(18): p. 4193-203.

283. Soriano, N.S. and S. Russell, The Drosophila SOX-domain protein Dichaete is required for the development of the central nervous system midline. Development, 1998. 125(20): p. 3989-96.

284. Nambu, P.A. and J.R. Nambu, The Drosophila fish-hook gene encodes a HMG domain protein essential for segmentation and CNS development. Development, 1996. 122(11): p. 3467-75.

285. Ma, Y., et al., Functional interactions between Drosophila bHLH/PAS, Sox, and POU transcription factors regulate CNS midline expression of the slit gene. J Neurosci, 2000. 20(12): p. 4596-605.

286. Zhao, G. and J.B. Skeath, The Sox-domain containing gene Dichaetelfish-hook acts in concert with vnd and ind to regulate cell fate in the Drosophila neuroectoderm. Development, 2002. 129(5): p. 1165-74.

287. Russell, S., et al., The Dichaete gene of Drosophila melanogaster encodes a SOX-domain protein required for embryonic segmentation. Development, 1996. 122(11): p. 3669-3676.

288. Yuan, H., et al., Developmental-specific activity of the FGF-4 enhancer requires the synergistic action of Sox2 and Oct-3. Genes \& development, 1995. 9(21): p. 2635-2645.

289. Chu, H., et al., Formation and specification of ventral neuroblasts is controlled by vnd in Drosophila neurogenesis. Genes Dev, 1998. 12(22): p. 3613-24.

290. Shen, S.P., J. Aleksic, and S. Russell, Identifying targets of the Sox domain protein Dichaete in the Drosophila CNS via targeted expression of dominant negative proteins. BMC Dev Biol, 2013. 13: p. 1.

291. Zander, M.A., et al., Snail coordinately regulates downstream pathways to control multiple aspects of Mammalian neural precursor development. J Neurosci, 2014. 34(15): p. 5164-75.

292. Unternaehrer, J.J., et al., The epithelial-mesenchymal transition factor SNAIL paradoxically enhances reprogramming. Stem Cell Reports, 2014. 3(5): p. 691-8.

293. Lloyd, A. and S. Sakonju, Characterization of two Drosophila POU domain genes, related to oct-1 and oct-2, and the regulation of their expression patterns. Mech Dev, 1991. 36(1-2): p. 87-102.

294. Urban, N., et al., Return to quiescence of mouse neural stem cells by degradation of a proactivation protein. Science, 2016. 353(6296): p. 292-5.

295. Andersen, J., et al., A transcriptional mechanism integrating inputs from extracellular signals to activate hippocampal stem cells. Neuron, 2014. 83(5): p. 1085-97.

296. Karlsson, D., M. Baumgardt, and S. Thor, Segment-specific neuronal subtype specification by the integration of anteroposterior and temporal cues. PLoS Biol, 2010. 8(5): p. e1000368.

297. Aleksic, J., et al., The role of Dichaete in transcriptional regulation during Drosophila embryonic development. BMC Genomics, 2013. 14: p. 861. 


\section{Papers}

The articles associated with this thesis have been removed for copyright reasons. For more details about these see:

http://urn.kb.se/resolve? urn:nbn:se:liu:diva-134459 